\title{
CARACTERÍSTICAS FÍSICO-QUÍMICAS, MICROBIOLÓGICAS E POLÍNICAS DE AMOSTRAS DE MÉIS DE Apis mellifera L., 1758 (HYMENOPTERA: APIDAE) DOS ESTADOS DO CEARÁ E PIAUÍ
}

\author{
GeNI DA Silva SODRÉ
}

\begin{abstract}
Tese apresentada à Escola Superior de Agricultura "Luiz de Queiroz", Universidade de São Paulo, para obtenção do título de Doutor em Ciências, Área de Concentração: Entomologia.
\end{abstract}

P I R A C I C A B A

Estado de São Paulo - Brasil

Fevereiro - 2005 


\title{
CARACTERÍSTICAS FÍSICO-QUÍMICAS, MICROBIOLÓGICAS E POLÍNICAS DE AMOSTRAS DE MÉIS DE Apis mellifera L., 1758 (HYMENOPTERA: APIDAE) DOS ESTADOS DO CEARÁ E PIAUÍ
}

\author{
Geni da Silva Sodré \\ Engenheiro Agrônomo
}

Orientador: Prof. Dr. LUÍS CARLOS MARCHINI

Tese apresentada à Escola Superior de Agricultura "Luiz de Queiroz", Universidade de São Paulo, para obtenção do título de Doutor em Ciências, Área de Concentração: Entomologia.

PIR A C I C A B A

Estado de São Paulo - Brasil

Fevereiro - 2005 
Dados Internacionais de Catalogação na Publicação (CIP) DIVISÃO DE BIBLIOTECA E DOCUMENTAÇÃO - ESALQIUSP

\section{Sodré, Geni da Silva}

Características físico-químicas, microbiológicas e polínicas de amostras de méis de Apis mellifera L., 1758 (Hymenoptera: Apidae) dos Estados do Ceará e Piauí I Geni da Silva Sodré. - - Piracicaba, 2005

127 p. : il.

Tese (Doutorado) - - Escola Superior de Agricultura Luiz de Queiroz, 2005.

Bibliografia.

1. Análise de alimento 2. Composição de alimento 3. Floração 4. Mel - Análise físico-química 5. Microbiologia de alimento 6. Pólen I. Título

CDD 638.16 
Aos meus pais, Raimunda da Silva Sodrée Luiz Sodré (in memorian), que com amor, carinho e dedicação, sempre me apoiaram em todas as etapas de minha vida, 


\section{AGRADECIMENTOS}

À Escola Superior de Agricultura "Luiz de Queiroz" ESALQ/USP, pelo apoio concedido por meio de sua estrutura, em especial ao Departamento de Entomologia, Fitopatologia e Zoologia Agrícola, pela oportunidade de realização do curso.

Ao Prof. Dr. Luís Carlos Marchini pela orientação, amizade, confiança e, principalmente, apoio concedido em todos os momentos.

Aos demais professores do curso de pós-graduação em Entomologia, pelos ensinamentos transmitidos.

À Dra. Augusta Carolina de C. C. Moreti pela amizade, atenção, constante apoio e colaboração.

À Profa. Dra. Orgeda Luiza Araújo Domingues Zucchi da FFCLRPUSP pela colaboração nas análises dos elementos químicos.

À MS Vanessa Pires da Rosa por todo o auxílio nas análises microbiológicas.

A pesquisadora Ivoni Pozar Otsuk, do Instituto de Zootecnia de Nova Odessa, pela análise estatística.

Ao professor Dr. Evoneo Berti Filho pelo auxílio na elaboração do "summary".

Aos Profs. da Escola de Agronomia da Universidade Federal da Bahia Dr. Carlos Alfredo Lopes de Carvalho e Dr. Oton Meira Marques pela amizade, incentivo e colaboração para minha formação.

Ao colega e amigo Luciano Pacelli Medeiros de Macedo pelas sugestões. 
Ao zootecnista Paulo Levy pelas amostras de méis fornecidas para a realização do trabalho.

Aos meus irmãos: Paulo, Lúcia, Rita, Antônio, Edvaldo e a Rogério e seus pais Odete e Hélio por estarem presentes em todos os momentos.

Aos colegas, amigos e funcionários do Setor de Entomologia, pelo convívio, amizade, apoio e simpatia. Em especial os companheiros do Laboratório de Insetos Úteis: Bruno, Carolina, Daniela, Gustavo, Kiára, Márcia e Vitor.

À Karina, Kércya, Adriana, Aline, Cláudia, Fernando, Gláucia, Keiko, Patrícia e Wyratan pelo convívio e amizade.

Às bibliotecárias da ESALQ pela colaboração nas pesquisas e correção das referências bibliográficas.

À Coordenação de Aperfeiçoamento de Pessoal de Nível Superior (CAPES), pela concessão da bolsa de estudo.

A Deus pelo dom da vida, e todos os anjos que acompanham meu caminho. 


\section{SUMÁRIO}

Página

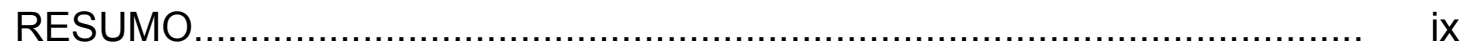

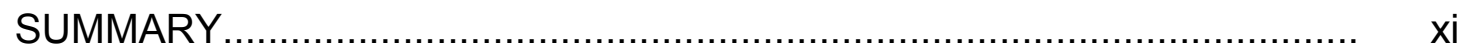

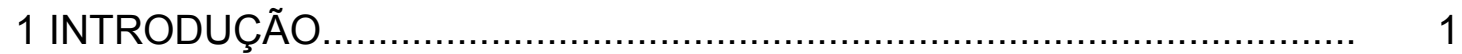

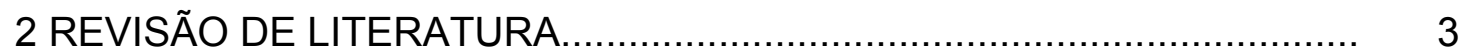

2.1 Composição físico-químicas dos méis................................................. 3

2.1.1 Açúcares.................................................................................. 4

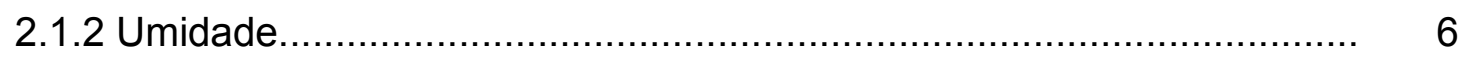

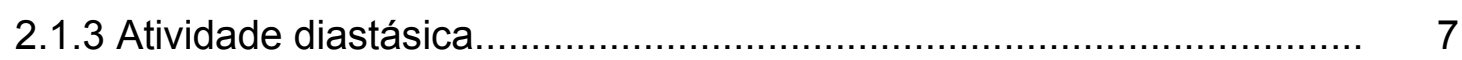

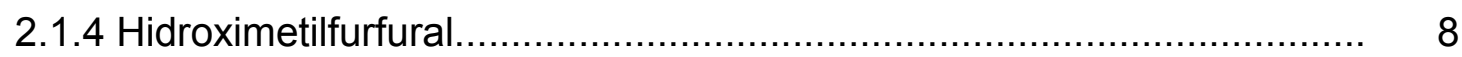

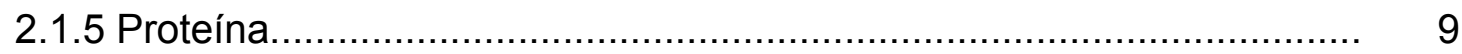

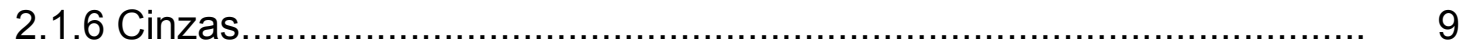

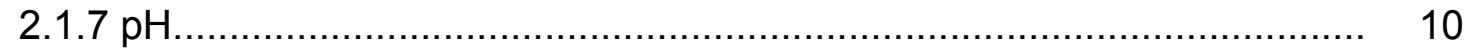

2.1.8 Acidez

2.1.9 Índice de formol.................................................................. 12

2.1.10 Condutividade elétrica.............................................................. 12

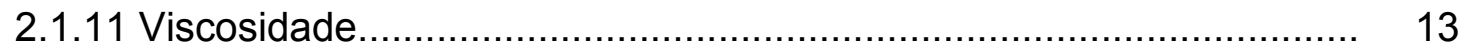

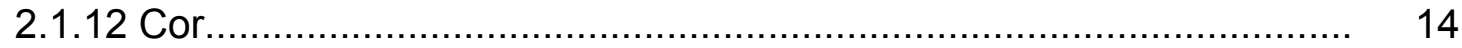

2.1.13 Elementos químicos............................................................... 15

2.2 Microorganismos no mel................................................................ 17

2.3 Análises polínicas no mel............................................................. 20 
3 MATERIAL E MÉTODOS ............................................................ 23

3.1 Análises físico-químicas dos méis............................................... 25

3.1.1 Açúcares totais (AT), açúcares redutores (AR) e sacarose aparente... 25

3.1 .2 Umidade............................................................................. 25

3.1.3 Atividade diastásica............................................................. 25

3.1.4 Hidroximetilfurfural............................................................. 25

3.1.5 Proteína.......................................................................... 26

3.1.6 Teor de Cinzas.................................................................... 26

$3.1 .7 \mathrm{pH}$ e Acidez.................................................................... 26

3.1.8 Índice de formol.................................................................. 26

3.1.9 Condutividade elétrica............................................................ 26

3.1.10 Viscosidade....................................................................... 27

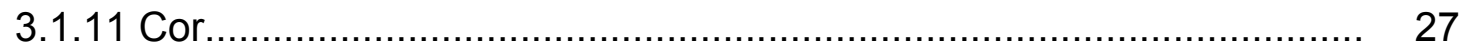

3.1.12 Elementos químicos.......................................................... 27

3.2 Análises de microorganismos dos méis......................................... 28

3.3 Análises polínicas dos méis........................................................ 28

3.3.1 Método qualitativo................................................................ 28

3.3.2 Método quantitativo............................................................ 28

3.4 Análise dos dados.................................................................... 29

4 RESULTADOS E DISCUSSÃO ................................................... 30

4.1 Análises físico-químicas................................................................. $\quad 30$

4.1.1 Açúcares totais.......................................................................... 34

4.1.2 Açúcares redutores................................................................... 34

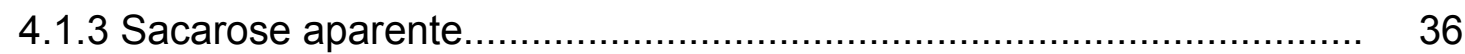

4.1.4 Umidade................................................................................... 37

4.1.5 Atividade diastásica.............................................................. 39

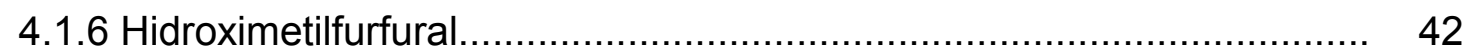

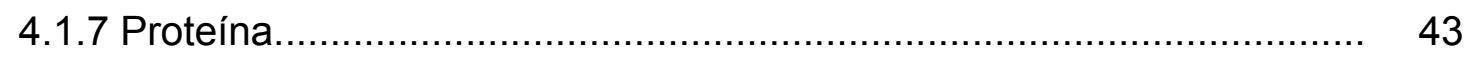

4.1 .8 Cinzas........................................................................... 45 


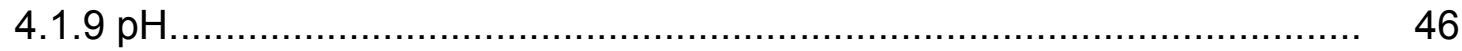

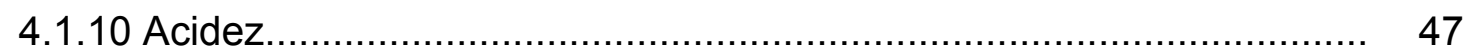

4.1.11 Índice de formol................................................................. 48

4.1.12 Condutividade elétrica........................................................... 49

4.1 .13 Viscosidade ........................................................................... 50

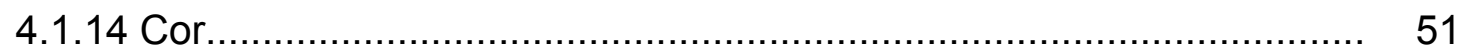

4.1.15 Análise de agrupamento para as análises físico-químicas............... 53

4.1.16 Elementos químicos............................................................. 62

4.1.17 Análise de agrupamento para os elementos químicos..................... 71

4.2 Microorganismos...................................................................... 79

4.3 Análises Polínicas......................................................................... 83

5 CONCLUSÕES.................................................................... 94

REFERÊNCIAS BIBLIOGRÁFICAS ............................................... 95 


\title{
CARACTERÍSTICAS FÍSICO-QUÍMICAS, MICROBIOLÓGICAS E POLÍNICAS DE AMOSTRAS DE MÉIS DE Apis mellifera L., 1758 (HYMENOPTERA: APIDAE) DOS ESTADOS DO CEARÁ E PIAUÍ
}

\author{
Autor: GENI DA SILVA SODRÉ \\ Orientador: Prof. Dr. LUÍS CARLOS MARCHINI
}

\section{RESUMO}

Com o objetivo de determinar as características físico-químicas, microbiológicas e a origem floral de méis produzidos por Apis mellifera L., 1758, foram determinados no Laboratório de Insetos Úteis do Departamento de Entomologia, Fitopatologia e Zoologia Agrícola da Escola Superior de Agricultura "Luiz de Queiroz" e no Laboratório de Instrumentação Nuclear do Centro de Energia Nuclear na Agricultura, USP: açúcares totais, açúcares redutores, sacarose aparente, umidade, atividade diastásica, hidroximetilfurfural, proteína, cinzas, $\mathrm{pH}$, acidez, índice de formol, condutividade elétrica, viscosidade, cor, elementos químicos ( $\mathrm{K}, \mathrm{Ca} \mathrm{Ti}, \mathrm{Cr}, \mathrm{Mn}, \mathrm{Fe}, \mathrm{Co}, \mathrm{Ni}, \mathrm{Cu}$, $\mathrm{Zn}$, Se, $\mathrm{Br} \mathrm{Rb}, \mathrm{Sr}, \mathrm{Ba}, \mathrm{Hg}$ e $\mathrm{Pb})$, microorganismos e realizadas análises polínicas de 58 amostras de méis colhidas no Estados do Ceará (20 
amostras) e Piauí (38 amostras). Os resultados demonstraram que a maioria dos valores médios para cada parâmetro físico-químico das amostras analisadas encontram-se dentro dos limites estabelecidos pela legislação vigente entretanto verifica-se, para amostras do Estado do Piauí, valor médio para a atividade diastásica abaixo do estabelecido. Para os elementos químicos foram verificados valores acima dos estabelecidos para os elementos $\mathrm{Cr}, \mathrm{Ni}, \mathrm{Zn}$ e $\mathrm{Pb}$. As amostras estudadas foram negativas para coliformes totais, entretanto, foram constatados fungos e leveduras. Pelas análises polínicas dos méis foram considerados como espécies vegetais dominantes para o Estado do Ceará a Mimosa caesalpiniaefolia, M. verrucosa, Borreria sp. I, Serjania sp. e tipo Fabaceae. No Estado do Piauí a Piptadenia sp., M. caesalpiniaefolia, $M$. verrucosa, Croton urucurana e Tibouchina sp.. 


\title{
PHYSICOCHEMICAL, MICROBIOLOGICAL AND POLLINIC CHARACTERISTICS OF Apis mellifera L., 1758 (HYMENOPTERA: APIDAE) HONEY SAMPLES FROM THE STATES OF CEARA AND PIAUI
}

\author{
Author: GENI DA SILVA SODRÉ \\ Adviser: LUÍS CARLOS MARCHINI
}

\section{SUMMARY}

This research deals with the physicochemical, microbiological and pollinic characteristics of 58 samples of Apis mellifera L., 1758 (Hymenoptera: Apidae) honey from the Brazilian states of Ceara (20 samples) and Piaui (38 samples). The following parameters were determined: total sugars, reducing sugars, apparent sucrose, humidity, diastase activity, hydroxymethylfurfural, protein, ashes, ph, acidity, formol index, electrical conductivity, viscosity, color, chemical elements (K, Ca, Ti, Cr, Mn, Fe, Co, Ni, Cu, Zn, Se, Br, Rb, Sr, Ba, Hg, $\mathrm{Pb}$ ) and microrganisms. The experiments were set in the "Laboratorio de Insetos Úteis", Department of Entomology, Phytopathology and Agricultural Zoology and in the "Laboratorio de Instrumentação Nuclear, Centro de Energia Nuclear na Agricultura" University of São Paulo, in Piracicaba, State of São Paulo. The results have indicated that most of the mean values for each physicochemical parameter are In accordance with the limits established by the Brazilian the 
diastase activity is below those limits. Concerning the chemical elements, one observed values above those limits, as follows: $\mathrm{Cr}, \mathrm{Ni}, \mathrm{Zn}$ and $\mathrm{Pb}$. The samples were negative for total coliforms. However fungi and yeast were detected. The pollinic analyses showed that the dominant plant species of the Ceara State were Mimosa caesalpiniaefolia, M. verrucosa, Borreria sp., Serjania sp. and type Fabaceae. The dominant plant species of the Piaui State were Piptadenia sp., $M$. caesalpiniaefolia, M. verrucosa, Croton urucurana and Tibouchina sp.. 


\section{INTRODUÇÃO}

Entende-se por mel, o produto alimentício produzido pelas abelhas melíferas, a partir do néctar das flores ou das secreções procedentes de partes vivas das plantas ou de excreções de insetos sugadores de plantas que ficam sobre partes vivas de plantas, que as abelhas recolhem, transformam, combinam com substâncias específicas próprias, armazenam e deixam madurar nos favos da colméia (Brasil, 2000).

É um alimento que tem sido utilizado pela humanidade, desde as mais remotas épocas, apreciado por seu sabor característico e seu considerável valor nutritivo (Daellen-Bach, 1981).

No mercado são encontrados méis de origens florais, obtidos do néctar das flores, tais como mel de flores de eucaliptos, de flores de laranjeira, de flores silvestres e os de origens não florais, sendo estes pouco apreciados pelos consumidores como o mel de exsudato de cana-de-açúcar, obtido com a queima da cultura e o de "honeydew" obtido por meio da excreção de insetos sugadores de plantas (Marchini, 2001).

As características físico-químicas, microbiológicas e polínicas do mel ainda são relativamente pouco conhecidas, principalmente nas regiões tropicais onde existe uma flora apícola bastante diversificada associada a taxas elevadas de umidade e temperatura. No Brasil devido a grande diversidade na flora apícola torna-se necessária uma caracterização e, posteriormente, criação de padrões do mel levando em consideração os fatores vegetais, edáficos e climáticos das respectivas regiões onde são produzidos. 
Na região nordeste do Brasil, os Estados do Ceará e Piauí destacamse pelo elevado potencial apícola, traduzindo-se em altos índices zootécnicos de produção. O mel destes estados apresenta excelente qualidade, ressaltando-se seu agradável aroma e sabor, características muito valorizadas pelo mercado, sendo ainda considerado como mel livre de contaminantes. No entanto, os produtos apícolas são muito sensíveis a contaminações ambientais, pois o néctar e o pólen são originários das flores, que estão permanentemente expostas às chuvas e ventos, além de locais com depósitos de lixo que são visitados pelas abelhas, podendo gerar contaminações por microorganismos e produtos químicos tóxicos.

Assim, a presente pesquisa teve como objetivo determinar as características físico-químicas, verificar a presença de microorganismos, a origem floral e as porcentagens de méis que se enquadram nas especificações da legislação brasileira, utilizando amostras de méis de Apis mellifera L., 1758, dos Estados do Ceará e Piauí. 


\section{REVISÃO DE LITERATURA}

\subsection{Composição físico-químicas dos méis}

Trabalhos científicos de análises físico-químicas de méis para fins de caracterização deste produto vêm se tornando de grande importância nos últimos anos. Pesquisadores de vários países têm o mel como objeto de seus estudos, destacando-se: Alemanha (Isengard \& Schulthei, 2003); Arábia Saudita (Mesallan \& El-Shaarawy, 1987; Al-Khalifa \& Al-Arify, 1999; Al-Hindi, 2003); Argentina (Dozo, 1980; Archenti \& Dasso, 1983; Baldi-Coronel et al., 1993; Archenti, 1984; DelLungo et al., 1991; Uñates et al.,1999; Tosi et al., 2002; Reynaldi et al., 2003); Austrália (Mossel et al., 2000; Sopade et al., 2002); Brasil (Flechtmann et al., 1963; Vidal \& Fregosi, 1984; Amaral et al., 1986; Pamplona, 1989; CortopassiLaurino \& Gelli, 1991; Dayrell \& Vital, 1991; Stonoga \& Freitas, 1991; Bastos \& Silva, 1994; Horn et al., 1996; Komatsu, 1996; Komatsu \& Marchini, 1996; Rodrigues et al., 1996, 2002; Komatsu et al., 2001, 2002; Marchini et al., 1996, 1998, 2000, 2002, 2003, 2004a,b,c; Marchini, 2001; Campos, 1998; Azeredo et al., 1999, 2003; Carvalho et al., 1998, 2000a,b, 2002; Costa et al., 1999; Sodré, 2000; Sodré et al., 2002a,b,c, 2003; Cano et al., 2001; Almeida, 2002; Almeida-Muradian et al., 2002; Bendini et al. 2002; Cano, 2002; Carneiro et al., 2002; Magalhães et al., 2002; Moura et al., 2002; Rêgo et al., 2002; Arruda, 2003; Silva et al., 2003); Canadá (Sporns et al.,1992; Ganzáles et al., 1999), Chile (Cornejo, 1988; Seemann \& Neira, 1988; Montenegro et al., 2003); China (Junzheng \& Changying, 1998); Egito (Ibrahim et al., 1977; El-Sherbiny et al., 1980; El-Etre \& Abdallah, 
2000; Shaltout, 2002); Espanha (Sancho et al., 1991, 1992; Fernandez-Salguero \& Gomez, 1992; Gómez et al. 1993; Martinez et al. 1993; Mateo \& Bosch-Reig; Mateo \& Bosch-Reig, 1997, 1998; Cavia et al., 2002; Hermosín et al., 2003; Serrano et al., 2004; Soria et al., 2004; Terrab et al., 2004); Estados Unidos (Tong et al., 1975; White Júnior, 1976, 1978, 1979, 1992, 1994; White Júnior \& Rudyj, 1978); França (Morlot et al., 2001; Devillers et al., 2004); Grécia (Thrasyvoulou,1986; Thrasyvoulou et al., 1982, 1994, Thrasyvoulou \& Manikis, 1995; Liakos et al., 2002); Índia (Narayama, 1970; Anupama et al., 2003; Nanda et al., 2003); Itália (Butta et al., 1983; Spettoli, et al.,1983; Stefanini, 1984; Sabatini et al., 1989; Persano-Oddo et al., 1995, 2004a,b; Caroli, et al., 2000; Celli et al., 2003; Fallico et al., 2004; Piano et al., 2004; Piazza \& Persano-Oddo, 2004); Japão (Hase \& Ainda, 1988); Paraguai (Escobar-Martínez et al., 1992); Portugal (Aira et al., 1998; Mendes et al., 1998; Andrade et al., 1999); Rússia (Ivanov \& Chervenakova, 1984); Taiwan (Lin et al., 1977); Turquia (Temiz, 1983); Venezuela (Vit-Oliver et al., 1994; Rodríguez et al., 2004), dentre outros países.

\subsubsection{Açúcares}

Os carboidratos são os componentes presentes em maior concentração no mel, sendo responsáveis por suas qualidades e propriedades, como: viscosidade, higroscopicidade, granulação, valor energético e a atividade antibacteriana (Crane, 1975 e White Júnior, 1979).

O mel é rico em açúcares, sendo encontrados: glicose, frutose, sacarose, maltose, isomaltotetraose, maltulose, isomaltulose, nigerose, turanose, cojibiose, neotrehalose, gentiobiose, laminaribiose, leucrose, melesitose, rafinose, isopanose, isomaltetraose, ${ }_{6} \mathrm{G}-\alpha-g$ licosilsacarose, arabogalactomanose, erlose, dextrantriose, maltotriose, isomaltopentose, centose, 1-cestose, panose, isomaltotriose, $3-\alpha$-isomaltosilglicose (Crane, 1983). 
Os açúcares redutores (glicose e frutose), são as frações dominantes, representando em torno de 85 a 95\% dos carboidratos presentes no mel, os quais têm a capacidade de reduzir íons de cobre em solução alcalina. A glicose, por ter pouca solubilidade, determina a tendência da cristalização do mel, e a frutose, por ter alta higroscopicidade, possibilita a sua doçura. A proporção média de frutose no mel é de $39,3 \%$, enquanto que a de glicose é de $32,9 \%$, sendo que mel com altas taxas de frutose pode permanecer líquido por longos períodos ou nunca cristalizar (White Júnior, 1979; Seemann \& Neira, 1988 e Horn et al., 1996).

$\mathrm{Na}$ maioria dos méis predomina a frutose embora, em alguns, a quantidade de glicose seja superior, como nos méis da flor de Brassica napus, Taraxacum officinale e Trichostema lanceolatum (White Júnior, 1979 e Seemann \& Neira, 1988).

Os demais açúcares do mel são representados por dissacarídeos e trissacarídeos (White Júnior, 1979). Dentre os dissacarídeos, a sacarose representa em média 2 a $3 \%$ dos carboidratos e quando superior a este valor, geralmente indica um mel verde ou adulterado. A sacarose é um açúcar não redutor, passível de hidrólise através de ácidos diluídos ou enzimas (invertase), resultando nos monossacarídeos, frutose e glicose (Vidal \& Fragosi, 1984).

O menor valor para açúcares totais foi constatado por Amin et al. (1999) que analisando amostras de méis egípcios, encontraram 62,27\%. Já Komatsu et al. (2002) analisando amostras de méis do Estado de São Paulo, constataram o maior valor $(88,3 \%)$.

Mesallan \& El-Shaarawy (1987) trabalhando com méis produzidos na Arábia Saudita, como também dos importados para suprir a demanda do mercado saudita, constataram o menor valor para os açúcares redutores (48\%) em méis importados. Já o maior valor $(87,39 \%)$ foi constatado por Carneiro et al. (2002) em amostras de méis da região de Simplício Mendes (Piauí). 
Para a sacarose aparente o menor valor encontrado nos trabalhos em estudo foi de $0,0 \%$ o qual foi constatado por Sporns et al. (1992) em amostras de méis canadense e por Vit-Oliver et al. (1994) em amostras de méis venezuelano. O maior valor foi encontrado por Komatsu et al. (2002) que, trabalhando com amostras de méis do Estado de São Paulo, verificaram em méis silvestres, $27,4 \%$.

\subsubsection{Umidade}

A umidade no mel é sem dúvida uma das características mais importantes, por influenciar na sua viscosidade, peso específico, maturidade, cristalização e sabor, interferindo na sua conservação e palatabilidade (Seemann $\&$ Neira, 1988). Este constituinte do mel pode ser alterado após a sua retirada da colméia, em função das condições de armazenamento após a extração.

O conteúdo de água no mel é o segundo constituinte em quantidade, variando antes da completa desidratação entre 15 e $21 \%$ do conteúdo total dependendo do clima, origem floral e condições de colheita. Normalmente, o mel maduro tem menos de $18,6 \%$ de umidade (Horn et al., 1996), tendo uma grande relação com a fermentação, já que quando encontrada acima de um limite máximo (20\%) o mel estará sujeito a fermentação (Frías \& Hardisson, 1992).

Certos microorganismos osmofílicos (tolerantes ao açúcar) quando presentes no mel multiplicam-se com o aumento da umidade, favorecendo o processo de fermentação. Estes microorganismos estão presentes nos corpos das abelhas, no néctar, no solo, nas áreas de extração e armazenamento do mel (White Júnior, 1978).

Dentre os trabalhos avaliados destaca-se o de Uñates et al. (1999) que, estudando méis da província de São Luis (Argentina), constataram o menor valor para a umidade (12,9 \%). Já o maior valor $27,2 \%$ foi encontrado por Pamplona (1989) em méis da região nordeste do Brasil. 


\subsubsection{Atividade diastásica}

A diastase ( $\alpha$-amilase) é uma das enzimas do mel, formada principalmente pelas glândulas hipofaringeanas das abelhas, sendo encontrada também, em baixa proporção, nos grãos de pólen (Pamplona, 1989). Ela tem a função de digerir a molécula de amido e está, possivelmente, envolvida na digestão do pólen. Segundo Vansell \& Freeborn (1926) existe uma perfeita correlação entre a quantidade de pólen no mel e a atividade da diastase.

Sua relevância principal para o mel é que essa enzima é ainda mais sensível ao calor que a enzima invertase (responsável pela transformação da sacarose em glicose e frutose), sendo recomendada para avaliar a qualidade do mel dando indicações sobre o grau de conservação e superaquecimento, o que compromete seriamente o produto (Soloveve, 1971).

White Júnior (1994) questionou o uso da atividade diastásica como indicadora de qualidade do mel devido à grande variação na quantidade de diastase em méis recém-colhidos, não aquecidos e sugeriu, através do histórico da atividade diastásica, que fosse excluída da análise de qualidade do mel por ser um teste redundante, enganoso e variável. Segundo White Júnior (1992), os méis produzidos em regiões quentes e secas apresentam menor quantidade de enzimas do que os de regiões quentes e úmidas.

Conforme Crane (1983), méis originários de fluxo de néctar muito rápido, onde as colméias têm muito néctar acumulado para processar, geralmente possuem níveis enzimáticos mais baixos do que aqueles provenientes de fluxos menos ricos, os quais as abelhas têm tempo para processar intensamente. Assim, como néctar com um conteúdo alto de açúcar, necessitam menos manipulação das abelhas para serem convertidos em mel que néctar mais diluídos. Em méis de néctar concentrado tendem a ter níveis mais baixos de invertase e diastase. 
Em trabalhos para avaliar a atividade diastásica, Persano-Oddo et al. (1995) constataram 0,0 escala de Gothe como o menor valor em amostras de méis uniflorais italiano. Já o maior valor (162,3 escala de Gothe) foi constado por Baldi-Coronel et al. (1996) em trabalho com amostras de méis da província de Entre Rios na Argentina.

\subsubsection{Hidroximetilfurfural}

O hidroximetilfurfural comumente chamado de HMF talvez seja o constituinte secundário do mel mais discutido. Ele é formado pela reação de certos açúcares com ácidos, principalmente pela decomposição da frutose em presença de ácidos (White Júnior, 1976).

Conforme Horn et al. (1996), uma pequena quantidade de HMF é encontrada nos méis recém-colhidos. Seemann \& Neira (1988) e Salinas et al. (1991) mencionam que é um constituinte que, além do superaquecimento, pode indicar a idade dos méis e que o seu conteúdo aumenta com o tempo de armazenamento, adição de açúcar invertido, podendo também ser afetado pela acidez, $\mathrm{pH}$, água e minerais no mel.

Segundo Veríssimo (1988), o HMF é um indicador de qualidade do mel, visto que, quando elevado indica uma queda no seu valor nutritivo, pela destruição, por meio de aquecimento de algumas vitaminas e enzimas que são termolábeis.

De acordo com White Júnior (1992), nos países subtropicais, em função das altas temperaturas, os méis podem ter naturalmente um alto conteúdo de HMF sem que o mesmo tenha sido superaquecido ou adulterado.

O menor valor $\left(0,0 \mathrm{mg} \cdot \mathrm{kg}^{-1}\right)$ para $\mathrm{HMF}$ foi constatado por Thrasyvoulou \& Manikis (1995) em amostras de méis da Grécia e por Soria et al. 
(2004) em amostras de méis de Madri na Espanha. Já o maior valor (471 mg. $\mathrm{kg}^{-1}$ ) foi verificado por Mendes et al. (1998) avaliando a qualidade do mel português.

\subsubsection{Proteína}

Apesar do pouco conhecimento sobre as características do material protéico, a ocorrência de proteína em mel é utilizada na detecção de adulteração do produto comercial (Crane, 1975).

Dentre os aminoácidos encontrados no mel, a prolina é o que está presente em maior quantidade, representando cerca de $50-85 \%$ do total (White Júnior \& Rudyj, 1978). Os aminoácidos são produtos da quebra da proteína e existem em quantidades mínimas nos méis, sendo mais provenientes das abelhas do que da planta (Crane, 1983).

Dentre os trabalhos avaliados, o menor valor $(0,02 \%)$ para a proteína foi constatado por Archenti \& Dasso (1983) em méis argentinos. Já o maior valor $(2,79 \%)$ foi constatado por Amaral et al. (1986) em amostras de méis de flores de laranjeira produzidos no Estado de São Paulo.

\subsubsection{Cinzas}

O teor de cinzas expressa os minerais presentes no mel, o qual é bastante utilizado nas determinações que visam verificar sua qualidade. Os sais minerais encontrados no mel podem ser modificados por fatores relativos às abelhas, ao apicultor, clima, solo e origem botânica (Lasceve \& Gonnet, 1974; Bogdanov et al., 1997 e Carvalho et al., 2000b).

O mel contém a maioria dos elementos químicos essenciais para o organismo, dessa forma a sua inclusão na dieta diária ajudaria a eliminar a sua deficiência. Já foram identificados no mel inúmeros elementos químicos: $\mathrm{K}, \mathrm{Na}$, $\mathrm{Ca}, \mathrm{Mg}, \mathrm{Mn}, \mathrm{Ti}, \mathrm{Co}, \mathrm{Mo}, \mathrm{Fe}, \mathrm{Cu}, \mathrm{Li}, \mathrm{Ni}, \mathrm{Pb}, \mathrm{Sn}, \mathrm{Zn}, \mathrm{Os}, \mathrm{Ba}, \mathrm{Ga}, \mathrm{Bi}, \mathrm{Ag}, \mathrm{Au}, \mathrm{Ge}, \mathrm{Sr}$, 
Be, Va e Zn (White Júnior, 1979). Apesar da baixa porcentagem de minerais presente no mel, eles são considerados importantes do ponto de vista alimentício por apresentarem-se em forma diretamente assimiláveis (Frias \& Hardisson, 1992).

Os minerais influem na coloração do mel, estando presente em maior concentração nos méis escuros em comparação com os claros (Ortiz-Valbuena, 1988). Segundo Bogdanov (1999) o conteúdo de cinzas no mel é um critério de qualidade e está relacionado com a sua origem botânica. Assim, o mel de origem floral tem menos cinzas que o mel de origem não floral como o de "honeydew".

Para as cinzas, o menor valor constatado foi de 0,003\% por Soria et al. (2004) em amostras de méis de Madri na Espanha. Já o maior valor 1,2\% foi verificado por Thrasyvoulou \& Manikis (1995) em amostras de méis da Grécia.

\subsection{7 pH}

$\mathrm{O} \mathrm{pH}$ determinado em mel refere-se aos íons hidrogênio presente numa solução e pode influenciar na formação de outros componentes, como na velocidade de produção do hidroximetilfurfural (HMF) (Vidal \& Fregosi, 1984).

Em geral todos os méis são ácidos, sendo formados por ácidos orgânicos, alguns voláteis e outros inorgânicos (fosfórico, clorídrico, etc.) (Simal \& Hardisson, 1984).

$\mathrm{O}$ pH do mel é influenciado pela origem botânica, sendo geralmente inferior a 4 para mel de origem floral e superior a 4,5 para os méis de melato (Frías \& Hardisson 1992). Pode ainda ser influenciado pela concentração de diferentes ácidos, cálcio, sódio, potássio e outros constituintes das cinzas (Seemann \& Neira, 1988). Os méis brasileiros de Apis têm o valor de $\mathrm{pH}$, variando de 3,95 a 4,09, e os de meliponídeos de 3,39 a 4,63 (Cortopassi-Laurino \& Gelli, 1991). 
Flechtmann et al. (1963) e Marchini (2001) trabalhando com amostras de méis do Estado de São Paulo constataram 2,3 como o menor valor para o pH, enquanto que o maior valor $(7,2)$ foi verificado por Persano-Oddo et al. (1995), em méis italiano.

\subsubsection{Acidez}

O mel contém ácidos que contribuem para sua estabilidade frente ao desenvolvimento de microorganismos. Dentre os ácidos encontrados nos méis, o mais comum é o glucônico que é formado pela ação da enzima glicose-oxidase produzida pelas glândulas hipofaringeanas das abelhas (Horn et al., 1996 e Seemann \& Neira, 1988). Todos os outros ácidos estão presentes em quantidades menores (acético, benzóico, butírico, cítrico, fenilacético, fórmico, isovalérico, láctico, maléico, oxálico, propiônico, piroglutânico, succínico e valérico) (Crane, 1983).

Conforme Frías \& Hardisson (1992), quando o mel é aquecido em excesso forma-se o hidroximetilfurfural, por decomposição de certos açúcares, os quais, por sua vez, se decompõem em ácidos levulínicos e fórmico, contribuindo ambos para valores maiores de acidez.

Os ácidos dos méis estão dissolvidos em solução aquosa e produzem íons de hidrogênio que promovem acidez ativa, permitindo assim, indicar as condições de armazenamento e o processo de fermentação (Cornejo, 1988).

Nos trabalhos analisados, o menor valor $\left(2,3\right.$ meq. $\left.\mathrm{kg}^{-1}\right)$ para a acidez foi constatado por Persano-Oddo et al. (2004a) em méis uniflorais europeu. Já Komatsu (1996) analisando amostras de méis silvestres do Estado de São Paulo, constatou o maior valor de $\left(75,5\right.$ meq. $\left.\mathrm{kg}^{-1}\right)$. 


\subsection{9 Índice de formol}

O índice de formol é importante no mel por representar, predominantemente, os compostos aminados, permitindo assim, avaliar o seu conteúdo em peptídios, proteína e aminoácidos. Trata-se, pois, de um indicativo da presença de nitrogênio no mel (Simal \& Huidobro, 1984).

É um importante componente indicador de adulteração, pois quando muito baixo pode indicar a presença de produtos artificiais. Em contrapartida, quando excessivamente alto, mostra que as abelhas foram alimentadas com proteína hidrolizada (Huidobro \& Simal, 1984). Assim, o índice de formol pode ser utilizado para comprovar a autenticidade do mel (Frías \& Hardisson, 1992).

Dentre os trabalhos analisados para o índice de formol, verificou-se que o menor valor $\left(1,67 \mathrm{~mL} . \mathrm{kg}^{-1}\right)$ foi constatado por Sodré et al. (2002a), em amostras de méis da região litoral norte do Estado da Bahia, assim como o maior valor (29 $\left.\mathrm{mL} . \mathrm{kg}^{-1}\right)$.

\subsubsection{Condutividade elétrica}

A condutividade elétrica do mel tem valor na indicação da adulteração do mel e da sua origem; se formado de néctar (com alguma diferenciação de acordo com a espécie) ou de melato (Vorwohl, 1964 e Crane, 1983). Segundo Aganin (1971), a condutividade elétrica pode ser utilizada como método suplementar na determinação da origem botânica do mel.

A medida da condutividade elétrica pode fornecer um método rápido para estabelecer se o mel é ou não adequado para estoques de inverno das abelhas, pois alguns dos constituintes que aumentam a condutividade elétrica, também fazem com que o mel se torne inadequado para as abelhas durante 0 tempo frio (Crane, 1983). 
A condutividade elétrica tem correlação com o conteúdo de cinzas, $\mathrm{pH}$, acidez, sais minerais, além da proteína e outras substâncias presentes no mel (Stefanini, 1984; Crane, 1975 e Bogdanov, 1999).

Nos trabalhos avaliados verificou-se que o menor valor para a condutividade elétrica foi de $66 \mu$ S. $\mathrm{cm}^{-1}$ encontrado por Crecente \& Latorre (1993) em amostras de méis da Espanha. Já Almeida (2002) trabalhando com amostras de méis do cerrado paulista, encontrou o maior valor $\left(2200 \mu \mathrm{S} . \mathrm{cm}^{-1}\right)$.

\subsubsection{Viscosidade}

O conhecimento das propriedades reológicas do mel é necessário para o controle de qualidade e o conhecimento de sua estrutura, como também para a avaliação sensorial deste produto (Campos, 1998). A viscosidade e as outras propriedades físico-químicas do mel dependem de muitos fatores, incluindo a composição e a temperatura, sendo que um dos fatores de maior importância para a viscosidade é o conteúdo de água. Geralmente a viscosidade do mel decresce com o aumento do conteúdo de água (Abu-Jdayil et al., 2002).

Quando um líquido newtoniano flui, está sujeito a fricção interna, caracterizada pela viscosidade do líquido. A viscosidade depende grandemente do seu conteúdo de água e está assim ligada à sua densidade relativa (quanto menos água, mais alta a densidade e a viscosidade) e a temperatura (o mel pode fluir três vezes mais rapidamente com a elevação de $7^{\circ} \mathrm{C}$ na temperatura) (Crane, $1983 \mathrm{e}$ Abu-Jdayil et al., 2002).

Alguns méis possuem propriedade de fluxo anormais (não newtonianos). Os méis de Calluna vulgaris, Fagopyrum esculentum, Trifolium repens e Leptospermum scoparium na Nova Zelândia e Carvia callosa na Índia são bem conhecidos, por sua consistência parecida com gel. Normalmente eles fluem suficientemente para um extrator centrífugo, o que será possível se 
agitarmos. Esta propriedade conhecida como tixotropia é devida ao conteúdo relativamente alto de proteína no mel (Munroe, 1943 e Crane, 1983).

Em trabalhos com viscosidade de mel pode-se verificar que o menor valor foi constatado por Soria et al. (2004), que em amostras de méis de Madri na Espanha, encontrou $68 \mathrm{mPa}$.s. O maior valor (19200 mPa.s) foi verificado por Marchini \& Moreti (2001) em méis de Eucalyptus camaldulensis, produzidos no Estado de São Paulo.

\subsubsection{Cor}

No mercado mundial, a cor do mel é um fator determinante; os méis claros são os preferidos pelos consumidores, conseqüentemente, têm um maior valor comercial que os escuros. $\mathrm{O}$ sabor e o aroma dos méis, como de qualquer outro gênero alimentício, são muito mais difíceis de serem avaliados quantitativamente que a cor. Existe uma relação imperfeita entre a cor e o sabor, pois acredita-se que os méis com sabor agradável são sempre claros, enquanto que os méis escuros têm, normalmente, um sabor forte (Wootton et al., 1976; Crane, 1983 e Gonzáles et al., 1999).

Durante o armazenamento pode ocorrer o escurecimento do mel e, paralelamente, mudanças em suas propriedades organolépticas, influenciando na sua qualidade e aromas originais (Aubert \& Gonnet, 1983).

De acordo com Milum (1948), o escurecimento do mel durante a estocagem depende da cor inicial deste produto. O escurecimento do mel tem uma relação como a origem botânica, o processamento, o armazenamento, os fatores climáticos durante o fluxo do néctar e a temperatura na qual o mel amadurece na colméia (Smith,1967 e Seemann \& Neira, 1988). Alguns componentes do mel são determinantes para o escurecimento deste produto como: proporção de frutose/glicose, o conteúdo de nitrogênio e aminoácidos livres, 
as substâncias polifenólicas, o conteúdo de minerais e a instabilidade da frutose em solução ácida (Lynn et al., 1936; Schade et al., 1958 e Bath \& Singh, 1999).

O mel parece ser mais claro depois de ter sido cristalizado, devido, principalmente, à transparência do mel líquido e à opacidade do mel cristalizado. $A$ cor de qualquer amostra de mel cristalizada depende do tamanho do cristal; os mais finos fornecem a aparência mais clara (Crane, 1983).

Os autores como Pfau \& Ruhle (1986); Pamplona (1989); EscobarMartinez et al. (1992); Baldi-Coronel et al. (1993); Gómez et al. (1993); SerraBonvehí \& Ventura-Coll (1995); Persano-Oddo et al. (1995); Campos (1998); Carvalho et al. (1998, 2000a); Marchini et al. (2004a,b); Azeredo et al. (1999); Uñates et al. (1999); Marchini (2001), Marchini \& Moreti (2001); Almeida (2002); Almeida \& Marchini (2002); Moura et al. (2002); Sodré et al. (2002a,b); Anupama et al. (2003); Arruda (2003); Devillers et al. (2004); Diez et al. (2004); Mendonça et al. (2004) e Terrab et al. (2004) analisaram a cor de méis de diferentes origens e obtiveram uma predominância de cores claras.

\subsubsection{Elementos químicos}

Os elementos químicos são normalmente encontrados nos méis, mas quando em excesso são considerados poluentes. Os méis podem ser contaminados por estes poluentes através do ar, do solo e da água. Sendo assim, a análise dos elementos químicos deste produto pode fornecer informações quanto a qualidade alimentícia ou a poluição ambiental (Nobre, 1990).

A contaminação acidental do mel provém de várias fontes, como: resíduos de medicamentos usados nos tratamentos das doenças de abelhas que são administrados por via oral, misturados a um xarope de açúcar e resíduos de pesticidas, particularmente os inseticidas organoclorados e organofosforados (Louveaux, 1985). Também os lixões visitados por abelhas podem ser fontes de contaminação de mel por poluentes químicos. 
Dentre os poluentes mais perigosos, os elementos químicos tóxicos são os que têm tido prioridade em estudos. Os principais são: Cádmio, Mercúrio, Chumbo, Cobre, Zinco e Níquel, que estão presentes em baixas concentrações nas funções essenciais dos sistemas vivos, porém, podem tornar-se tóxicos quando são encontrados acima dos níveis normais, dependendo do tipo de organismo exposto (Nürnberg, 1982). O mesmo autor menciona que uma propriedade particular dos elementos químicos tóxicos é que são continuamente emitidos de fontes naturais do ambiente terrestre ou marinho.

Tong et al. (1975) relatam que fontes de poluição do ar e água por elementos químicos tóxicos e outros elementos químicos incluem a indústria, a mineração, a geração de energia e o escapamento de automóvel. Conforme os citados autores, a poluição a partir de mineração em um dado local pode ser limitada a um ou outro elemento químico, mas a contaminação industrial ou por geração de energia inclui um grande número de elementos químicos tóxicos ou a combinação destes. Emitidos por poluição atmosférica por meio da queima de óleo combustível ou outras fontes de tráfego urbano tem-se limites intoleráveis de: Alumínio, Cálcio, Cobre, Ferro, Chumbo, Magnésio, Silício, Bário, Cádmio, Crômio, Níquel, Paládio, Platina e outros que em certas regiões são prejudiciais à saúde.

Os elementos químicos tóxicos formam o único grupo de poluentes ambientais não biodegradáveis, atingindo o homem por meio dos alimentos e água para consumo. Embora uma fração da quantidade ingerida seja excretada, eles têm uma pronunciada tendência de acumulação nos órgãos vitais do homem, exercendo progressivamente, ação tóxica por longos períodos, que depende também da dose total acumulada, que por sua vez varia em função do tempo de exposição (Nürnberg, 1984).

A utilização das abelhas e seus produtos em trabalhos científicos, com análise de elementos químicos, visando a qualidade do produto e o 
monitoramento da poluição ambiental, vem sendo desenvolvido por pesquisadores como: Svoboda (1962); Tong et al. (1975); Bunzl \& Kracke (1981); Demalsy et al. (1989); Nobre (1990); Veleminskly et al. (1990); Iskander (1996); Kump et al. (1996); Leita et al. (1996); Merin et al. (1998); El-Etre (1998); Yilmaz \& Yavuz (1998); Caroli et al. (1999, 2000); Latorre et al. (1999); López-Garcia et al. (1999); Conti (2000); Sanna et al. (2000); Buldini et al. (2001); Celechovska \& Vorlova (2001); Przybylowski \& Wilczynska (2001); Braziewiez et al. (2002); Vorlova \& Celechovska (2002); Yazgan et al. (2002); Bogdanov et al. (2003); Nanda et al. (2003); Atrouse et al. (2004) e Taddia et al. (2004). Os autores constataram as seguintes variações, em $\mu \mathrm{g} \cdot \mathrm{g}^{-1}$ : Cálcio de 1-310; Cobre de 0,01-651; Silício de 1621; Cádmio de 0,0004-3,93; Zinco de 0,20-1144; Vanádio de <0,3-3,47; Manganês de 0,3-1905; Potássio de 95-1345; Sódio de 23-115; Estrôncio de 0,03-2,6; Selênio <3; Estanho de 1,22-27; Enxofre de 31-66; Ferro de 2,1-926; Titânio de 0,04-3,1; Magnésio de 5,8-173; Níquel de 0,02-186; Chumbo de 0,1-186; Prata $<0,3$; Cromo de 0,3-6,1; Cobalto de 0,05-1,0; Lítio de <0,3-9,2; Bário de 0,005-1,4; Molibdênio <0,6; Arsênio <0,4-3,18; Boro de 1,5-13; Fósforo de 37-150; Bromo 0,009-0,7; Rubídio 0,5-350; Mercúrio 0,67-2,93 e Alumínio de 0,09-71.

\subsection{Microorganismos no mel}

O mel é um produto com tipos e níveis mínimos de microorganismos que são atribuídos às suas propriedades naturais e ao seu controle na indústria. Porém, podem ser encontrados esporos de leveduras, fungos e bactérias vindas de fontes primárias quando o néctar está sendo colhido, armazenado e amadurecido. Os esporos também podem contaminar o mel durante 0 processamento, por estarem sempre no ar (Snowdon \& Cliver, 1996).

Existe um elevado interesse no número e tipo de microorganismos no mel, já que o mesmo é usado como alimento ou como componente de 
remédios ou cosméticos. Embora estes microorganismos (exceto algumas leveduras e fungos) não possam crescer no mel, podem persistir, serem transmitidos para um produto novo, no qual o mel é usado como ingrediente, e se multiplicarem até deteriorar este produto (Snowdon, 1999).

Os microorganismos podem ser introduzidos no mel ainda quando as abelhas estão elaborando-o (fonte primária) ou depois que o mel for colhido (fonte secundária). As fontes primárias de microorganismos são: pólen, trato digestivo da abelha, poeira, ar e flores (Gilliam, 1971 e Snowdon \& Cliver, 1996). Conforme (Gilliam et al., 1983), o néctar e o pólen contêm muitos microorganismos. Tysset \& Rousseau (1981) relatam que as fontes secundárias de microorganismos no mel como o homem, os equipamentos, os recipientes, o vento, a poeira, os insetos, os animais e a água sejam provavelmente iguais a de outros alimentos.

Normalmente, fungos e leveduras no mel são encontrados abaixo de 100 ufc. $^{-1}$ por serem controladas por práticas industriais que impedem a fermentação. Na teoria um microorganismo pode ser adicionado ao produto se não forem seguidas práticas sanitárias (Snowdon, 1999).

As leveduras são microorganismos que podem crescer no mel por tolerar as condições ácidas e níveis altos de sacarose, enquanto que as leveduras osmofílicas crescem quando a pressão osmótica é alta. Elas podem crescer até mesmo no mel maduro, fermentando-o facilmente (Snowdon, 1999). A fermentação do mel resulta no crescimento da levedura convertendo o açúcar em álcool, gás carbônico, ácidos orgânicos, e outras combinações com sabores e odores indesejáveis (Snowdon, 1999). As leveduras encontradas no mel com predominância são: Saccharomyces, Schizosaccharomyces e Torula (Migdal et al., 2000).

A porcentagem de umidade crítica para que as leveduras iniciem seu crescimento é da ordem de $21 \%$. Alguns fatores podem determinar o crescimento das leveduras como a inversão da sacarose em glicose e frutose, realizada pelas abelhas e a quantidade de nitrogênio disponível (Frazier \& Westhoff, 1993). Para 
Crane (1975), condições que favorecem a fermentação no mel incluem elevada umidade, temperatura moderada, granulação, alto conteúdo de leveduras e presença de cinzas e nitrogênio.

Os fungos estão associados com o conteúdo intestinal das abelhas, colméias e pasto apícola. Fungos, incluindo Aspergillus, Chaetomium, Penicillium, e Peyronelia, têm sido isolados de fezes de larvas de abelhas e do mel (Gilliam \& Prest, 1987).

A quantidade de bactérias presentes no mel pode variar com o tipo de mel (néctar ou "honeydew"), tipo da amostra (mel verde ou mel maduro), idade, tempo de colheita e técnica de análise utilizada (Snowdon, 1999). A presença de esporos da bactéria Clostridium botulinum em mel é especialmente perigosa para bebês e crianças pequenas que não têm o sistema imunológico completamente desenvolvido, também causam problemas se o mel for aplicado terapeuticamente. No primeiro caso, o mel pode provocar principalmente infecção alimentar enquanto no segundo pode ter princípio de contaminação em ferimento (Migdal et al., 2000). Segundo Snowdon \& Cliver (1996), alguns cientistas acreditam que C. botulinum possa se multiplicar em larvas de abelhas mortas no mel ou em colônias que são infectadas com Bacillus alvei.

A presença de esporos de leveduras, fungos e bactérias em méis são de grande importância, já que se trata de um alimento. Trabalhos científicos visando o conhecimento de microorganismos em méis tornam-se de grande importância, dos quais destacam-se: Gilliam (1971); Crane (1975); Ruiz-Argueso \& Rodríguez-Navarro (1975); Gilliam \& Valentine (1976); Furuta \& Okimoto (1978); Midura et al. (1979); Tysset \& Rousseau (1981); Gilliam et al. (1983); Gilliam \& Prest (1987); Nakano et al. (1990); Nakano \& Sakaguchi (1991); Piana et al. (1991); Frazier \& Westhoff (1993); Snowdon \& Cliver (1996); Snowdon (1999); Comi et al. (2000); Matuella \& Torres (2000); Migdal et al. (2000); Tantillo et al. (2000); Zucchi et al. (2001); Nevas et al. (2002); Shamala et al. (2002); Baggio et 
al. (2003); Barros et al. (2003); Hebbar et al. (2003); Martins te al. (2003) e Roll et al. (2003).

\subsection{Análises polínicas no mel}

Flora apícola é o conjunto de plantas em cujas flores as abelhas obtêm o néctar e o pólen. O conhecimento das plantas nectaríferas e poliníferas de cada região, a determinação da época da floração, o seu valor relativo como fonte de néctar e pólen é indispensável para aumentar a produção apícola (Ferreira, 1981).

A identificação das plantas utilizadas pelas abelhas assume grande importância, por indicar para os apicultores fontes adequadas e de abundante suprimento de néctar e pólen (Howes, 1953), principalmente considerando que a apicultura do Brasil visa o maior aproveitamento das riquezas que a vegetação natural oferece espontaneamente.

O pólen e o néctar das flores constituem praticamente a única fonte de alimento das abelhas, desde a fase larval à adulta (Freitas, 1991). O pólen é o fornecedor natural de proteína, graxas, vitaminas e sais minerais para as abelhas, sendo a única fonte de alimento nitrogenado disponível para a alimentação das larvas e a sua ausência pode levar a colméia à extinção (Bastos, 1998).

O conhecimento da flora apícola é importante na identificação de espécies vegetais que contribuíram na formação do mel produzido na região, como também é necessário na preservação e multiplicação destas plantas de potencial melífero, auxiliando para estabelecer uma apicultura sustentável (Moreti et al., 1998 e Santos Júnior \& Santos, 2002).

O pólen coletado involuntariamente pelas abelhas, no momento da coleta do néctar, tornando-se presente no mel elaborado, constitui importante 
indicador de sua origem botânica e, principalmente, geográfica (Barth, 1989 e Bastos, 2002).

A origem botânica dos méis é caracterizada por sua análise microscópica, especialmente a identificação e contagem de grãos de pólen. $O$ método é baseado na identificação do grão de pólen pela avaliação microscópica e comparação com laminário referência ou com os tipos polínicos descritos na literatura (D'Albore \& Persano-Oddo, 1978; Moore \& Webb, 1978 e Sawyer \& Pickard, 1988).

O levantamento palinológico quantitativo e qualitativo de uma amostra de mel constitui o seu espectro polínico (obtido pela análise polínica da amostra). Este espectro diz respeito às plantas produtoras de néctar, às não produtoras, as contaminações, falsificação e mistura (Barth, 1989). Através da análise quantitativa de grãos de pólen, é possível estabelecer a proporção que cada planta nectarífera contribui na constituição do mel, determinando assim a espécie botânica que deu origem ao mel (Iwama \& Melhem, 1979). A análise polínica qualitativa pode fornecer importantes dados, principalmente para a caracterização dos méis quanto a sua origem geográfica, origem botânica, época de coleta e posteriormente, quanto à determinação do mel de origem desconhecida ou duvidosa (Barth, 1989).

Trabalhos desenvolvidos por Santos (1961, 1963, 1964, 1974, 1978); Barth (1969, 1970 a,b,c,d,e, 1971a,b, 1989, 1990, 1996, 1998, 2004); Fernandes (1967); Durkee (1971); Bastos et al. (1991, 1995); Cortopassi-Laurino \& Gelli (1991); Freitas (1991); Seijo et al. (1992); Brandão et al. (1993); Bastos \& Brandão (1994); Brandão \& Bastos (1995); Chaves (1995); Magalhães et al. (1996); Marchini et al. (1997); Bastos (1998); Al-Khalifa \& Al-Arify (1999); Andrade et al. (1999); Carvalho \& Marchini (1999); Costa et al. (1999); De-Leonardis et al. (2000); Moreti et al. (2000a,b); Silva \& Absy (2000); Sodré (2000); Freitas (2001); Morlot et al. (2001); Sodré et al. (2001); Almeida (2002); Cano (2002); Motta Júnior 
et al. (2002); Santos Júnior \& Santos (2002); Arruda (2003); Bastos et al. (2003); Montenegro et al. (2003); Seijo et al. (2003); Terrab et al. (2003, 2004); Ampuero et al. (2004); Atrouse et al. (2004); Diez et al. (2004); Persano-Oddo et al. (2004b); Soria et al. (2004) e Van Der Ohe, et al. (2004) evidenciam a importância do pólen encontrado no mel para o conhecimento da origem botânica e geográfica da planta fornecedora de recursos, aumentando assim, a utilização desses recursos tróficos. 


\section{MATERIAL E MÉTODOS}

Foram colhidas 58 amostras de méis produzidos por Apis mellifera L., 1758 (Hymenoptera: Apidae) no período de fevereiro a agosto de 2002, diretamente de apicultores de diferentes municípios dos Estados do Ceará e Piauí: Ceará (Araripe 1 amostra; Santana do Cariri 1 amostra; Assaré 1 amostra; Iguatu 8 amostras; Crato 4 amostras; Missão Velha 2 amostras e Pacajús 3 amostras) e Piauí (Pimenteiras 2 amostras; Picos 35 amostras e Socorro do Piauí 1 amostra) (Figura 1).

As análises físico-químicas, microbiológicas e polínicas dos méis foram realizadas no Laboratório de Insetos Úteis do Departamento de Entomologia, Fitopatologia e Zoologia Agrícola da Escola Superior de Agricultura "Luiz de Queiroz", Campus de Piracicaba da Universidade de São Paulo. As análises dos elementos químicos foram realizadas no Laboratório de Apicultura da Escola Superior de Agricultura "Luiz de Queiroz" (obtenção das cinzas) e no Laboratório de Instrumentação Nuclear do Centro de Energia Nuclear na Agricultura/Universidade de São Paulo, Piracicaba, Estado de São Paulo.

Foram realizadas três repetições por amostra para cada parâmetro físico-químico e microbiológico analisado. Para a análise polínica foram realizadas duas contagens por amostras. 


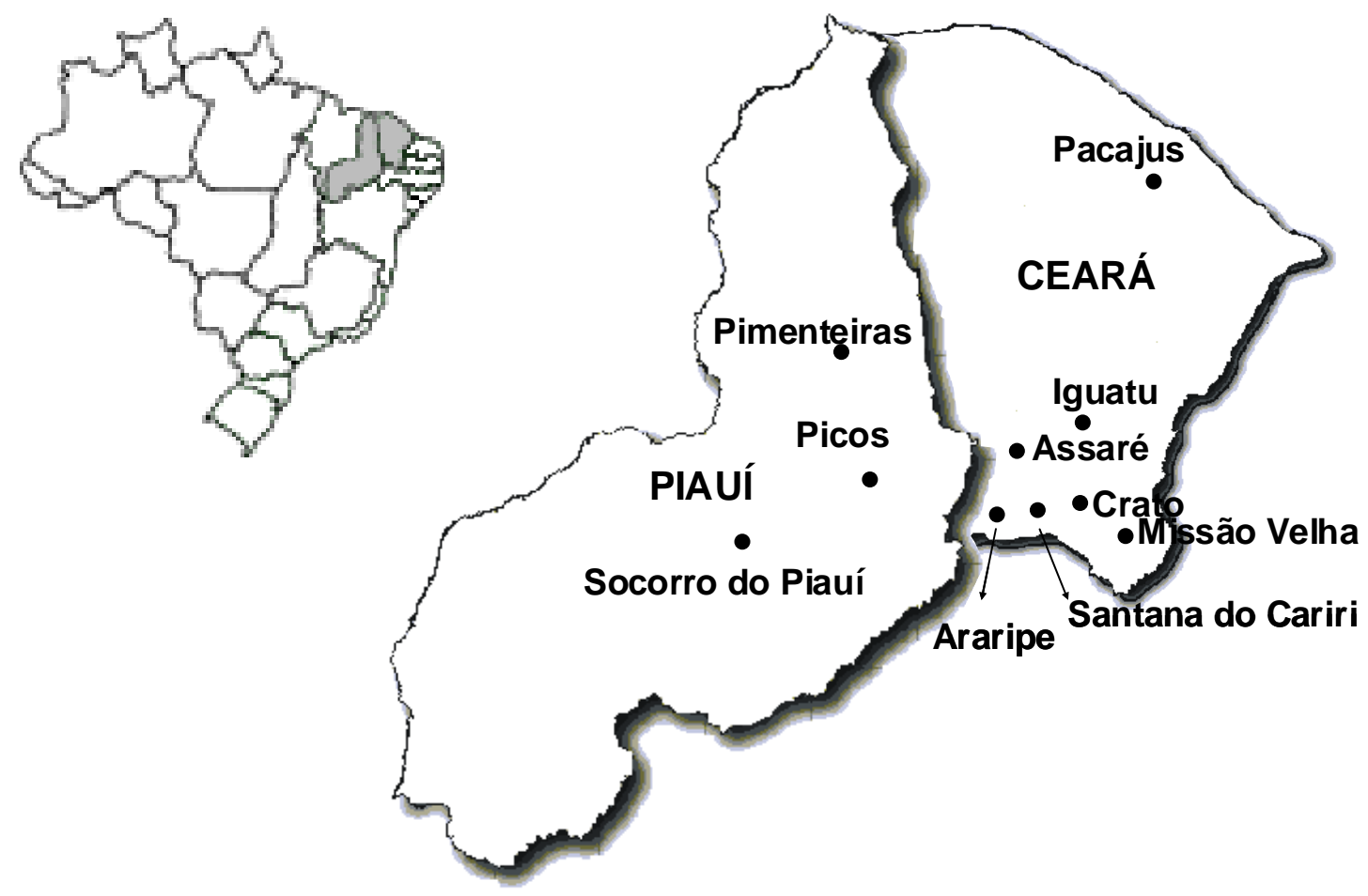

Figura 1- Localização geográfica dos Estados do Ceará e Piauí e respectivos municípios estudados 


\subsection{Análises físico-químicas dos méis}

3.1.1 Açúcares totais (AT), açúcares redutores (AR) e sacarose aparente (\%)

A determinação de açúcares totais (\%), açúcares redutores (\%) e sacarose aparente (\%) foram realizadas conforme o método Copersucar (1987) modificado por Marchini et al. (2004c).

\subsubsection{Umidade (\%)}

A umidade das diferentes amostras de méis foi determinada por meio de um refratômetro manual ATAGO (luz natural, temperatura ambiente) específico para mel. Este aparelho foi adaptado a partir do refratômetro Abbe e possui um alto contraste no campo de visão (ATAGO Co., 1988).

\subsubsection{Atividade diastásica (escala de Gothe)}

A atividade diastásica foi determinada conforme a metodologia de C.A.C. $(1990)$.

\subsubsection{Hidroximetilfurfural $\left(\mathrm{mg} \cdot \mathrm{kg}^{-1}\right)$}

O hidroximetilfurfural foi determinado conforme a metodologia de A.O.A.C. (1990). 


\subsubsection{Proteína (\%)}

A proteína do mel foi determinada seguindo a metodologia de Silva \& Queiroz (2002).

\subsubsection{Teor de Cinzas (\%)}

A determinação de cinzas foi realizada por meio da calcinação em mufla a $550^{\circ} \mathrm{C}$ até um peso constante (Pregnolato \& Pregnolato, 1985).

\subsection{7 pH e Acidez (meq. $\mathrm{kg}^{-1}$ )}

$\mathrm{O} \mathrm{pH}$ e a acidez foram determinados segundo a metodologia adotada pelo Laboratório do Centro de Apicultura Tropical do Instituto de Zootecnia de Pindamonhangaba, SP (Moraes \& Teixeira, 1998).

\subsection{8 Índice de formol ( ${\left.\mathrm{mL} . \mathrm{kg}^{-1}\right)}^{-1}$}

O índice de formol foi determinado segundo a metodologia adotada pelo Laboratório do Centro de Apicultura Tropical do Instituto de Zootecnia de Pindamonhangaba, SP (Moraes, 1994).

\subsubsection{Condutividade elétrica $\left(\mu \mathrm{S} . \mathrm{cm}^{-1}\right)$}

A condutividade elétrica foi obtida em uma solução a $20 \%$ de matéria seca de mel a $20^{\circ} \mathrm{C}$ (B.O.E., 1986). Para tanto foi utilizado o condutivímetro modelo HI 8820. 


\subsubsection{Viscosidade (mPa.s)}

A viscosidade foi determinada por meio do viscosímetro Brookfield, modelo 100 S digital (A.S.T.M., s.d.p.).

\subsubsection{Cor}

A classificação da cor dos méis foi realizada em espectrofotômetro a $560 \mathrm{~nm}$ em célula de $1 \mathrm{~cm}$ e usando-se como branco a glicerina pura. Posteriormente o valor encontrado foi transformado em cor pela escala de Pfund (Vidal \& Fregosi, 1984).

\subsubsection{Elementos químicos}

Inicialmente obtiveram-se as cinzas do mel por meio da queima de aproximadamente $10 \mathrm{~g}$ da amostra em cadinho de porcelana por calcinação em mufla a $550^{\circ} \mathrm{C}$ até um peso constante, obtendo-se assim a porcentagem de cinzas (Pregnolato \& Pregnolato, 1985).

As amostras de cinzas foram submetidas a digestão via úmida (Ward et al. 1980) em sistema aberto usando-se $\mathrm{HNO}_{3} / \mathrm{H}_{2} \mathrm{O}_{2}\left(\mathrm{t}=130^{\circ} \mathrm{C} \pm 5^{\circ} \mathrm{C}\right)$. Após a obtenção de uma solução límpida o volume foi completado a $10 \mathrm{~mL}$ com água deionizada. Para um volume de $1 \mathrm{~mL}$ desta solução foram adicionados $10 \mu \mathrm{L}$ de Ga (padrão interno, $1000 \mu \mathrm{g} \cdot \mathrm{mL}^{-1}$ ). Uma alíquota de $20 \mu \mathrm{L}$ foi pipetada no centro de um disco de lucite ( $3 \mathrm{~cm}$ de diâmetro) e seco sob ação de luz infravermelha. As amostras foram preparadas em triplicata e detectadas em espectrômetro de raio- $\mathrm{x}$ por $300 \mathrm{~s}$. 


\subsection{Análises de microorganismos dos méis}

Foram analisados coliformes totais (número mais provável -nmp), fungos e leveduras (plaqueamento em superfície usando o ágar batata dextrose acidificado) utilizando as metodologias descritas por Vanderzant \& Splittstoesser (1992).

\subsection{Análises polínicas dos méis}

Todas as amostras de méis foram preparadas utilizando-se o método da acetólise (Erdtman, 1952) e em seguida submetidas a uma análise qualitativa e outra quantitativa.

\subsubsection{Método qualitativo}

A análise qualitativa (tipos polínicos presentes nas amostras) foi determinada por comparação com o laminário referência e as descrições obtidas em literatura especializada (Barth, 1970 a,b,c, 1971a,b, 1989, 1990).

\subsubsection{Método quantitativo}

A análise quantitativa foi realizada por meio de contagem consecutiva de 300 grãos de pólen/repetição/amostra determinando-se as porcentagens e classes de ocorrência que segundo Louveaux et al. (1978) são: pólen dominante (>45\% do total de grãos) (PD), pólen acessório (16 a 45\%) (PA), pólen isolado importante (3 a 15\%) (Pii) e pólen isolado ocasional (<3\%) (Pio). Os resultados apresentados são as médias de duas contagens. 


\subsection{Análise dos dados}

Os dados foram processados usando o SAS (1990), obtendo-se as médias (três repetições), o intervalo de confiança e análise multivariada.

A análise de componentes principais foi utilizada para avaliar a importância de cada caracter físico-químico e elemento químico estudado sobre a variação total disponível (Mardia et al., 1979). Esta técnica baseia-se na padronização e rotação dos eixos ortogonais (caracteres físico-químicos e elementos químicos), gerando um novo conjunto de coordenadas (componentes principais) não correlacionadas entre si (Morrison, 1981). Foi realizado um descarte dos caracteres altamente correlacionados, utilizando-se o critério proposto por Joliffe (1973) desprezando-se a variável de maior coeficiente em cada componente com autovalor menor que 0,70 .

Para a análise de agrupamento utilizou-se a distância euclideana média e o método UPGMA (unweighted pair-group average) a partir dos dados padronizados (Cruz \& Regazzi, 1994). 


\section{RESULTADO E DISCUSSÃO}

\subsection{Análises físico-químicas}

Os resultados das análises físico-químicas em 58 amostras de méis produzidos por Apis mellifera, de diferentes municípios dos Estados do Ceará (20 amostras) e Piauí (38 amostras) estão apresentados nas Tabelas 1 e 2.

$\mathrm{Na}$ Tabela 3 observam-se os valores estabelecidos pela norma vigente, as médias, os intervalos de confiança, os valores máximos e mínimos de cada um dos parâmetros analisados. 
Tabela 1. Valores médios dos parâmetros físico-químicos de 20 amostras de méis de Apis mellifera de diferentes municípios do Estado do Ceará

\begin{tabular}{|c|c|c|c|c|c|c|c|c|c|c|c|c|c|c|}
\hline Amostras & $\begin{array}{l}\mathrm{AT}^{*} \\
(\%)\end{array}$ & $\begin{array}{l}\mathrm{AR}^{*} \\
(\%)\end{array}$ & $\begin{array}{l}\mathrm{S}^{*} \\
(\%)\end{array}$ & $\begin{array}{l}\mathrm{U}^{*} \\
(\%)\end{array}$ & $\begin{array}{c}\mathrm{AD}^{*} \\
\text { (escala de } \\
\text { Gothe) }\end{array}$ & $\begin{array}{c}\mathrm{HMF}^{*} \\
\left(\mathrm{mg} \cdot \mathrm{kg}^{-1}\right)\end{array}$ & $\begin{array}{c}\text { Proteína } \\
(\%)\end{array}$ & $\begin{array}{c}\text { Cinzas } \\
(\%)\end{array}$ & $\mathrm{pH}$ & $\begin{array}{c}\text { Acidez } \\
\left(\text { meq.kg }{ }^{1}\right)\end{array}$ & $\begin{array}{c}\mathrm{IF}^{*} \\
\left(\mathrm{~mL} . \mathrm{Kg}^{1}\right)\end{array}$ & $\begin{array}{c}\mathrm{CE}^{*} \\
\left(\mu \mathrm{S} . \mathrm{cm}^{1}\right)\end{array}$ & $\begin{array}{l}\text { Viscosidade } \\
\text { (mPa.s) }\end{array}$ & Cor \\
\hline 1 & 85,5 & 79,3 & 5,9 & 15,7 & 12,2 & 1,75 & 0,298 & 0,085 & 3,6 & 17,6 & 9,6 & 292,6 & 1516,0 & branco água \\
\hline 2 & 86,0 & 80,1 & 5,6 & 17,2 & 5,3 & 8,78 & 0,172 & 0,013 & 3,5 & 10,0 & 4,0 & 192,0 & 2080,0 & branco \\
\hline 3 & 84,8 & 84,6 & 0,1 & 19,0 & 6,5 & 3,79 & 0,199 & 0,033 & 3,6 & 14,6 & 7,6 & 226,6 & 1772,0 & âmbar extra claro \\
\hline 4 & 79,7 & 76,4 & 3,1 & 19,0 & 5,3 & 20,76 & 0,181 & 0,115 & 3,5 & 18,3 & 6,0 & 240,6 & 1888,0 & âmbar extra claro \\
\hline 5 & 83,4 & 82,4 & 0,9 & 18,3 & 10,4 & 36,73 & 0,297 & 0,220 & 3,7 & 28,0 & 10,0 & 488,6 & 1048,0 & âmbar claro \\
\hline 6 & 79,4 & 79,1 & 0,2 & 18,3 & 11,7 & 98,40 & 0,458 & 0,405 & 3,7 & 35,0 & 7,0 & 798,6 & 1052,0 & âmbar claro \\
\hline 7 & 80,0 & 78,6 & 1,3 & 19,5 & 11,7 & 3,99 & 0,258 & 0,165 & 3,3 & 33,0 & 8,0 & 317,0 & 728,0 & branco \\
\hline 8 & 81,6 & 78,6 & 2,9 & 18,8 & 7,1 & 2,20 & 0,130 & 0,116 & 3,4 & 23,0 & 5,0 & 208,0 & 996,0 & âmbar extra claro \\
\hline 9 & 83,9 & 82,0 & 1,8 & 19,8 & 7,1 & 37,57 & 0,159 & 0,143 & 3,4 & 26,0 & 7,0 & 240,0 & 536,0 & âmbar extra claro \\
\hline 10 & 80,7 & 80,2 & 0,4 & 19,3 & 10,5 & 13,27 & 0,240 & 0,178 & 3,4 & 30,0 & 6,0 & 353,6 & 740,0 & âmbar \\
\hline 11 & 80,0 & 78,2 & 1,7 & 18,2 & 26,9 & 6,94 & 0,403 & 0,107 & 3,4 & 37,0 & 10,0 & 434,0 & 1188,0 & âmbar \\
\hline 12 & 81,0 & 73,8 & 6,8 & 17,8 & 31,2 & 18,11 & 0,580 & 0,157 & 3,5 & 40,0 & 11,0 & 584,3 & 1368,0 & âmbar \\
\hline 13 & 77,8 & 76,8 & 0,9 & 19,7 & 13,5 & 71,46 & 0,295 & 0,183 & 3,3 & 35,0 & 9,0 & 556,3 & 696,0 & âmbar claro \\
\hline 14 & 79,6 & 79,1 & 0,4 & 18,7 & 10,6 & 126,50 & 0,363 & 0,164 & 3,6 & 37,0 & 8,0 & 658,3 & 1052,0 & âmbar \\
\hline 15 & 76,9 & 73,3 & 3,4 & 20,2 & 19,6 & 8,43 & 0,399 & 0,216 & 3,5 & 33,0 & 10,0 & 381,6 & 552,0 & âmbar extra claro \\
\hline 16 & 82,4 & 79,9 & 2,3 & 19,4 & 7,3 & 74,85 & 0,349 & 0,327 & 3,7 & 38,0 & 7,0 & 603,0 & 788,0 & âmbar claro \\
\hline 17 & 79,9 & 79,3 & 0,6 & 20,2 & 6,9 & 17,02 & 0,312 & 0,171 & 3,5 & 25,0 & 6,0 & 345,0 & 608,0 & âmbar claro \\
\hline 18 & 86,0 & 78,0 & 7,6 & 18,3 & 40,4 & 26,90 & 0,569 & 0,205 & 3,5 & 42,0 & 11,0 & 678,6 & 1440,0 & âmbar claro \\
\hline 19 & 86,8 & 80,5 & 5,9 & 18,2 & 43,3 & 26,80 & 0,706 & 0,271 & 3,7 & 38,0 & 13,0 & 766,3 & 1150,0 & âmbar claro \\
\hline 20 & 77,6 & 75,9 & 1,6 & 18,6 & 41,3 & 24,70 & 0,613 & 0,273 & 3,5 & 42,0 & 12,0 & 689,6 & 1410,0 & âmbar claro \\
\hline
\end{tabular}


Tabela 2. Valores médios dos parâmetros físico-químicos de 38 amostras de méis de Apis mellifera de diferentes municípios do Estado do Piauí

\begin{tabular}{|c|c|c|c|c|c|c|c|c|c|c|c|c|c|c|}
\hline Amostras & $\begin{array}{l}\mathrm{AT}^{*} \\
(\%)\end{array}$ & $\begin{array}{l}\mathrm{AR}^{*} \\
(\%)\end{array}$ & $\begin{array}{l}\mathrm{S}^{*} \\
(\%)\end{array}$ & $\begin{array}{l}U^{*} \\
(\%)\end{array}$ & $\begin{array}{c}\mathrm{AD}^{*} \\
\text { (escala de } \\
\text { Gothe) }\end{array}$ & $\begin{array}{c}\mathrm{HMF}^{*} \\
\left(\mathrm{mg}^{-1} \mathrm{~kg}^{-1}\right)\end{array}$ & $\begin{array}{c}\text { Protéńa } \\
(\%)\end{array}$ & $\begin{array}{c}\text { Cinzas } \\
(\%)\end{array}$ & $\mathrm{pH}$ & $\begin{array}{c}\text { Acidez } \\
\left(\text { meq.kg }{ }^{-1}\right)\end{array}$ & $\begin{array}{c}\mathrm{IF}^{*} \\
\left(\mathrm{~mL} \cdot \mathrm{Kg}^{-1}\right)\end{array}$ & $\begin{array}{c}\mathrm{CE}^{\star} \\
\left(\mathrm{mS} \cdot \mathrm{cm}^{-1}\right)\end{array}$ & $\begin{array}{l}\text { Viscosidade } \\
\text { (mPa.s) }\end{array}$ & Cor \\
\hline 1 & 81,5 & 76,2 & 5,1 & 18,7 & 15,9 & 1,9 & 0,193 & 0,019 & 3,4 & 18,0 & 6,7 & 228,3 & 3276,0 & branco \\
\hline 2 & 88,7 & 88,4 & 0,3 & 17,5 & 17,1 & 2,6 & 0,216 & 0,054 & 3,4 & 20,7 & 6,3 & 318,0 & 1928,0 & branco \\
\hline 3 & 80,3 & 79,7 & 0,6 & 18,5 & 7,9 & 24,6 & 0,235 & 0,142 & 3,5 & 25,0 & 8,0 & 352,3 & 1224,0 & âmbar extra claro \\
\hline 4 & 82,4 & 79,1 & 3,2 & 16,4 & 5,9 & 7,2 & 0,122 & 0,139 & 3,6 & 11,0 & 5,0 & 225,3 & 2972,0 & branco \\
\hline 5 & 80,7 & 78,6 & 2,0 & 18,7 & 8,1 & 21,7 & 0,190 & 0,151 & 3,5 & 23,0 & 5,0 & 302,0 & 976,0 & âmbar claro \\
\hline 6 & 83,3 & 78,0 & 5,1 & 17,3 & 7,3 & 19,2 & 0,188 & 0,116 & 3,6 & 15,0 & 6,0 & 283,0 & 2056,0 & âmbar extra claro \\
\hline 7 & 84,2 & 80,9 & 3,1 & 16,8 & 6,2 & 9,1 & 0,115 & 0,165 & 3,9 & 10,0 & 5,0 & 235,7 & 2524,0 & branco \\
\hline 8 & 81,7 & 74,7 & 6,7 & 16,8 & 6,1 & 8,3 & 0,137 & 0,072 & 3,6 & 12,0 & 5,0 & 221,0 & 2600,0 & branco \\
\hline 9 & 84,7 & 81,0 & 3,5 & 18,9 & 9,1 & 9,3 & 0,366 & 0,161 & 3,4 & 30,0 & 11,0 & 381,0 & 1076,0 & âmbar extra claro \\
\hline 10 & 84,5 & 81,0 & 3,3 & 18,7 & 7,9 & 5,4 & 0,184 & 0,154 & 3,6 & 19,0 & 7,0 & 272,3 & 1320,0 & âmbar extra claro \\
\hline 11 & 80,9 & 79,7 & 1,2 & 18,1 & 9,1 & 115,2 & 0,289 & 0,155 & 3,6 & 24,0 & 7,0 & 373,0 & 1396,0 & escuro \\
\hline 12 & 78,3 & 78,0 & 0,2 & 18,2 & 6,6 & 1,5 & 0,287 & 0,047 & 3,5 & 17,0 & 6,0 & 203,7 & 1592,0 & âmbar extra claro \\
\hline 13 & 83,0 & 82,8 & 0,2 & 17,1 & 6,2 & 5,9 & 0,187 & 0,092 & 3,6 & 11,0 & 5,0 & 193,0 & 2396,0 & âmbar extra claro \\
\hline 14 & 84,6 & 82,8 & 1,7 & 17,8 & 6,1 & 3,9 & 0,169 & 0,073 & 3,6 & 14,0 & 5,0 & 229,3 & 1604,0 & âmbar extra claro \\
\hline 15 & 83,4 & 81,0 & 2,2 & 17,9 & 6,8 & 14,0 & 0,187 & 0,112 & $\begin{array}{l}3,0 \\
3,5\end{array}$ & 15,0 & $\begin{array}{l}6,0 \\
6,0\end{array}$ & 204,0 & 1780,0 & âmbar extra claro \\
\hline 16 & 85,7 & 80,9 & 4,6 & 17,2 & 5,6 & 7,7 & 0,131 & 0,096 & 3,6 & 11,0 & 5,0 & 192,0 & 2476,0 & branco \\
\hline 17 & 84,1 & 78,8 & 5,0 & 18,9 & 9,8 & 12,1 & 0,212 & 0,143 & 3,5 & 19,0 & 6,0 & 316,0 & 960,0 & âmbar extra claro \\
\hline 18 & 77,3 & 74,7 & 2,5 & 19,0 & 9,7 & 11,8 & 0,210 & 0,149 & 3,5 & 22,0 & 7,0 & 318,3 & 1020,0 & âmbar extra claro \\
\hline 19 & 84,7 & 78,8 & 5,6 & 18,6 & 10,3 & 9,1 & 0,214 & 0,114 & 3,4 & 23,0 & 8,0 & 330,0 & 1192,0 & âmbar extra claro \\
\hline 20 & 84,1 & 77,6 & 6,2 & 18,1 & $\begin{array}{l}12,1 \\
12,0\end{array}$ & 11,3 & 0,191 & 0,088 & $\begin{array}{l}3,4 \\
3,5\end{array}$ & 17,0 & $\begin{array}{l}6,0 \\
6,0\end{array}$ & 288,0 & 1448,0 & $\begin{array}{l}\text { branco } \\
\text { bant }\end{array}$ \\
\hline 21 & 82,6 & 77,6 & 4,8 & 17,8 & 11,7 & 10,2 & 0,197 & 0,073 & 3,5 & 16,0 & 5,0 & 276,0 & 1560,0 & branco \\
\hline 22 & 84,2 & 78,4 & 5,5 & 18,1 & 12,7 & 9,6 & 0,178 & 0,078 & 3,5 & 19,0 & 6,0 & 293,7 & 1456,0 & âmbar extra claro \\
\hline 23 & 84,7 & 80,8 & 3,7 & 17,5 & 9,2 & 12,0 & 0,135 & 0,114 & 3,5 & 15,0 & 5,0 & 243,7 & 1804,0 & branco \\
\hline 24 & 84,7 & 78,6 & 5,8 & 17,3 & 5,6 & 7,4 & 0,119 & 0,075 & 3,6 & 12,0 & 5,0 & 194,3 & 2092,0 & branco \\
\hline 25 & 83,7 & 79,3 & 4,2 & 17,7 & $\begin{array}{l}7,0 \\
7,1\end{array}$ & $\begin{array}{l}9,0 \\
9,0\end{array}$ & 0,155 & 0,072 & $\begin{array}{l}3,0 \\
3,6\end{array}$ & 16,0 & $\begin{array}{l}5,0 \\
5,0\end{array}$ & 230,3 & 1568,0 & âmbar extra claro \\
\hline 26 & 82,9 & 78,1 & 4,6 & 16,7 & 5,6 & 6,2 & 0,128 & 0,050 & 3,6 & 12,0 & 5,0 & 195,7 & 2696,0 & âmbar extra claro \\
\hline 27 & 83,8 & 81,7 & 2,0 & 18.6 & 5,3 & 4.4 & 0,176 & 0,077 & 3,5 & 22,0 & 6,0 & 233,7 & 1136,0 & âmbar claro \\
\hline 28 & 81,4 & $\begin{array}{l}0,1 \\
79,9\end{array}$ & 1,5 & 18,3 & 6,4 & $\begin{array}{r}4,4 \\
44,1\end{array}$ & 0,180 & 0,111 & 3,5 & 19,0 & $\begin{array}{l}7,0 \\
7,0\end{array}$ & 215,7 & 1756,0 & âmbar claro \\
\hline 29 & 81,2 & 80,3 & 0,8 & 18,1 & 6,5 & 15,1 & 0,196 & 0,113 & 3,5 & 17,0 & 5,0 & 219,0 & 1056,0 & âmbar claro \\
\hline 30 & 77,1 & 75,5 & 1,5 & 18,7 & 8,6 & 6,4 & 0,141 & 0,115 & 3,5 & 25,0 & $\begin{array}{l}6,0 \\
6,0\end{array}$ & 220,0 & 1624,0 & âmbar extra claro \\
\hline 31 & 82,6 & 76,8 & 5,5 & 17,6 & 10,6 & 10,3 & 0,151 & 0,112 & 3,5 & 16,0 & 6,0 & 267,3 & 1624,0 & branco \\
\hline 32 & 81,9 & 77,5 & 4,1 & 18,7 & 11,0 & 10,4 & 0,157 & 0,179 & 3,5 & 25,0 & 6,0 & 315,0 & 1048,0 & âmbar extra claro \\
\hline 33 & 85,8 & 80,4 & 5,2 & 18,7 & 11,1 & 9,7 & 0,200 & 0,164 & 3,5 & 20,0 & 6,0 & 319,0 & 1024,0 & âmbar extra claro \\
\hline 34 & 82,8 & 81,7 & 1,0 & 18,0 & 11,8 & 10,1 & 0,186 & 0,092 & 3,5 & 16,0 & 6,0 & 305,7 & 1448,0 & âmbar extra claro \\
\hline 35 & 83,7 & 78,7 & 4,8 & 18,8 & 11,8 & 8,2 & 0,224 & 0,136 & 3,5 & 24,0 & $\begin{array}{l}7,0 \\
7,0\end{array}$ & 358,7 & 1044,0 & âmbar extra claro \\
\hline 36 & 84,2 & 80,1 & 3,9 & 18,7 & 5,4 & 15,3 & 0,162 & 0,085 & 3,5 & 21,0 & 6,0 & 286,7 & 1240,0 & âmbar \\
\hline 37 & 87,0 & 74,9 & 11.4 & 189 & 7,3 & 25,9 & 0,165 & 0,074 & 3,6 & 13,0 & 5,0 & 272,3 & 3436,0 & âmbar extra claro \\
\hline 38 & 86,8 & 80,8 & 5,7 & 17,8 & 7,3 & 7,4 & 0,197 & 0,048 & 3,8 & 16,0 & 6,0 & 294,7 & 1964,0 & âmbar claro \\
\hline
\end{tabular}

condutividade elétrica. 
Tabela 3. Valores estabelecidos pela norma vigente, médias, intervalos de confiança, mínimos e máximos encontrados nas análises físico-químicas de 58 amostras de méis de Apis mellifera dos Estados do Ceará (20 amostras) e do Piauí (38 amostras)

\begin{tabular}{|c|c|c|c|c|c|c|c|}
\hline \multirow{2}{*}{ Parâmetros analisados } & \multirow{2}{*}{$\begin{array}{l}\text { Brasil } \\
(2000)\end{array}$} & \multicolumn{3}{|c|}{ Ceará } & \multicolumn{3}{|c|}{ Piauí } \\
\hline & & Média & Mínimo & Máximo & Média & Mínimo & Máximo \\
\hline Açúcares totais $(\%)$ & ---------- & $81,69 \pm 1,32^{*}$ & 76,95 & 86,82 & $83,13 \pm 0,77^{*}$ & 77,09 & 88,66 \\
\hline Açúcares redutores (\%) & Mínimo 65 & $78,84 \pm 1,18^{*}$ & 73,37 & 84,65 & $79,31 \pm 0,82^{*}$ & 74,68 & 88,39 \\
\hline Sacarose aparente (\%) & Máxima 6 & $2,71 \pm 1,05^{*}$ & 0,16 & 7,63 & $3,64 \pm 0,73^{*}$ & 0,15 & 11,44 \\
\hline Umidade (\%) & Máxima 20 & $18,73 \pm 0,46^{*}$ & 15,77 & 20,27 & $18,03 \pm 0,22^{*}$ & 16,44 & 19,00 \\
\hline Atividade diastásica (escala de Gothe) & Mínimo 8 & $16,48 \pm 5,62^{*}$ & 5,30 & 43,39 & $8,64+0,92^{*}$ & 5,29 & 17,13 \\
\hline $\mathrm{HMF}\left(\mathrm{mg} \cdot \mathrm{kg}^{-1}\right)$ & Máxima 60 & $31,45+15,21^{*}$ & 1,75 & 126,50 & $13,78 \pm 5,91^{*}$ & 1,53 & 115,22 \\
\hline Proteína (\%) & -------- & $0,35 \pm 0,07^{*}$ & 0,13 & 0,71 & $0,19 \pm 0,01^{*}$ & 0,11 & 0,37 \\
\hline Cinzas (\%) & Máxima 0,6 & $0,18 \pm 0,04^{*}$ & 0,01 & 0,41 & $0,11 \pm 0,01^{*}$ & 0,02 & 0,18 \\
\hline $\mathrm{PH}$ & --------- & $3,57 \pm 0,05^{*}$ & 3,36 & 3,78 & $3,53 \pm 0,02^{*}$ & 3,39 & 3,87 \\
\hline Acidez (meq. $\mathrm{kg}^{-1}$ ) & Máxima 50 & $30,13+4,14^{*}$ & 10,00 & 42,00 & $17,91 \pm 1,54^{*}$ & 10,00 & 30,00 \\
\hline Índice de formol (mL. $\left.\mathrm{kg}^{-1}\right)$ & --------- & $8,37 \pm 1,06^{*}$ & 4,00 & 13,00 & $6,03 \pm 0,37^{*}$ & 5,00 & 11,00 \\
\hline Condutividade elétrica $\left(\mu \mathrm{S} . \mathrm{cm}^{-1}\right)$ & --------- & $452,77 \pm 87,62^{*}$ & 192,00 & 798,67 & $268,62 \pm 17,27^{\star}$ & 192,00 & 381,00 \\
\hline Viscosidade (mPa.s) & --------- & $1130,40 \pm 198,26^{*}$ & 536,00 & 2080,00 & $1720,84 \pm 210,68^{*}$ & 960,00 & 3436,00 \\
\hline
\end{tabular}

* intervalo de confiança 


\subsubsection{Açúcares totais}

As porcentagens de açúcares totais encontradas nas 58 amostras de méis analisadas variaram de 76,95 a 86,82\% (com o valor médio de 81,69 \%) para o Estado do Ceará e 77,09 a 88,66\%, (com o valor médio de 83,13\%) para o Estado do Piauí (Tabelas 1, 2 e 3). Para os açúcares totais não existe valor estabelecido na norma vigente, e por esta razão não foram feitas comparações.

Os valores observados para os dois estados estão próximos aos obtidos por: Rodrigues et al. (1996), Campos (1998), Marchini (2001), Almeida (2002), Komatsu et al. (2002), Sodré et al. (2002a), Arruda (2003) e Marchini et al. $(2004 a, b)$ que em méis brasileiros de diferentes origens florais, constataram para os açúcares totais, uma variação de 67,8 a $88,3 \%$.

\subsubsection{Açúcares redutores}

Os teores de açúcares redutores das 58 amostras analisadas variaram de 73,37 a $84,65 \%$ (com o valor médio de 78,84\%) para o Estado do Ceará e 74,68 a $88,39 \%$ (com o valor médio de 79,3\%) para o Estado do Piauí (Tabelas 1, 2 e 3). A norma vigente estabelece um valor mínimo de $65 \%$. No trabalho em estudo observou-se que os valores de todas as amostras encontramse acima do estabelecido como limite mínimo. A Figura 2 (a,b) representa as porcentagens das amostras de méis analisadas que se enquadram nas normas vigentes, onde verifica-se que $100 \%$ das amostras dos Estados do Ceará (a) e do Piauí (b) estão em conformidade com a norma vigente. 


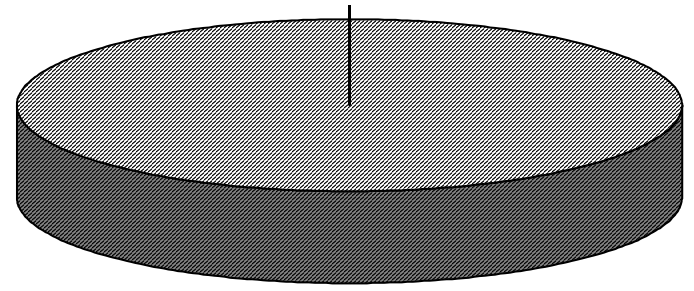

$100 \%$

$\square$ Aceitável-

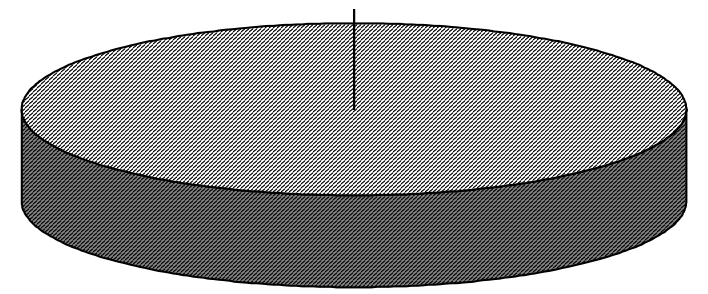

$100 \%$

글 Aceitável

(a)

(b)

Figura $2(a, b)$ - Porcentagens de amostras de méis dos Estados do Ceará (20 amostras) e do Piauí (38 amostras) que apresentaram o parâmetro açúcares redutores aceitáveis, segundo a legislação brasileira

No presente trabalho os valores obtidos estão próximos aos encontrados por Arruda (2003) que analisando amostras de méis da Região da Chapada do Araripe no Estado do Ceará encontrou valores para açúcares redutores variando de 74,76 a $81,99 \%$. Já Carneiro et al. (2002) estudando méis de Simplício Mendes no Estado do Piauí constataram uma variação de 70,38 a $87,39 \%$ para açúcares redutores, com limite inferior e superior pouco abaixo dos constatados no presente estudo para o Estado do Piauí.

Os valores médios constatados nos dois estados estão próximos aos observados por: Flechtmann et al. (1963); Dozo (1980); Moraes \& Mantovani (1986); Baldi-Coronel et al. (1993); Vit-Oliver et al. (1994); Komatsu (1996); Rodrigues et al. (1996); Uñates et al. (1999); Marchini (2001); Almeida (2002); Anupama et al. (2003); Montenegro et al. (2003) e Marchini et al. (2004a,b) que em méis de diferentes origens florais constataram para os açúcares redutores, valores médios variando de 75,7 a $81,9 \%$. 


\subsubsection{Sacarose aparente}

As concentrações de sacarose aparente encontradas nas 58 amostras analisadas variaram de 0,16 a 7,63\% (com valor médio de 2,71\%), para o Estado do Ceará e 0,15 a 11,44\% (com valor médio de 3,64\%), para o Estado do Piauí (Tabelas 1, 2 e 3). Os valores médios não excederam o valor máximo $(6 \%)$ permitido pela legislação vigente, entretanto, foram observadas em duas amostras (12 e 18) do Ceará e em duas amostras (8 e 37) do Piauí valores acima do permitido pela norma vigente (Brasil, 2000). Na Figura 3 (a,b) observam-se as porcentagens de amostras de méis do Ceará (a) (90\%) e do Piauí (b) (94,7\%) que estão em conformidade ou não com a norma vigente e desta forma são aceitáveis ou não como mel de mesa.

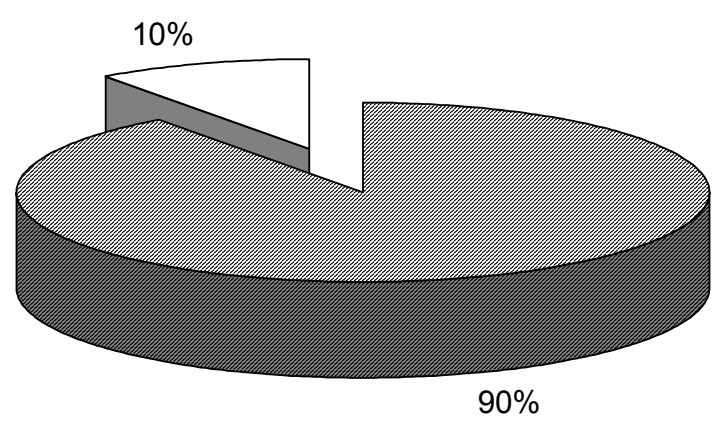

Aceitável $\square$ Não aceitável

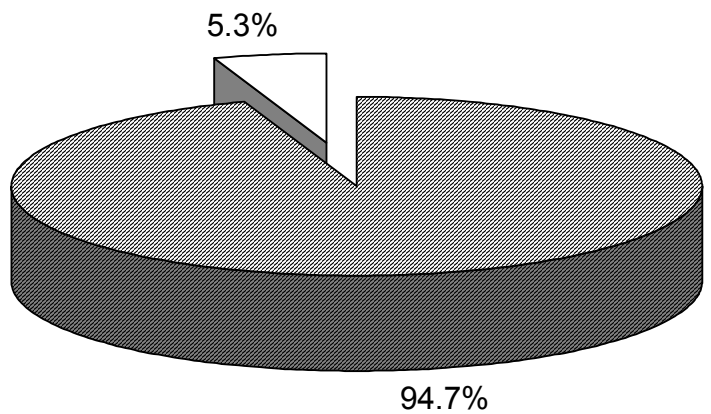

Aceitável $\square$ Não aceitável

(b)

Figura $3(a, b)$ - Porcentagens de amostras de méis dos Estados do Ceará (20 amostras) e do Piauí (38 amostras) que apresentaram sacarose aparente aceitável ou não, segundo a legislação brasileira 
Os valores observados para a sacarose aparente, no presente estudo, estão próximos aos verificados por: Baldi-Coronel et al. (1993) que na Argentina determinaram variações de 1 a 13\%; Vit-Oliver et al. (1994) analisando amostras de méis venezuelanos constataram variações de 1,74 a 11,99\%; na Espanha, Bonvehí \& Coll (1995) verificaram uma variação de 2,37 a 16,3\% e em méis indianos Anupama et al. (2003) constataram uma variação de 1,2 a 5,7\%.

Comparando os valores médios no presente estudo verifica-se que estão próximos aos de Arruda (2003) que em méis da Chapada do Araripe, Estado do Ceará constatou valor médio para sacarose aparente de 3,45\%. Já no Estado de São Paulo, Komatsu et al. (2002) em méis de diferentes origens florais constataram para a sacarose aparente, uma média de $2,4 \%$ para méis de flores silvestres e de eucalipto e 2,0\% para méis de flores de laranjeira, valores estes inferiores aos observados para o Estado do Ceará e Piauí.

No presente estudo verifica-se que $10 \%$ das amostras do Estado do Ceará (Figura 3a) e 5,3\% das amostras de méis do Estado do Piauí (Figura 3b) encontram-se acima do estabelecido pela norma vigente. De acordo com Azeredo et al. (1999) o alto conteúdo de sacarose aparente nos méis pode indicar um mel "verde", isto é, quando o produto ainda não foi totalmente transformado em glicose e frutose, pela ação da enzima invertase secretada pelas abelhas além de também indicar uma adulteração do produto.

\subsubsection{Umidade}

As porcentagens de umidade encontradas nas 58 amostras analisadas variaram de 15,77 a 20,27\% (com valor médio de 18,73\%) para o Estado do Ceará e 16,44 a 19\% (com valor médio de 18,3\%) para o Estado do Piauí (Tabelas 1, 2 e 3). Os valores médios não excederam o valor máximo (20\%) permitido pela legislação vigente, entretanto, foram observados em duas amostras 
(15 e 17) do Ceará valores acima do permitido pela norma vigente. Na Figura 4 $(a, b)$ observam-se as porcentagens de amostras de méis do Ceará (a) (90\%) e do Piauí (b) (100\%) que estão dentro dos limites estabelecidos pela norma vigente.

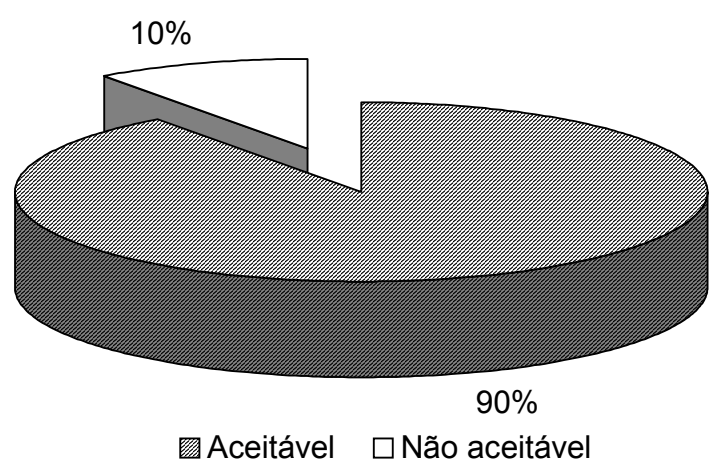

(a)

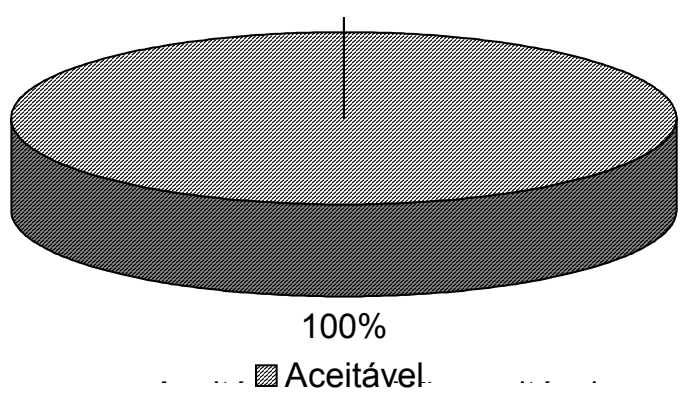

(b)

Figura $4(a, b)$ - Porcentagens de amostras de méis dos Estados do Ceará (20 amostras) e do Piauí (38 amostras) que apresentaram umidade aceitável ou não, segundo a legislação brasileira

Trabalhos que citam valores próximos ao do presente estudo foram desenvolvidos por: Rendón (1996) em amostras de méis da Espanha no qual constatou valores variando de 15,00 a 18,80\%; Almeida (2002) em méis do cerrado paulista obteve 16,6 a 20,8\%; Marchini et al. (2002) constataram variações de 15,1 a 21,5\% em méis de flores de laranjeira; Arruda (2003) em méis da Chapada do Araripe, Estado do Ceará verificou valores variando de 14,97 a $17,23 \%$ para a umidade.

Valores acima dos estabelecidos pela norma vigente também foram constatados por: Horn et al. (1996) que analisando amostras de méis do Brasil verificaram valor médio para a umidade de $18,7 \%$, entretanto, encontraram no Estado da Bahia amostras com $22,4 \%$ de umidade. Os autores relatam que isto 
confirma a observação dos apicultores, os quais mencionam que os méis da região nordeste são mais líquidos. No Estado da Bahia, Sodré et al. (2002a) também constataram uma variação de 17 a 22,9\%, com valor médio de 19,77\%. Anupama et al. (2003) analisando amostras de méis indianos verificaram umidade de 17,0 a $22,6 \%$.

No presente estudo constata-se que $10 \%$ das amostras de méis do Estado do Ceará (Figura 4a) encontram-se acima do estabelecido pela norma vigente. Rodríguez et al. (2004) mencionam que a umidade dos méis é influenciada pela origem botânica, por condições climáticas, época de colheita e o grau de maturação do mel, sendo um parâmetro de grande importância durante o armazenamento do produto. Cornejo (1988) afirma que uma maior umidade favorece o processo de fermentação e conseqüente deterioração do produto.

\subsubsection{Atividade diastásica}

Os valores de atividade diastásica encontrados nas 58 amostras de méis analisadas variaram de 5,30 a 43,39 escala de Gothe (com valor médio de 16,48 escala de Gothe), para o Estado do Ceará e 5,29 a 17 escala de Gothe (com valor médio de 8,64 escala de Gothe), para o Piauí (Tabelas 1, 2 e 3). Os valores médios estão acima do valor mínimo (8 escala de Gothe) permitido pela legislação vigente, entretanto, foram observadas em sete amostras $(2,3,4,8,9$, 16 e 17) do Ceará e em 20 amostras $(3,4,6,7,8,10,12,13,14,15,16,24,25$, $26,27,28,29,36,37$ e 38) do Piauí valores abaixo do permitido pela norma vigente. Na Figura $5(a, b)$ observam-se as porcentagens de amostras de méis do Ceará (a) (65\%) e do Piauí (a) (47,37\%) que se encontram em conformidade com a norma vigente, desta forma um grande número de amostras não são aceitáveis como mel de mesa, para este parâmetro segundo a legislação brasileira. 


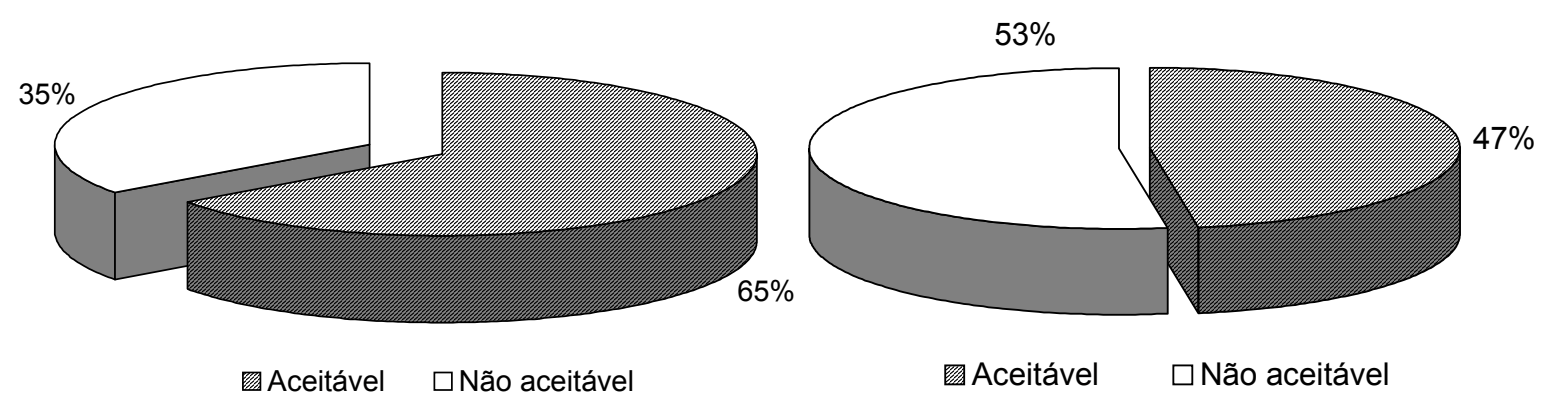

(a)

(b)

Figura $5(a, b)$ - Porcentagens de amostras de méis dos Estados do Ceará (20 amostras) e do Piauí (38 amostras) que apresentaram atividade diastásica aceitável ou não, segundo a legislação brasileira

Alguns autores também constataram valores abaixo do estabelecido para atividade diastásica como: Balenovic et al. (1988) analisaram 44 amostras de méis e obtiveram $45,6 \%$ destas amostras fora da especificação estabelecida; na Venezuela Vit-Oliver et al. (1994) constataram valores para atividade diastásica variando de 1 a 5 escala de Gothe e Mendes et al. (1998) analisando amostras de méis de Portugal constataram para a atividade diastásica variações de 2 a 22 escala de Gothe.

No Brasil, Costa et al. (1999) encontraram em amostras de méis de diferentes origens florais valores variando de 5,9 a 66,7 escala de Gothe para a atividade diastásica; Persano-Oddo et al. (1990) estudando méis italianos, de diferentes origens botânicas, encontraram valores para a atividade diastásica variando de 0 a 62,1 escala de Gothe. Trabalho realizado por Serrano et al. (2004) analisando amostras de méis de flores de Eucalypus e Citrus, constataram para a atividade diastásica valores altos para os méis de flores de Eucalyptus e baixos para os méis de flores de Citrus. 
Valores acima do estabelecido como mínimo na norma vigente também foram verificados por: Rendón (1996) que analisando amostras de méis da Espanha constatou para a atividade diastásica valores variando de 15,8 a 47,10 escala de Gothe; Sodré et al. (2002a) analisando amostras de méis da Bahia encontraram uma variação de 16,66 a 62,81 escala de Gothe; Terrab et al. (2003) analisaram amostras de méis de Marrocos e constataram para a atividade diastásica valor médio de 39,05 escala de Gothe.

No trabalho em estudo constata-se que $35 \%$ das amostras de méis do Estado do Ceará (Figura 5a) e 52,62\% das amostras do Estado do Piauí (Figura 5b) encontram-se abaixo do estabelecido pela norma vigente. A legislação brasileira (Brasil, 2000) determina para a atividade diastásica um mínimo de 8 escala de Gothe, no entanto para os méis com baixo conteúdo enzimático devem ter como mínimo uma atividade diastásica correspondente a 3 escala de Gothe, sempre que o conteúdo de hidroximetilfurfural não exceda a $15 \mathrm{mg} \cdot \mathrm{kg}^{-1}$. Observase (Tabelas 1 e 2) que a maioria das amostras em estudo que estão abaixo de 8 escala de Gothe encontram-se nessa faixa, porém são encontradas amostras com um baixo conteúdo de atividade diastásica e com um alto conteúdo de hidroximetilfurfural.

Segundo White Júnior (1992) os méis produzidos em regiões quentes e secas apresentam menor quantidade de enzimas do que os de regiões quentes e úmidas. White Júnior (1994) questionou o uso da atividade diastásica como indicadora de qualidade do mel devido a grande variação na quantidade de diastase em méis recém colhidos e não aquecidos.

Este é um dos parâmetros que merece uma atenção especial por parte dos pesquisadores para verificar a possibilidade de adequar os valores as nossas condições. 


\subsubsection{Hidroximetilfurfural (HMF)}

As quantidades de hidroximetilfurfural (HMF) encontradas nas 58 amostras de méis analisadas variaram de 1,74 a $126,50 \mathrm{mg} \cdot \mathrm{kg}^{-1}$ (com valor médio de $31,45 \mathrm{mg} \cdot \mathrm{kg}^{-1}$ ), para o Estado do Ceará e 1,53 a $115 \mathrm{mg} \cdot \mathrm{kg}^{-1}$ (com valor médio de 13,78 mg. $\mathrm{kg}^{-1}$ ), para o Piauí (Tabelas 1, 2 e 3). Os valores médios encontramse abaixo do valor máximo $\left(60 \mathrm{mg} \cdot \mathrm{kg}^{-1}\right)$ permitido pela legislação vigente, entretanto, foram observados em quatro amostras $(6,13,14$ e 16) do Ceará e em uma amostra (11) do Piauí valores acima do permitido pela norma vigente. $\mathrm{Na}$ Figura $6(a, b)$ observam-se as porcentagens de amostras de méis do Ceará (a) (80\%) e do Piauí (b) $(97,37 \%)$ que se encontram em conformidade com a norma vigente.

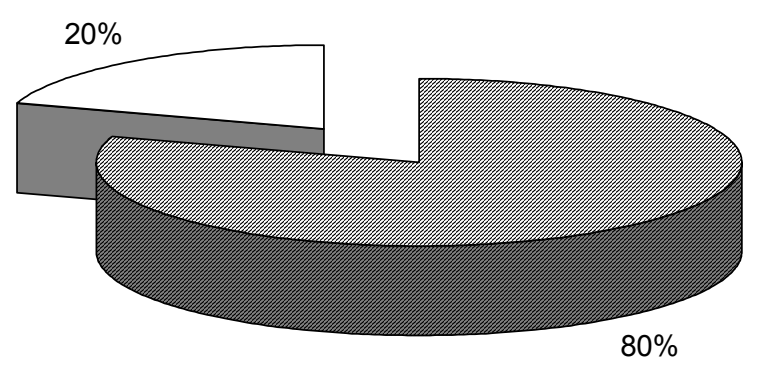

Aceitável $\square$ Não aceitável

(a)

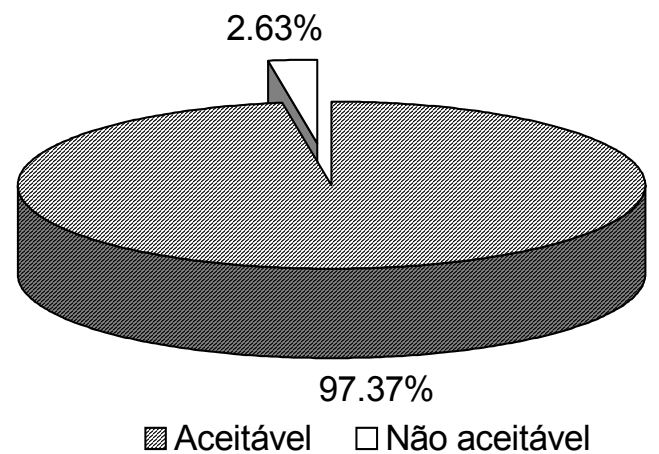

(b)

Figura $6(a, b)$ - Porcentagens de amostras de méis dos Estados do Ceará (20 amostras) e do Piauí (38 amostras) que apresentaram hidroximetilfurfural aceitável ou não, segundo a legislação brasileira

Semelhantemente aos valores altos encontrados no presente estudo, Reio \& Englund (1985) analisaram na Suíça 55 amostras de méis importados de 14 países, constataram em algumas amostras da Bulgária, Romênia, Cuba, 
Caribe, México e Estados Unidos (Califórnia), HMF na faixa de 6,6 a 95,2 mg. gg $^{-1}$; Dayrell \& Vital (1991) analisaram amostras de méis brasileiros e encontraram valores variando de 1,1 a 248,2 mg.kg-1; Horn et al. (1996) também com amostras de méis brasileiros encontraram para a região nordeste valor médio de 113,7 mg. $\mathrm{kg}^{-1}$, valor esse muito acima do estabelecido pela norma vigente; Mendes et al. (1998) determinaram para méis portugueses valores de 1,7 a 94,9 mg. $\mathrm{kg}^{-1}$; Sodré et al. (2002a) em amostras de méis do litoral norte na Bahia constataram uma variação de 1,5 a $136 \mathrm{mg} \cdot \mathrm{kg}^{-1}$.

Em estudos realizados em diferentes países os autores constataram na maioria das amostras valores em conformidade com a norma vigente como: Thrasyvoulou (1986) analisando amostras de méis da Grécia constataram uma variação de 0,0 a 15,2 mg. $\mathrm{kg}^{-1}$; Na Espanha Serrano et al. (2004) obtiveram como valor médio para o HMF $16,5 \mathrm{mg} \cdot \mathrm{kg}^{-1}$; no Chile Montenegro et al. (2003) determinaram para o HMF valores abaixo de $15,9 \mathrm{mg} \cdot \mathrm{kg}^{-1}$ e no Brasil Arruda (2003) constatou uma variação de 1,5 a $8,08 \mathrm{mg} \cdot \mathrm{kg}^{-1}$.

No estudo em questão verifica-se que $20 \%$ das amostras do Estado do Ceará e 2,63\% das amostras de méis do Estado do Piauí encontram-se acima do estabelecido pela norma vigente. O HMF é considerado um parâmetro que está relacionado com a qualidade do mel. Seemann \& Neira (1988) mencionam que o alto valor do HMF no mel é um indicador de superaquecimento, armazenamento ou adulteração com açúcar invertido. Conforme White Júnior (1992) méis de países subtropicais podem ter naturalmente um alto conteúdo de HMF sem que o mel tenha sido superaquecido ou adulterado, devido as altas temperaturas.

\subsubsection{Proteína}

Os teores de proteínas encontrados nas 58 amostras de méis analisados variaram de 0,13 a $0,71 \%$ (com valor médio de $0,35 \%$ ) para o Estado 
do Ceará e 0,11 a 0,37\% (com valor médio de 0,19\%) para o Estado do Piauí (Tabelas 1, 2 e 3). Para a proteína não existe valor estabelecido na norma vigente.

Archenti (1984) analisando amostras de méis da Argentina constatou valor médio de $0,18 \%$, sendo muito próximo ao verificado no presente trabalho no Estado do Piauí. Marchini (2001) trabalhando com méis do Estado de São Paulo constataram valor médio para a proteína de $0,32 \%$ para méis de flores de Eucalyptus e 0,18\% para méis de flores silvestres.

Valores próximos aos encontrados no presente trabalho também foram constatados por: White Júnior \& Rudyj (1978) que verificaram nos Estados Unidos variação para proteína de 0,2 a 0,99\%; Peng \& Pan (1994) analisaram a proteína de méis de origem floral da China, encontraram variações entre 0,048 e 0,42\%; Sodré et al. (2002a) analisando amostras do litoral norte do Estado da Bahia determinou uma variação de 0,056 a 0,971\%; Arruda (2003) trabalhando com amostras de mel da Chapada do Araripe, Estado do Ceará constatou uma variação de 0,118 a 0,254\% e Montenegro et al. (2003) analisando amostras do Chile constataram uma variação de 0,073 a $0,67 \%$.

Valores considerados altos para a proteína foram constatados por Imperatriz-Fonseca et al. (1985) que estudando amostras de méis das regiões norte, nordeste e sul do Brasil, encontraram um conteúdo médio igual a 1,58\% para mel de flores de Citrus e 1,92\% para mel de flores de Eucalyptus; Komatsu (1996) trabalhando com méis silvestres de diferentes regiões do Estado de São Paulo, obteve como valor máximo para a proteína 1,6\%. Semelhantemente Escobar-Martínez et al. (1992) em méis paraguaios constataram para a proteína o valor médio de $1,63 \%$.

Crane (1975) menciona que o material protéico do mel pode ser utilizado na detecção de adulteração deste produto. Rodríguez et al. (2004) descrevem que o conteúdo de proteína no mel é usado como um indicador de adulteração por uso de carboidratos. 


\subsubsection{Cinzas}

As porcentagens de cinzas encontradas nas 58 amostras de méis analisadas variaram de 0,01 a $0,41 \%$ (com valor médio de $0,18 \%$ ) para o Estado do Ceará e 0,02 a 0,18\% (com valor médio de 0,11\%) para o Estado do Piauí (Tabelas 1, 2 e 3). A norma vigente estabelece um valor máximo para cinzas de $0,6 \%$. No trabalho em estudo observou-se que os valores de todas as amostras encontram-se abaixo do estabelecido como limite máximo. A Figura $7(a, b)$ representa as porcentagens (100\%) das amostras de méis dos Estados do Ceará (a) e do Piauí (b) analisadas que se enquadram na norma vigente.

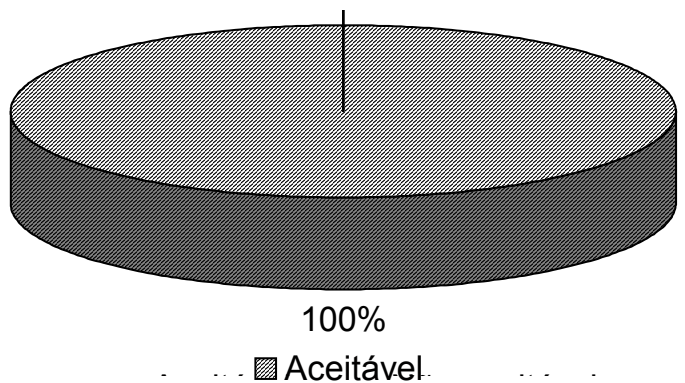

(a)

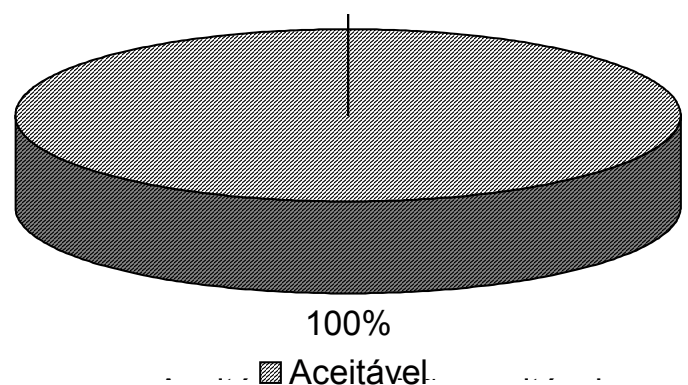

(b)

Figura $7(a, b)$ - Porcentagens de amostras de méis dos Estados do Ceará (20 amostras) e do Piauí (38 amostras) que apresentaram cinzas aceitáveis, segundo a legislação brasileira

Valores médios semelhantes aos encontrados no presente estudo foram constatados por: Flechtmann et al. (1963) 0,17\% e Marchini (2001) 0,16\% no Estado de São Paulo; Sodré et al. (2002b) 0,19\% no Estado da Bahia e Arruda (2003) 0,185\% em méis da Chapada do Araripe no Estado do Ceará.

Trabalhos realizados por diferentes autores também verificaram uma faixa de variação semelhante a constatada no presente estudo: Vit-Oliver et al. (1994) analisando amostras de méis da Venezuela constataram para as cinzas 
uma variação de 0,04 a 0,48\%; Archenti \& Dasso (1983), Uñates et al. (1999) e Baldi-Coronel et al. (1993) analisaram amostras de méis da Argentina e encontraram valores variando de 0,03 a 0,65\%. Conforme Bogdanov et al. (1997) o conteúdo de cinzas é influenciado pela origem botânica.

Lasceve \& Gonnet (1974) mencionam que além da origem botânica podem ocorrer variações por motivos relacionados às abelhas (durante o forrageamento), ao apicultor e ao clima da região onde foi produzido.

\section{$4.1 .9 \mathrm{pH}$}

Os valores de $\mathrm{pH}$ encontrados nas 58 amostras de méis analisadas variaram de 3,36 a 3,78 (com o valor médio de 3,57) para o Estado do Ceará e 3,39 a 3,87 (com valor médio de 3,57) para o Estado do Piauí (Tabelas 1, 2 e 3). Para o pH não existe valor estabelecido na norma vigente.

Horn et al. (1996) analisaram amostras de méis brasileiros e constataram uma média de 3,8 por estado e de 3,9 por região. Os autores citaram que o maior valor de pH foi obtido na Região Sul $(4,3)$ e o menor valor na Região Nordeste $(3,4)$. Arruda (2003) trabalhando com amostras de méis da chapada do Araripe no Estado do Ceará constatou uma variação de 3,58 a 3,83; Anupama et al. (2003) analisando amostras de méis indianos determinaram para o pH 3,62 a 4,00 e Rodríguez et al. (2004) trabalhando com méis da Venezuela encontraram para o $\mathrm{pH}$ variação de 3,3 a 4,3.

Os valores médios encontrados no presente trabalho são bastante próximos aos constatados por: Komatsu (1996) que analisando amostras de méis do Estado de São Paulo obteve valor médio de 3,4; Rendón (1996) que trabalhando com méis da Espanha encontrou valor médio de 3,67 e Azeredo et al. (1999) que em amostras de méis de São Fidélis, Rio de Janeiro, obtiveram valores médios de $\mathrm{pH}$ de 3,65 . 
Frias \& Hardisson (1992) mencionam que todos os méis são ácidos, podendo ser influenciado pela sua origem botânica. Conforme Rodríguez et al. (2004) o pH do mel não é diretamente relacionado com a acidez por causa da relação com as concentrações dos vários ácidos e os minerais presentes no mel.

\subsubsection{Acidez}

Os valores da acidez das 58 amostras de méis analisadas variaram de 10 a 42 meq. $\mathrm{kg}^{-1}$ (com valor médio de 30,13 meq. $\mathrm{kg}^{-1}$ ), para o Estado do Ceará e 10 a 30 meq. $\mathrm{kg}^{-1}$ (com valor médio de 17,91 meq. $\mathrm{kg}^{-1}$ ) para o Estado do Piauí (Tabelas 1, 2 e 3). A norma vigente estabelece um valor máximo para acidez de 50 meq. $\mathrm{kg}^{-1}$. No trabalho em estudo observou-se que os valores de todas as amostras encontram-se abaixo do estabelecido como limite máximo. A Figura 8 $(a, b)$ representa as porcentagens $(100 \%)$ das amostras de méis analisadas dos Estados do Ceará (a) e Piauí (a) que se enquadram na norma vigente.

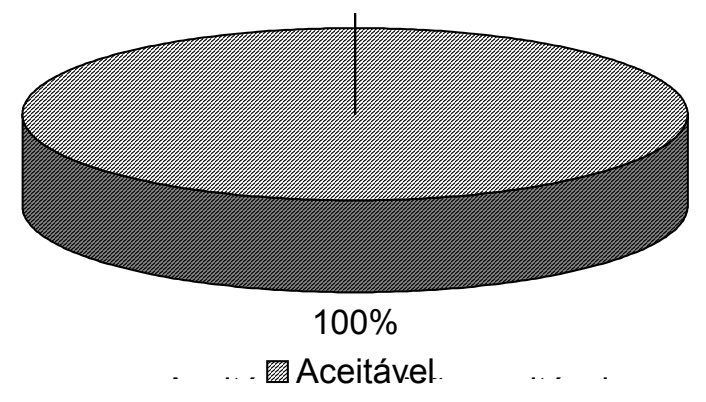

(a)

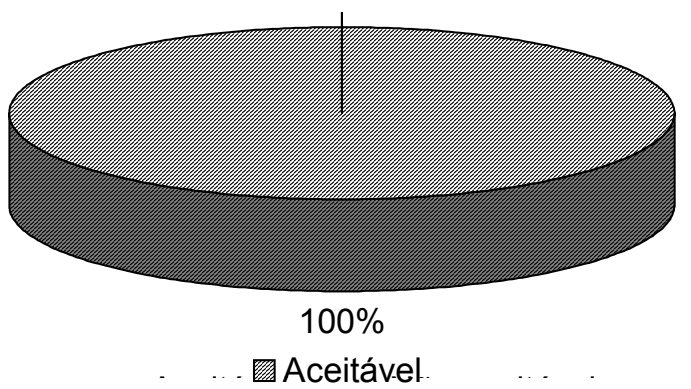

(b)

Figura $8(a, b)$ - Porcentagens de amostras de méis dos Estados do Ceará (20 amostras) e do Piauí (38 amostras) que apresentaram acidez aceitável, segundo a legislação brasileira 
Semelhantemente às faixas de variações do trabalho em estudo, pesquisadores como: Archenti \& Dasso (1983) analisaram amostras de méis da Argentina, verificaram uma variação para o acidez de 8,06 a 31,07 meq. $\mathrm{kg}^{-1}$; VitOliver et al. (1994) analisando amostras de méis venezuelanos constataram para a acidez valores variando de 9,75 a 40,3 meq. $\mathrm{kg}^{-1}$. Já Rodríguez et al. (2004), também trabalhando com méis da Venezuela, verificaram para a acidez variação de 24,40 a 53,30 meq. $\mathrm{kg}^{-1}$; Campos (1998) analisando amostras de méis brasileiros encontraram valores variando de 8,20 a 50,0 meq/kg; Almeida (2002) trabalhando com amostras de méis do cerrado paulista constatou variação para a acidez de 6 a 46 meq. $\mathrm{kg}^{-1}$. Já Bendini et al. (2002), também em méis no Estado de São Paulo, constataram uma variação de 10 a 35 meq. $\mathrm{kg}^{-1}$.

A acidez no mel permite detectar o processo de fermentação e as condições de armazenamento deste produto, contribuindo para avaliar a sua qualidade (Cornejo, 1988). Pamplona (1989) relata que o ácido glucônico, formado através da glicose pela ação da enzima glicose-oxidase, tende sempre a aumentar, mesmo durante o armazenamento do mel; dessa forma a acidez do mel também aumenta durante o armazenamento. Conforme Rodríguez et al. (2004) a época de colheita e a origem botânica podem influenciar na acidez deste produto.

\subsubsection{1 Índice de formol}

Os valores encontrados para o índice de formol das 58 amostras de méis analisadas variaram de 4 a $13 \mathrm{~mL} \mathrm{~kg}^{-1}$ (com médio de $8,37 \mathrm{~mL} . \mathrm{kg}^{-1}$ ) para o Estado do Ceará e 5 a $11 \mathrm{~mL} \cdot \mathrm{kg}^{-1}$ (com valor médio de $8,37 \mathrm{~mL}^{\mathrm{kg}}{ }^{-1}$ ) para o Estado do Piauí (Tabelas 1, 2 e 3). Para o índice de formol não existe valor estabelecido na norma vigente.

Valores próximos aos verificados no presente estudo foram encontrados por: Temiz (1983) na Turquia que constatou em amostras recém- 
colhidas variações do índice de formol de 4,5 a 8,6 mL. $\mathrm{kg}^{-1}$; Komatsu (1996) analisando amostras de méis do Estado de São Paulo de diferentes origens florais encontrou para o índice de formol os valores médios de 10,1; 6,9 e 6,3 mL. $\mathrm{kg}^{-1}$ para méis de flores silvestres, de flor de eucaliptos e de flor de laranjeira, respectivamente. Almeida (2002), também no Estado de São Paulo trabalhando com amostras de méis do cerrado paulista, constatou para o índice de formol valores variando de 3,5 a $19,0 \mathrm{~mL}^{\mathrm{kg}}{ }^{-1}$; Sodré et al. (2002 a) trabalhando com amostras do litoral norte no Estado da Bahia verificaram para o índice de formol valores variando de 1,67 a 29 mL. $\mathrm{kg}^{-1}$; Marchini et al. (2004b) analisando amostras de méis do Estado do Paraná encontrou para o índice de formol valores variando de 6,33 a 14,33 mL. $\mathrm{kg}^{-1}$; Mendonça et al. (2004) estudando amostras de méis de diferentes municípios do Mato Grosso encontraram para o índice de formol valores variando de 5,0 a $7,0 \mathrm{~mL} \cdot \mathrm{kg}^{-1}$.

Conforme Frías \& Hardisson (1992) o índice de formol pode ser usado com um indicador da autenticidade do mel, podendo informar adulteração com produtos artificiais.

\subsubsection{Condutividade elétrica}

Os valores encontrados para a condutividade elétrica das 58 amostras de méis analisadas variaram de 192 a 798,67 $\mu \mathrm{S} . \mathrm{cm}^{-1}$ (com valor médio de $452,77 \mu \mathrm{S} . \mathrm{cm}^{-1}$ ), para o Estado do Ceará e 192 a $381 \mu \mathrm{S} . \mathrm{cm}^{-1}$ (com valor médio de 268,62 $\mu$ S.cm ${ }^{-1}$ ) para o Estado do Piauí (Tabelas 1, 2 e 3). Para a condutividade elétrica não existe valor estabelecido na norma vigente.

Os dados constatados no presente estudo são semelhantes aos de: Arruda (2003) que analisando amostras de méis da Chapada do Araripe no Estado do Ceará constatou valores variando de 154,67 a 253,33 $\mu \mathrm{S} . \mathrm{cm}^{-1}$ e Mendonça et 
al. (2004) que estudaram amostras de diferentes municípios do Mato Grosso encontram valores variando de 272,7 a $356 \mu$ S. $\mathrm{cm}^{-1}$.

A condutividade elétrica tem uma relação com a origem floral do mel, dessa forma apresenta uma grande variação em função de sua origem. Autores como: Persano-Oddo et al. (1995) encontraram variações de 90 a $2110 \mu \mathrm{S} . \mathrm{cm}^{-1}$ em méis italianos de diferentes origens florais; Horn et al. (1996) analisaram amostras de méis de diferentes regiões do Brasil e constataram para a condutividade elétrica valores variando de 100 a $2103 \mu$ S.cm ${ }^{1}$; Rendón (1996) analisando amostras de méis da Espanha obteve para a condutividade elétrica valores variando de 127 a $1393 \mu \mathrm{S} . \mathrm{cm}^{-1}$; Sodré (2000) analisando amostras de méis da região litoral norte da Bahia constataram valores variando de 271,67 a $1634 \mu \mathrm{S} . \mathrm{cm}^{-1}$; Almeida (2002) analisando amostras de méis do cerrado paulista verificou para a condutividade elétrica valores variando de 284 a $2200 \mu$ S.cm ${ }^{-1}$.

Conforme Bogdanov (1999) a condutividade elétrica é influenciada pela origem botânica do mel, sendo considerado um bom critério de identificação da origem do mel. Sancho et al. (1991) menciona que a condutividade elétrica é um indicador da origem botânica do mel (floral ou melato) e pode informar se a abelha foi alimentada artificialmente com xarope de açúcar.

\subsubsection{Viscosidade}

Os valores encontrados para a viscosidade das 58 amostras de méis analisadas variaram de 536 a 2080 mPa.s (com valor médio de $1130 \mathrm{mPa}$.s) para o Estado do Ceará e 960 a 3436 mPa.s (com valor médio de 1720 mPa.s) para o Estado do Piauí (Tabelas 1, 2 e 3). Para a viscosidade não existe valor estabelecido na norma vigente.

Valores próximos aos constatados no presente estudo foram observados por: Marchini et al. (2002) que verificou para a viscosidade valores 
variando de 98 a 5090 mPa.s, com uma média de 1362,70 mPa.s; Anupama et al. (2003) que estudando amostras de méis indianos verificaram para a viscosidade valores variando de 138 a 179 mPa.s; Arruda (2003) trabalhando com amostras da Chapada do Araripe no Estado do Ceará obteve para a viscosidade valores variando de 1620 a 6770 mPa.s; Marchini et al. (2004a,b) trabalharam com amostras dos Estados do Paraná e Tocantins e constataram valores variando de 1096 a 4640 mPa.s e Mendonça et al. (2004) determinaram a viscosidade em amostras de méis do Mato Grosso e encontraram uma variação de 2773 a 3850 mPa.s.

De acordo com Crane (1983) e Abu-Jdayil et al. (2002) a viscosidade do mel pode ser influenciada por muitos fatores incluindo a composição, a temperatura, o conteúdo de água, a densidade relativa e o alto conteúdo de proteína.

\subsubsection{Cor}

As cores das 58 amostras de méis analisadas são apresentadas nas Tabelas 1 e 2 e as porcentagens de amostras classificadas nas diferentes cores na Figura 9, para os Estados do Ceará (a) e para o Piauí (b). 


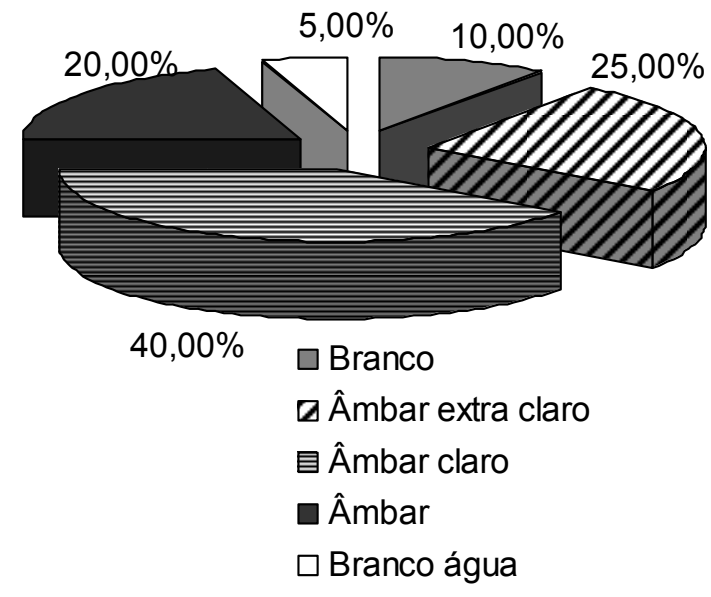

(a)

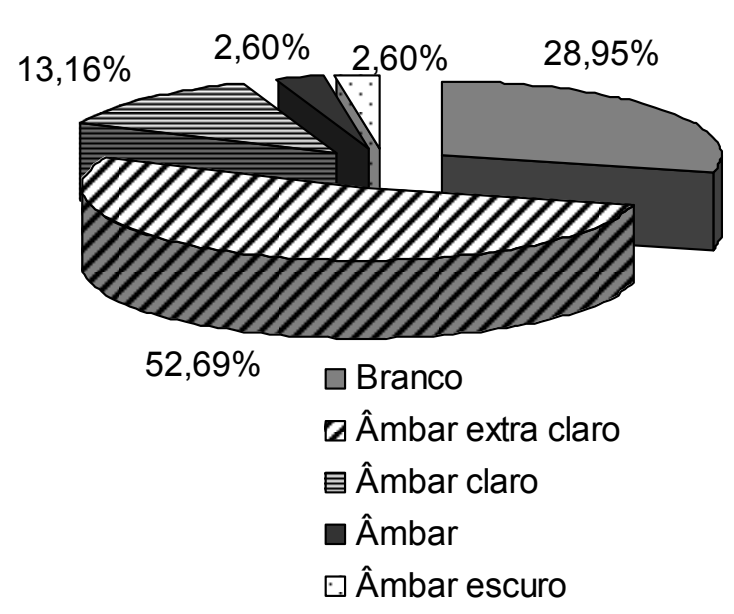

(b)

Figura $9(a, b)$ - Porcentagens de amostras classificadas nas diferentes classes de cor do mel observados nos méis dos Estados do Ceará (20 amostras) e do Piauí (38 amostras)

No trabalho em estudo constatou-se para os méis do Estado do Ceará (Figura 9a) uma predominância da cor âmbar claro (40\%), sendo ainda verificadas amostras âmbar extra claro (25\%), âmbar (20\%), branco (10\%) e branco água (5\%). Já para as amostras do Estado do Piauí (Figura 9b) uma predominância da cor âmbar extra claro (52,69\%), seguidas de branco $(28,95 \%)$, âmbar claro (13,16\%), âmbar e âmbar escuro (2,6\%).

Para as cores dos méis analisados no presente estudo verificam-se as predominâncias das cores claras. Baldi-Coronel et al. (1993) trabalhando com amostras de méis da província de Entre Rios (Argentina), dividindo-a em quatro zonas de acordo com a flora apícola existente observaram uma forte predominância da cor âmbar claro e âmbar extra claro, como no presente estudo.

Trabalhos realizados com amostras de méis da Bahia por Carvalho et al. (2000a) e Sodré et al. (2002a) também foram constatadas as 
predominâncias da cor âmbar claro como no presente estudo para o Estado do Ceará. Escobar-Martínez et al. (1992) analisando amostras de méis do Paraguai também verificaram a predominância da cor âmbar claro. Já Uñates et al. (1999) analisando amostras de méis da Argentina constataram a predominância da cor âmbar claro e âmbar seguido de âmbar extra claro.

A cor do mel tem uma relação com a origem botânica, condições climáticas e edáficas. Entretanto o armazenamento, a luz, o calor e as possíveis reações enzimáticas também podem influenciar esta propriedade (Smith, 1967).

\subsubsection{Análise de agrupamento para os parâmetros físico-químicos}

Para a análise de agrupamento de componentes principais de 58 amostras de méis (20 Ceará e 38 Piauí) e dos 14 caracteres físico-químicos (Tabelas 1 e 2), foram selecionados para o Estado do Ceará 11 caracteres, sendo descartados condutividade elétrica, índice de formol e diastase, em função da alta correlação existente entre eles. Já para o Estado do Piauí foram utilizados os 14 caracteres físico-químicos.

Os resultados das estimativas das variâncias (autovalores) obtidas encontram-se nas Tabelas (4 e 5). 
Tabela 4. Estimativas das variâncias (autovalores) e porcentagem acumulada da variância total $(\%)$, obtidas por meio da análise de componentes principais, considerando-se as 20 amostras de méis do Estado do Ceará e os 11 caracteres físico-químicos

\begin{tabular}{ccc}
\hline Componentes principais & Autovalores & \% Acumulada \\
\hline $\mathrm{Y}_{1}$ & 5,349 & 38,21 \\
$\mathrm{Y}_{2}$ & 3,439 & 62,78 \\
$\mathrm{Y}_{3}$ & 2,045 & 77,39 \\
\hline
\end{tabular}

Tabela 5. Estimativas das variâncias (autovalores) e porcentagem acumulada da variância total $(\%)$ obtidas por meio da análise de componentes principais, considerando-se as 38 amostras de méis do Piauí e os 14 caracteres físico-químicos

\begin{tabular}{ccc}
\hline Componentes principais & Autovalores & \% Acumulada \\
\hline $\mathrm{Y}_{1}$ & 5,330 & 38,07 \\
$\mathrm{Y}_{2}$ & 2,053 & 52,74 \\
$\mathrm{Y}_{3}$ & 1,684 & 64,76 \\
$\mathrm{Y}_{4}$ & 1,407 & 74,81 \\
\hline
\end{tabular}

Observando a Tabela 4 verifica-se que o primeiro componente concentrou $38,21 \%$ da variância total, o segundo $62,78 \%$ e o terceiro $77,39 \%$ para o Estado do Ceará. Para o Piauí analisando a Tabela 5 o primeiro componente 
concentrou $38,07 \%$ da variância total, o segundo $52,73 \%$, o terceiro $64,76 \%$ e o quarto $74,81 \%$.

Em uma análise de componentes principais se os dois ou os três primeiros componentes acumularem uma porcentagem relativamente alta da variação total, em geral acima de $70 \%$, eles explicarão satisfatoriamente a variabilidade manifestada entre as amostras avaliadas (Mardia et al., 1979).

No presente trabalho verifica-se que a porcentagem acumulada da variação total para o Estado do Ceará $(77,39)$ explica satisfatoriamente a variabilidade nas amostras avaliadas. Já para o Piauí observa-se que foram necessários quatro componentes principais para explicar $70 \%$ da variância total disponível entre os caracteres físico-químicos, constatando-se assim uma maior dispersão da variância no material estudado.

Nas Figuras 10 e 11 observam-se os fenogramas elaborados pelas distâncias euclidiana média e o método UPGMA envolvendo as 58 amostras (20 Ceará e 38 Piauí) de méis e os caracteres físico-químicos selecionados.

Adotou-se como critério para definição dos grupos os gráficos das distâncias de ligação nos sucessivos passos da análise de agrupamento (Figuras 12 e 13). Este método baseia-se na identificação de um platô no sentido vertical, o que significa que muitos grupos foram formados na mesma distância de ligação, sendo essa distância um ponto ótimo de corte no fenograma determinando o número de grupos formados. No presente estudo, o ponto ótimo para corte escolhido foi em 180 para o Estado do Ceará e 225 para o Estado do Piauí representados pelas linhas horizontais nas Figuras 10 e 11 e pelas setas nas Figuras 12 e 13. 


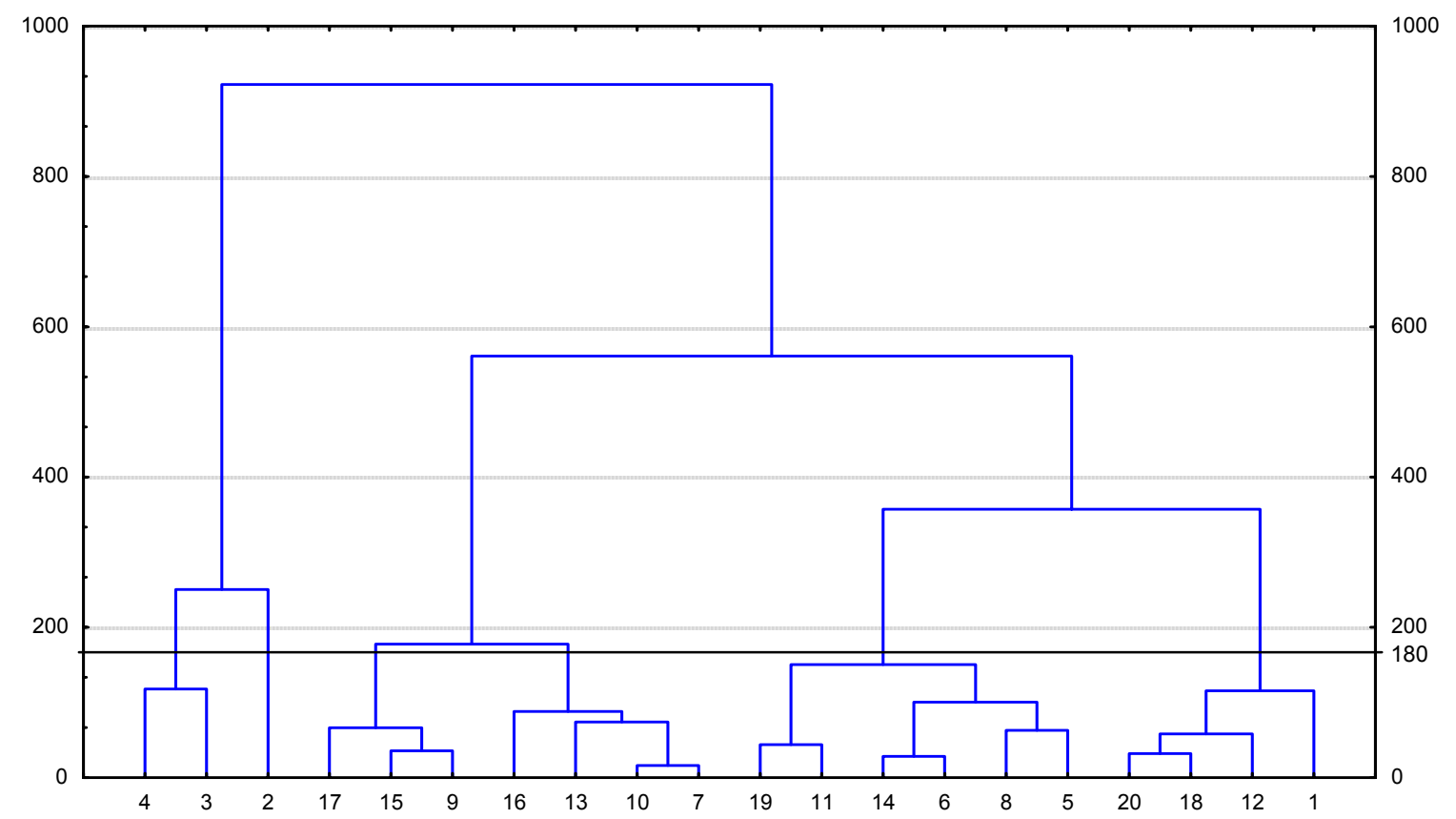

Figura 10 - Fenograma obtido pela análise de agrupamento, utilizando-se a distância euclideana média e o método UPGMA para as 20 amostras de méis de Apis mellifera do Estado do Ceará e os 11 caracteres físico-químicos selecionados 


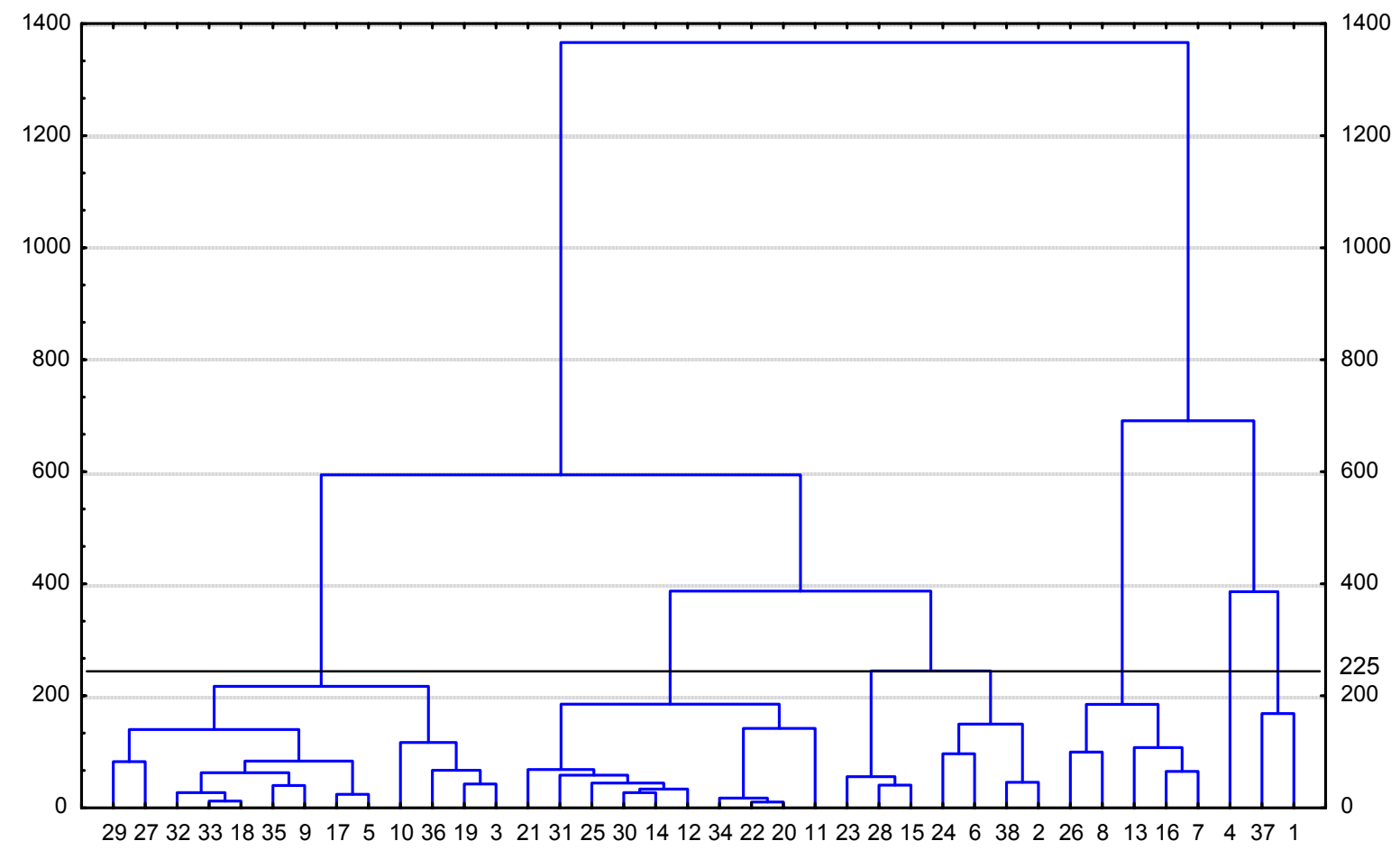

Figura 11 - Fenograma obtido pela análise de agrupamento, utilizando-se a distância euclideana média e o método UPGMA para as 38 amostras de méis de Apis mellifera do Estado do Piauí e os 14 caracteres físico-químicos selecionados 


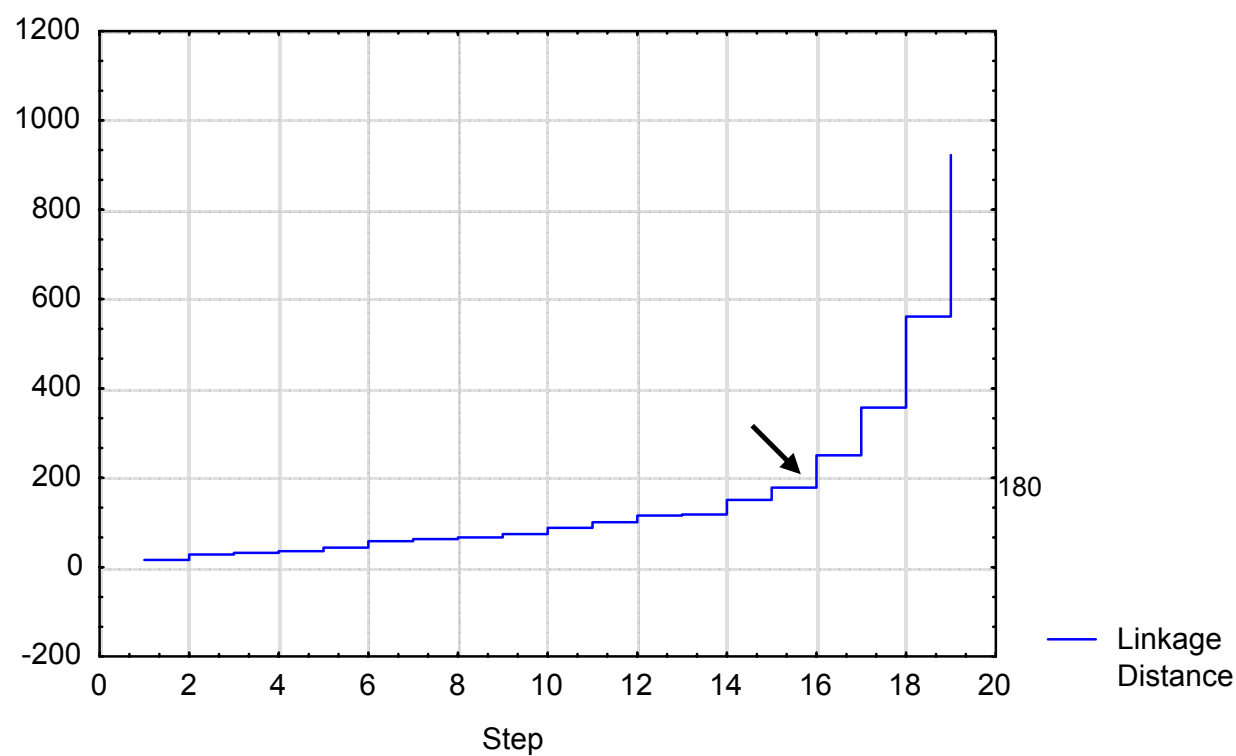

Figura 12- Gráfico das distâncias de ligação nos sucessivos passos de agrupamento utilizando a distância euclideana média e o método do UPGMA. A seta está indicando a distância de corte no fenograma para a definição dos grupos na Figura 10 


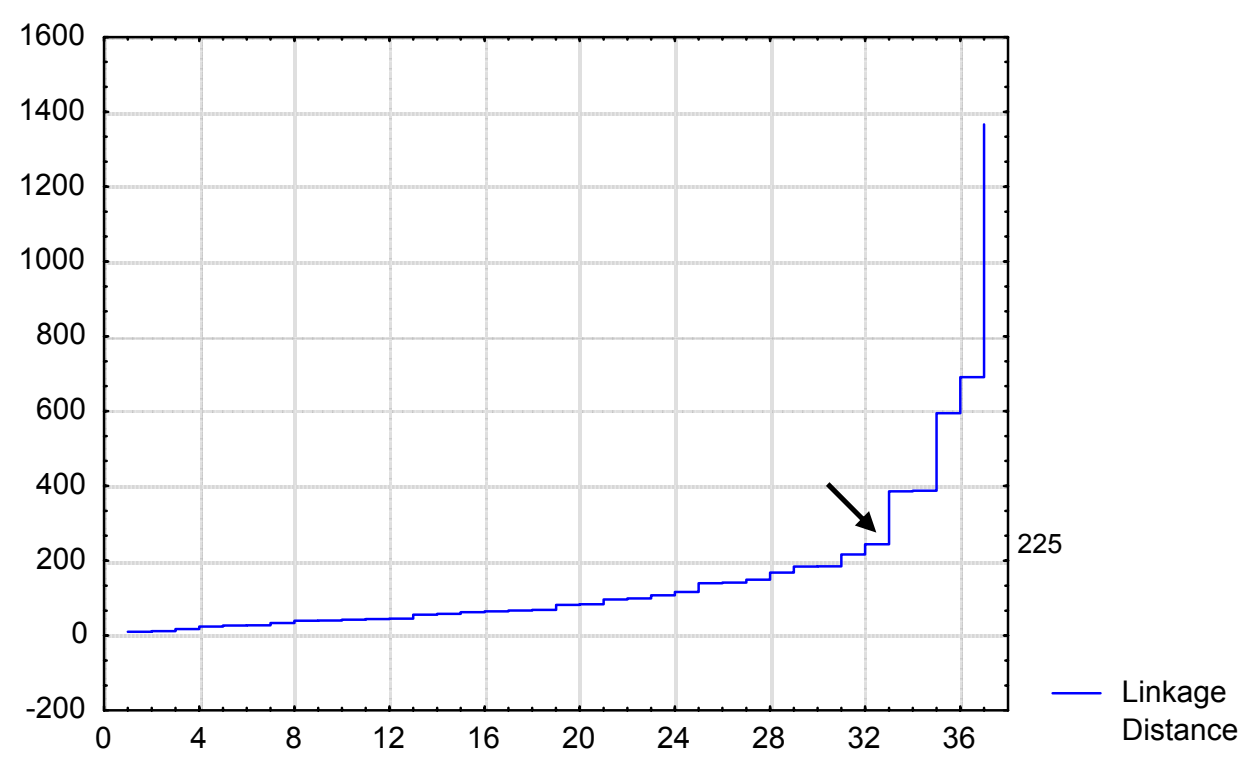

Figura 13 - Gráfico das distâncias de ligação nos sucessivos passos de agrupamento utilizando a distância euclideana média e o método do UPGMA. A seta está indicando a distância de corte no fenograma para a definição dos grupos na Figura 11

Pelo fenograma (Figura 10) foi possível observar a formação de 6 grupos para as amostras do Estado do Ceará, identificados a seguir: grupo 1 encontram-se 2 amostras ( $N^{\circ} 4$ e 3); grupo 2 encontra-se 1 amostra ( $\left.N^{\circ} 2\right)$; grupo 3 encontram-se 3 amostras ( $N^{\circ} 17,15$ e 9); grupo 4 encontram-se 4 amostras $\left(N^{\circ}\right.$ 16, 13, 10 e 7); grupo 5 encontram-se 6 amostras ( $N^{\circ} 19,11,14,6,8$ e 5$)$ e no grupo 6 encontram-se 4 amostras $\left(N^{\circ} 20,18,12\right.$ e 1$)$. 
Para as amostras do Estado do Piauí pode ser observado no fenograma (Figura 11) que também formaram-se 6 grupos: grupo 1 encontram-se 13 amostras $\left(\mathrm{N}^{\circ} 29,27,32,33,18,35,9,17,5,10,36,19\right.$ e 3); grupo 2 encontram-se 10 amostras $\left(\mathrm{N}^{\circ} 21,31,25,30,14,12,34,22,20\right.$ e 11); grupo 3 encontram-se 7 amostras $\left(\mathrm{N}^{\circ} 23,28,15,24,6,38\right.$ e 2); grupo 4 encontram-se 5 amostras $\left(\mathrm{N}^{\circ} 26\right.$, 8, 13, 16 e 7); grupo 5 encontra-se 1 amostra $\left(N^{\circ} 4\right)$ e no grupo 6 encontram-se 2 amostras $\left(\mathrm{N}^{\circ} 37\right.$ e 1$)$.

Para o Estado do Ceará dos caracteres físico-químicos analisados para cada eixo foi possível observar que a condutividade elétrica, no eixo $X$ foi 0 que mais contribuiu para o agrupamento e no eixo $\mathrm{Y}$ a sacarose aparente (Tabela 6). Bogdanov (1999) menciona que a condutividade elétrica é considerada um bom critério para a identificação da origem floral do mel, e que é influenciada pelos açúcares e o conteúdo de cinzas; os méis de diferentes origens florais têm valores diferentes de condutividade elétrica.

No trabalho em estudo foi possível observar a predominância de grãos de pólen pertencentes à família das mimosáceas com 62,5\% de Mimosa caesalpiniaefolia, sendo verificada a presença do gênero Mimosa em 100\% das amostras. Campos (1998) trabalhando com amostras de méis de Minas Gerais constatou que méis de mesma origem floral apresentam condutividade elétrica muito semelhante às obtidas nas amostras analisadas no presente trabalho.

No eixo $\mathrm{Y}$ a sacarose aparente foi a que mais contribuiu para o agrupamento das amostras do Estado do Ceará. A sacarose aparente é um caracter de grande importância no mel por estar associada à sua qualidade; quando seu valor encontrado for acima de $6 \%$ pode indicar um mel "verde" ou adulterado (Brasil, 2000). 
No Estado do Piauí observa-se que para os caracteres físicoquímicos analisados o que mais contribuiu no eixo $X$ foi a acidez e no eixo $Y$ a atividade diastásica (Tabela 6).

A acidez em análise de mel é de grande importância, sendo um caracter de qualidade, pois está associada à sua estabilidade com relação ao desenvolvimento de microorganismos (Horn et al., 1996).

A atividade diastásica é um outro caracter de relevância no mel por ser uma enzima produzida pelas abelhas. Soloveve (1971) considerou a atividade diastásica como um importante critério para avaliar sua qualidade, podendo indicar o superaquecimento, o que compromete seriamente o produto.

Tabela 6. Autovalores calculados para as 58 amostras de méis analisadas dos Estados do Ceará (20 amostras) e Piauí (38 amostras) para os parâmetros físico-químicos

\begin{tabular}{lcccc}
\hline \multicolumn{1}{c}{ Parâmetro analisado } & \multicolumn{2}{c}{ Ceará } & \multicolumn{2}{c}{ Piauí } \\
& Eixo X & Eixo Y & Eixo X & Eixo Y \\
\hline Cor & 0,27320 & $-0,21802$ & 0,27418 & $-0,00883$ \\
Umidade & 0,02772 & $-0,43998$ & 0,20771 & $-0,42436$ \\
Condutividade elétrica & $\mathbf{0 , 4 0 6 0 6}$ & 0,02702 & 0,36370 & 0,29092 \\
$\mathrm{pH}$ & 0,14985 & 0,16928 & 0,00546 & 0,03225 \\
Acidez & 0,40194 & $-0,08699$ & $\mathbf{0 , 4 0 8 5 0}$ & $-0,02025$ \\
Índice de formol & 0,31999 & 0,21579 & 0,33125 & 0,18084 \\
Viscosidade & $-0,11426$ & 0,38889 & $-0,20589$ & 0,33077 \\
HMF & 0,19262 & $-0,21941$ & 0,24379 & 0,03527 \\
Cinzas & 0,33251 & $-0,15173$ & 0,33099 & 0,17026 \\
Açúcares totais & $-0,12017$ & 0,38533 & $-0,15813$ & 0,43323 \\
Açúcares redutores & $-0,18543$ & 0,01502 & $-0,07821$ & 0,34729 \\
Sacarose aparente & 0,05502 & $\mathbf{0 , 4 4 4 1 6}$ & $-0,08832$ & 0,07897 \\
Proteína & 0,39040 & 0,19938 & 0,37260 & 0,07198 \\
Atividade diastásica & 0,32906 & 0,25922 & 0,28919 & $\mathbf{0 , 4 9 1 5 7}$ \\
\hline
\end{tabular}




\subsubsection{Elementos químicos}

Os valores referentes às concentrações dos elementos químicos analisados nas 58 amostras de méis produzidos por Apis mellifera, de diferentes municípios dos Estados do Ceará (20 amostras) e Piauí (38 amostras) estão apresentados nas Tabelas 7 e 8.

$\mathrm{Na}$ Tabela 9 verificam-se os valores estabelecidos pela legislação brasileira, as médias, os intervalos de confiança, os valores mínimos e máximos de cada um dos elementos químicos analisados para as amostras dos Estados Ceará e do Piauí. 
Tabela 7. Valores médios $\left(\mu \mathrm{g} \cdot \mathrm{g}^{-1}\right.$ ) dos elementos químicos de 20 amostras de méis da Apis mellifera de diferentes municípios do Estado do Ceará

\begin{tabular}{|c|c|c|c|c|c|c|c|c|c|c|c|c|c|c|c|c|c|}
\hline Amostras & $\mathrm{K}$ & $\mathrm{Ca}$ & $\mathrm{Ti}$ & $\mathrm{Cr}$ & $\mathrm{Mn}$ & $\mathrm{Fe}$ & Co & $\mathrm{Ni}$ & $\mathrm{Cu}$ & $\mathrm{Zn}$ & $\mathrm{Se}$ & $\mathrm{Br}$ & $\mathrm{Rb}$ & $\mathrm{Sr}$ & $\mathrm{Ba}$ & $\mathrm{Hg}$ & $\mathrm{Pb}$ \\
\hline 1 & 284,710 & 14,044 & nd & $\mathrm{Nd}$ & 1,166 & 4,366 & nd & nd & 0,308 & 0,793 & nd & nd & 1,919 & nd & nd & nd & nd \\
\hline 2 & 16,862 & 2,791 & nd & 0,404 & 0,164 & 1,284 & nd & 0,069 & 0,020 & 0,088 & nd & 0,910 & 0,061 & 0,027 & nd & nd & nd \\
\hline 3 & 46,686 & 9,715 & nd & 0,090 & 0,494 & 1,110 & nd & nd & 0,073 & 0,889 & nd & nd & 0,169 & nd & nd & nd & nd \\
\hline 4 & 147,163 & 19,621 & nd & nd & 1,082 & 2,262 & nd & nd & 0,372 & 1,812 & nd & nd & 0,656 & 0,255 & nd & nd & nd \\
\hline 5 & 718,981 & 38,259 & nd & nd & 2,396 & 3,861 & nd & nd & 0,438 & 2,940 & nd & nd & 1,202 & 0,403 & nd & nd & nd \\
\hline 6 & 383,760 & 263,424 & nd & 0,640 & 1,560 & 13,386 & nd & nd & 0,220 & 312,589 & nd & nd & 1,069 & 4,432 & 2,041 & 0,518 & nd \\
\hline 7 & 255,025 & 13,823 & nd & 0,393 & 0,958 & 1,907 & nd & nd & 0,196 & 0,858 & nd & nd & 0,716 & 0,265 & nd & nd & nd \\
\hline 8 & 79,734 & 8,277 & nd & 0,050 & 0,289 & 0,615 & nd & 0,011 & 0,049 & 1,108 & nd & nd & 0,201 & 0,143 & nd & nd & nd \\
\hline 9 & 175,332 & 39,533 & nd & 0,075 & 1,109 & 2,292 & nd & 0,069 & 0,673 & 1,058 & nd & nd & 0,801 & 0,374 & nd & nd & nd \\
\hline 10 & 200,961 & 28,329 & nd & 0,147 & 1,499 & 4,324 & 0,071 & 0,050 & 0,298 & 0,899 & nd & nd & 1,123 & 0,219 & nd & nd & nd \\
\hline 11 & 328,054 & 14,534 & nd & 0,407 & 1,195 & 3,018 & nd & nd & 0,255 & 1,512 & nd & nd & 0,828 & nd & nd & nd & nd \\
\hline 12 & 271,039 & 8,767 & nd & nd & 0,906 & 1,554 & nd & nd & 0,286 & 0,448 & nd & nd & 1,463 & nd & nd & nd & nd \\
\hline 13 & 154,824 & 10,783 & nd & nd & 0,502 & 1,047 & nd & nd & 0,104 & 1,141 & nd & nd & 0,585 & nd & nd & nd & nd \\
\hline 14 & 222,250 & 7,140 & 0,148 & 0,063 & 0,436 & 1,027 & nd & nd & 0,100 & 0,579 & nd & nd & 0,452 & nd & nd & nd & nd \\
\hline 15 & 844,092 & 8,496 & 0,462 & 0,160 & 0,759 & 1,587 & nd & nd & 0,312 & 1,167 & nd & 0,118 & 2,906 & nd & nd & nd & nd \\
\hline 16 & 794,422 & 36,625 & nd & 0,337 & 2,184 & 3,012 & nd & nd & 0,428 & 1,214 & nd & nd & 1,512 & 0,806 & nd & nd & nd \\
\hline 17 & 189,602 & 26,081 & 0,235 & 0,137 & 0,885 & 2,293 & nd & nd & 0,369 & 0,842 & 0,054 & nd & 0,358 & 0,347 & nd & nd & nd \\
\hline 18 & 288,296 & 30,445 & nd & $\mathrm{Nd}$ & 1,941 & 1,503 & nd & 0,101 & 0,258 & 0,457 & nd & 0,017 & 1,082 & 0,207 & nd & nd & nd \\
\hline 19 & 368,424 & 37,571 & nd & $\mathrm{Nd}$ & 3,169 & 3,615 & nd & nd & 0,199 & 0,525 & nd & nd & 1,241 & 0,329 & nd & nd & nd \\
\hline 20 & 493,033 & 53,708 & nd & $\mathrm{Nd}$ & 4,447 & 4,721 & nd & nd & 0,342 & 0,992 & nd & nd & 1,626 & 0,670 & nd & nd & nd \\
\hline
\end{tabular}

nd - não detectado 
Tabela 8. Valores médios $\left(\mu \mathrm{g} \cdot \mathrm{g}^{-1}\right)$ dos elementos químicos de 38 amostras de méis da Apis mellifera de diferentes municípios do Estado do Piauí

\begin{tabular}{|c|c|c|c|c|c|c|c|c|c|c|c|c|c|c|c|c|}
\hline Amostras & $\mathrm{K}$ & $\mathrm{Ca}$ & $\mathrm{Ti}$ & $\mathrm{Cr}$ & $\mathrm{Mn}$ & $\mathrm{Fe}$ & Co & $\mathrm{Ni}$ & $\mathrm{Cu}$ & $\mathrm{Zn}$ & $\mathrm{Se}$ & $\mathrm{Br}$ & $\mathrm{Rb}$ & $\mathrm{Sr}$ & $\mathrm{Ba}$ & $\mathrm{Hg}$ \\
\hline 1 & 40,145 & 3,874 & nd & nd & 0,182 & 0,513 & nd & 0,021 & 0,055 & 0,206 & nd & nd & 0,230 & nd & nd & $\mathrm{nd}$ \\
\hline 2 & 131,354 & 11,997 & nd & nd & 0,568 & 3,862 & nd & nd & 0,082 & 10,756 & nd & nd & 0,686 & 0,537 & 11,681 & $\mathrm{nd}$ \\
\hline 3 & 159,004 & 18,775 & 0,266 & nd & 0,725 & 2,694 & nd & nd & 0,125 & 0,683 & nd & nd & 0,802 & 0,207 & nd & nd \\
\hline 4 & 163,979 & 76,759 & nd & 0,110 & 0,865 & 1,394 & nd & nd & 0,241 & 0,487 & nd & nd & 0,589 & 0,108 & nd & $\mathrm{nd}$ \\
\hline 5 & 144,347 & 21,208 & 0,242 & nd & 1,434 & 4,143 & nd & nd & 0,209 & 0,679 & nd & nd & 0,614 & 0,261 & nd & nd \\
\hline 6 & 140,359 & 16,698 & nd & nd & 0,661 & 1,328 & nd & nd & 0,258 & 0,398 & nd & nd & 0,466 & 0,166 & nd & nd \\
\hline 7 & 161,322 & 30,020 & nd & nd & 0,921 & 3,777 & nd & 0,144 & 0,311 & 0,663 & nd & nd & 0,471 & 0,219 & nd & nd \\
\hline 8 & 58,209 & 12,425 & nd & nd & 0,388 & 0,728 & nd & nd & 0,130 & 3,907 & nd & nd & 0,218 & 0,134 & nd & nd \\
\hline 9 & 123,960 & 10,949 & nd & nd & 0,331 & 1,169 & nd & 3,241 & 0,908 & 6,838 & nd & nd & 0,197 & nd & nd & nd \\
\hline 10 & 174,743 & 18,663 & nd & nd & 0,766 & 4,636 & nd & 0,075 & 0,254 & 1,387 & nd & nd & 0,348 & 0,138 & nd & $\mathrm{nd}$ \\
\hline 11 & 163,952 & 19,569 & nd & nd & 0,445 & 7,053 & nd & nd & 0,228 & 0,783 & nd & nd & 0,703 & 0,265 & nd & nd \\
\hline 12 & 46,870 & 9,587 & nd & nd & 0,345 & 1,306 & nd & nd & 0,163 & 0,356 & nd & nd & 0,142 & 0,127 & nd & nd \\
\hline 13 & 138,434 & 19,627 & nd & nd & 0,773 & 2,592 & nd & nd & 0,193 & 0,490 & nd & nd & nd & nd & nd & nd \\
\hline 14 & 103,285 & 14,102 & 0,197 & nd & 0,371 & 2,003 & 0,037 & 0,021 & 0,183 & 0,241 & nd & nd & 0,385 & 0,110 & nd & nd \\
\hline 15 & 123,649 & 15,680 & nd & nd & 0,685 & 2,468 & nd & nd & 0,336 & 0,634 & nd & nd & 0,648 & 0,182 & nd & nd \\
\hline 16 & 152,359 & 17,278 & nd & nd & 0,613 & 1,568 & nd & 0,061 & 0,262 & 0,434 & nd & nd & 0,320 & 0,080 & nd & nd \\
\hline 17 & 101,229 & 10,634 & nd & nd & 0,770 & 1,239 & nd & 0,021 & 0,062 & 0,192 & nd & nd & 0,332 & 0,057 & nd & $\mathrm{nd}$ \\
\hline 18 & 128,453 & 18,959 & nd & 0,181 & 0,849 & 2,245 & nd & 0,163 & 0,244 & 0,348 & nd & nd & 0,303 & nd & nd & $\mathrm{nd}$ \\
\hline 19 & 123,090 & 11,783 & nd & nd & 0,575 & 1,356 & nd & 0,038 & 0,107 & 0,681 & nd & nd & 0,310 & 0,117 & nd & $\mathrm{nd}$ \\
\hline 20 & 87,802 & 9,684 & nd & nd & 0,317 & 1,019 & nd & 0,102 & 0,140 & 0,918 & nd & nd & 0,338 & nd & nd & nd \\
\hline 21 & 50,543 & 6,658 & nd & nd & 0,212 & 0,677 & nd & nd & 0,078 & 0,171 & nd & nd & 0,109 & nd & nd & nd \\
\hline 22 & 69,546 & 6,816 & nd & 0,038 & 0,160 & 0,536 & nd & 0,030 & 0,053 & 0,425 & nd & nd & 0,166 & nd & nd & nd \\
\hline 23 & 82,259 & 13,219 & nd & nd & 0,471 & 0,931 & nd & nd & 0,133 & 0,395 & nd & nd & 0,303 & nd & nd & nd \\
\hline 24 & 12,398 & 2,149 & 0,035 & 0,412 & 0,062 & 0,398 & 0,039 & 7,191 & 0,094 & 0,032 & nd & nd & 0,035 & nd & nd & nd \\
\hline 25 & 21,237 & 3,361 & 0,058 & nd & 0,085 & 0,567 & nd & 0,337 & 0,041 & 0,069 & nd & nd & 0,094 & 0,032 & nd & nd \\
\hline 26 & 8,862 & 1,687 & 0,028 & nd & 0,053 & 0,355 & nd & 0,006 & 0,029 & 0,085 & nd & nd & 0,034 & 0,026 & nd & nd \\
\hline 27 & 204,777 & 22,212 & nd & nd & 1,318 & 1,954 & nd & nd & 0,104 & 0,801 & nd & nd & 0,427 & nd & nd & nd \\
\hline 28 & 2,180 & 0,385 & 0,007 & nd & 0,014 & 0,067 & nd & nd & 0,007 & 0,010 & nd & nd & 0,007 & 0,006 & nd & nd \\
\hline 29 & 31,736 & 4,309 & 0,061 & 0,114 & 0,151 & 0,846 & nd & 1,408 & 0,078 & 0,078 & nd & nd & 0,144 & 0,054 & nd & $\mathrm{nd}$ \\
\hline 30 & 106,820 & 13,988 & nd & nd & 0,479 & 1,698 & nd & 0,122 & 0,257 & 0,391 & nd & nd & 0,185 & nd & nd & nd \\
\hline 31 & 183,062 & 14,435 & nd & nd & 0,296 & 0,862 & nd & nd & 0,145 & 0,333 & nd & nd & 0,423 & nd & nd & nd \\
\hline 32 & 203,133 & 19,678 & nd & nd & 0,467 & 2,027 & nd & 0,091 & 0,208 & 0,310 & nd & nd & 0,433 & nd & nd & nd \\
\hline 33 & 113,789 & 9,567 & nd & nd & 0,258 & 1,427 & nd & nd & 0,070 & 0,326 & nd & nd & 0,313 & nd & nd & nd \\
\hline 34 & 129,765 & 11,836 & nd & nd & 0,341 & 1,439 & nd & 0,102 & 0,269 & nd & nd & nd & 1,528 & 0,136 & nd & nd \\
\hline 35 & 138,828 & 11,846 & nd & nd & 0,451 & 1,724 & nd & 0,026 & 0,160 & 0,358 & nd & nd & 0,456 & 0,136 & nd & $\mathrm{nd}$ \\
\hline 36 & 132,732 & 13,036 & nd & nd & 0,618 & 0,875 & nd & 0,036 & 0,224 & 0,634 & nd & nd & 0,461 & 0,147 & nd & $\mathrm{nd}$ \\
\hline 37 & 140,107 & 16,643 & nd & 0,322 & 0,399 & 1,313 & nd & 2,669 & 0,222 & 0,141 & nd & nd & 0,373 & 0,094 & nd & $\mathrm{nd}$ \\
\hline 38 & 69,169 & 9,801 & nd & nd & 0,303 & 0,642 & nd & 0,112 & 0,125 & 0,127 & nd & nd & 0,147 & nd & nd & $\mathrm{nd}$ \\
\hline
\end{tabular}

(nd - não detectado) 
Tabela 9. Valores estabelecidos pela legislação brasileira, valor médio, intervalo de confiança (5\%), mínimo e máximo dos elementos químicos encontrados em 58 amostras de méis de Apis mellifera de diferentes municípios dos Estados do Ceará (20) e do Piauí (38)

\begin{tabular}{|c|c|c|c|c|c|c|c|}
\hline \multirow[b]{2}{*}{$\begin{array}{l}\text { Elementos } \\
\text { Químicos }\end{array}$} & \multirow{2}{*}{$\begin{array}{c}\text { Legislação } \\
\text { Brasileira* }^{*}\left(\mu \mathrm{g} \cdot \mathrm{g}^{-1}\right)\end{array}$} & \multicolumn{3}{|c|}{ Ceará } & \multicolumn{3}{|c|}{ Piauí } \\
\hline & & $\begin{array}{l}\text { Média } \\
\left(\mu g \cdot g^{-1}\right)\end{array}$ & $\begin{array}{l}\text { Mínimo } \\
\left(\mu g . g^{-1}\right)\end{array}$ & $\begin{array}{l}\text { Máximo } \\
\left(\mu \mathrm{g} \cdot \mathrm{g}^{-1}\right)\end{array}$ & $\begin{array}{l}\text { Média } \\
\left(\mu g \cdot g^{-1}\right)\end{array}$ & $\begin{array}{l}\text { Mínimo } \\
\left(\mu g \cdot g^{-1}\right)\end{array}$ & $\begin{array}{l}\text { Máximo } \\
\left(\mu \mathrm{g} \cdot \mathrm{g}^{-1}\right)\end{array}$ \\
\hline $\mathrm{K}$ & -- & $313,162 \pm 102,85^{\star \star \star *}$ & 16,862 & 844,092 & $109,671 \pm 17,487$ & 2,180 & 204,777 \\
\hline $\mathrm{Ca}$ & -- & $33,598 \pm 24,497^{* * * *}$ & 2,791 & 263,424 & $14,471 \pm 3,8797$ & 0,385 & 76,759 \\
\hline $\mathrm{Ti}$ & -- & $0,282 \pm 0,184^{* * * *}$ & 0,148 & 0,462 & $0,112 \pm 0,07$ & 0,007 & 0,266 \\
\hline $\mathrm{Cr}$ & $<0,10$ & $0,242 \pm 0,11^{* * * *}$ & 0,050 & 0,640 & $0,196 \pm 0,11$ & 0,038 & 0,412 \\
\hline $\mathrm{Mn}$ & -- & $1,357 \pm 0,4611^{\star * * *}$ & 0,164 & 4,447 & $0,493 \pm 0,103$ & 0,014 & 1,434 \\
\hline $\mathrm{Fe}$ & -- & $2,939 \pm 1,208^{* * * *}$ & 0,615 & 13,386 & $1,722 \pm 0,446$ & 0,067 & 7,053 \\
\hline Co & -- & $0,071^{* * *}$ & - & -- & 0,038 & 0,037 & 0,039 \\
\hline $\mathrm{Ni}$ & $<5,00$ & $0,060 \pm 0,029^{* * * *}$ & 0,011 & 0,101 & $0,728 \pm 0,706$ & 0,006 & 7,191 \\
\hline $\mathrm{Cu}$ & $<10,00^{* *}$ & $0,265 \pm 0,068^{\star * * *}$ & 0,020 & 0,673 & $0,179 \pm 0,0471$ & 0,007 & 0,908 \\
\hline $\mathrm{Zn}$ & $<50,00$ & $16,59 \pm 30,53^{* * * *}$ & 0,088 & 312,589 & $0,967 \pm 0,653$ & 0,010 & 10,756 \\
\hline $\mathrm{Se}$ & $<0,30$ & $0,054^{* * *}$ & - & -- & nd & nd & nd \\
\hline $\mathrm{Br}$ & -- & $0,348 \pm 0,21^{\star * * *}$ & 0,017 & 0,910 & nd & nd & nd \\
\hline $\mathrm{Rb}$ & -- & $0,998 \pm 0,299^{* * * *}$ & 0,061 & 2,906 & $0,371 \pm 0,097$ & 0,007 & 1,528 \\
\hline $\mathrm{Sr}$ & -- & $0,652 \pm 0,627^{* * * *}$ & 0,027 & 4,432 & $0,145 \pm 0,045$ & 0,006 & 0,537 \\
\hline $\mathrm{Ba}$ & -- & $2,041^{* * *}$ & -- & -- & $11,681^{* * *}$ & -- & -- \\
\hline $\mathrm{Hg}$ & -- & $0,518^{* * *}$ & -- & nd & nd & nd & nd \\
\hline $\mathrm{Pb}$ & $<0,80$ & nd & nd & nd & $0,863^{* * *}$ & -- & -- \\
\hline
\end{tabular}

nd: não detectado

*Brasil (1998)

**Brasil (1965)

*** presença em uma amostra;

****intervalo de confiança 
A maioria dos valores médios dos elementos químicos obtidos nas amostras de méis dos Estados do Ceará (20) e do Piauí (38) encontram-se em conformidade com a legislação brasileira (Brasil, 1965 e Brasil, 1998) (Tabelas 7, 8 e 9). Entretanto, nas mesmas tabelas podem ser observadas amostras que não estão em conformidade com a legislação brasileira.

Lasceve \& Gonnet (1974) descrevem que os elementos químicos do mel podem ser modificados por fatores relativos às abelhas, ao apicultor, data de colheita, clima, variações nas condições florais, proporção dos diferentes néctares coletados e possíveis introduções de alguns elementos químicos devido a poluição.

Feller-Demalsy et al. (1989) mencionam que as concentrações de minerais são mais baixas nas regiões secas (índice pluviométrico de menos $600 \mathrm{~mm}$ ) e mais altas nas regiões mais úmidas (mais de $800 \mathrm{~mm}$ ).

White Junior et al. (1962) afirmaram que a composição de méis de mesma origem floral é semelhante e tem variação de mesma magnitude, mesmo quando as amostras são colhidas em anos diferentes, não especificando variações de clima.

Para o elemento $\mathrm{Cr}$ a legislação brasileira estabelece um valor máximo de $0,10 \mu \mathrm{g} \cdot \mathrm{g}^{-1}$. No presente estudo foi constatada uma variação de 0,050 a $0,640 \mu \mathrm{g} \cdot \mathrm{g}^{-1}$, para as amostras do Estado do Ceará (40\% estão acima do valor estabelecido) e 0,038 a $0,412 \mu \mathrm{g} \cdot \mathrm{g}^{-1}$ no Estado do Piauí (13,15\% das amostras acima do estabelecido). Morse \& Lisk (1980) analisaram amostras de méis de diferentes países e constataram para o $\mathrm{Cr}$ valores variando de 0,843 a 2,67 $\mu \mathrm{g} \cdot \mathrm{g}^{-1}$. Braziewicz et al. (2002) constataram uma variação de $<0,5$ a 6,1 $\mu \mathrm{g} \cdot \mathrm{g}^{-1}$. Já Caroli et al. (1999 e 2000) encontraram valores entre 1,03 a 3,93 $\mu \mathrm{g} \cdot \mathrm{g}^{-1}$. Estes autores verificaram valores acima do encontrado no presente estudo.

A legislação brasileira estabelece para o elemento $\mathrm{Ni}$ um valor máximo de $5 \mu \mathrm{g} \cdot \mathrm{g}^{-1}$. No Estado do Piauí foi constatado em uma amostra $(2,63 \%$ 
do total) um valor de $7,19 \mu \mathrm{g} \cdot \mathrm{g}^{-1}$, sendo assim acima do permitido pela legislação. Semelhantemente ao valor constatado no presente estudo foi verificado por Kump et al. (1996) que encontraram um valor máximo de $7 \mu \mathrm{g} \cdot \mathrm{g}^{-1}$.

No Estado do Ceará foi observado o Zn em uma amostra (5\% do total) com valor bem acima do permitido (589 $\mu \mathrm{g} \cdot \mathrm{g}^{-1}$ ) na legislação que estabelece valor máximo de $50 \mu \mathrm{g} \cdot \mathrm{g}^{-1}$. Valores considerados altos para o $\mathrm{Zn}$ também foram constatados por: Leita et al. (1996), Kump et al. (1996) e Carloi et al. (1999) que variaram de 65,8 a $1144 \mu \mathrm{g} \cdot \mathrm{g}^{-1}$.

O elemento $\mathrm{Pb}$ foi constatado em apenas uma amostra $(2,63 \%$ do total) no Estado do Piauí com valor de $0,863 \mu \mathrm{g} \cdot \mathrm{g}^{-1}$. O valor constatado encontra-se pouco acima do estabelecido que é de no máximo $0,8 \mu \mathrm{g} \cdot \mathrm{g}^{-1}$. O Pb também foi encontrado em amostras de méis por: Morse \& Lisk (1980) que analisando méis de diferentes países constataram valores variando de 1,79 a $3,19 \mu \mathrm{g} \cdot \mathrm{g}^{-1}$ e Kump et al. (1996) detectaram valores entre 0,6 a 110,8 $\mu \mathrm{g} \cdot \mathrm{g}^{-1}$.

As altas concentrações de $\mathrm{Cr}, \mathrm{Ni}, \mathrm{Zn}$ e $\mathrm{Pb}$ nas amostras analisadas podem indicar possível contaminação ambiental conforme os trabalhos de Tong et al.,1975; Nobre, 1990; Merin et al., 1998; Caroli et al., 2000 e Braziewiez et al. 2002. Segundo Morse \& Lisk (1980) a presença elevada de $\mathrm{Cd}, \mathrm{Cr}$, Co, $\mathrm{Fe}, \mathrm{Ni}, \mathrm{Zn}$ e $\mathrm{Pb}$ em amostras de méis pode ter como origem recipiente de aço galvanizado usado no processamento $\mathrm{e}$ armazenamento deste produto. Tong et al. (1975) observaram que méis que entram em contato com recipientes de metal, durante o processamento, apresentaram grande quantidade de zinco.

O Cu foi encontrado com um valor médio de $0,265 \mu \mathrm{g} \cdot \mathrm{g}^{-1}(0,020 \mathrm{a}$ $\left.0,673 \mu \mathrm{g} \cdot \mathrm{g}^{-1}\right)$ para o Estado de Ceará e $0,179 \mu \mathrm{g} \cdot \mathrm{g}^{-1}\left(0,007\right.$ a $\left.0,908 \mu \mathrm{g} \cdot \mathrm{g}^{-1}\right)$ para o Piauí. Para este elemento químico o valor estabelecido na legislação brasileira é de no máximo $10,00 \mu \mathrm{g} \cdot \mathrm{g}^{-1}$; desta forma todas as amostras analisadas encontram-se em conformidade com a legislação. Valores próximos aos do presente estudo foram constatados por Marchini (2001) em amostras de 
méis do Estado de São Paulo que obteve valores variando de 0,2 a 0,6 $\mu \mathrm{g} \cdot \mathrm{g}^{-1}$ para amostras de méis de flores de Eucalyptus e de 0,1 a 2,0 $\mu \mathrm{g}^{-\mathrm{g}^{-1}}$ para amostras de méis de flores silvestres. Já Nanda et al. (2003) trabalhando com méis de diferentes origens florais da Índia, constataram para o $\mathrm{Cu}$ valores variando de 1,74 a $2,9 \mu \mathrm{g} \cdot \mathrm{g}^{-1}$.

O elemento Se foi encontrado em apenas uma amostra (5\% do total) do Estado do Ceará, com o valor de 0,054 $\mu \mathrm{g} \cdot \mathrm{g}^{-1}$ (amostra 17). Para este elemento químico o valor estabelecido na legislação brasileira é de no máximo $0,30 \mu \mathrm{g} \cdot \mathrm{g}^{-1}$; desta forma todas as amostras analisadas encontram-se em conformidade com a legislação. Iskander (1996) analisando amostras de méis do Texas (Estados Unidos) constatou para o Se valores $<3 \mu \mathrm{g} \cdot \mathrm{g}^{-1}$.

Já para os elementos químicos $\mathrm{K}, \mathrm{Ca}, \mathrm{Ti}, \mathrm{Mn}, \mathrm{Fe}, \mathrm{Co}, \mathrm{Br}, \mathrm{Rb}, \mathrm{Sr}$, $\mathrm{Ba}$ e $\mathrm{Hg}$ que não se encontram na legislação brasileira foram obtidos os seguintes valores:

- O K foi o elemento químico que apareceu em maior quantidade em comparação com os demais elementos. O valor médio encontrado foi de $313,162 \mu \mathrm{g} \cdot \mathrm{g}^{-1}$, com uma variação de 16,962 a $844,092 \mu \mathrm{g} \cdot \mathrm{g}^{-1}$ para as amostras do Estado do Ceará e para as do Piauí o valor médio foi de $109,671 \mu \mathrm{g} \cdot \mathrm{g}^{-1}$, com variação de 2,180 a 204,77 $\mu \mathrm{g} \cdot \mathrm{g}^{-1}$. Azeredo et al. (1998) constataram em amostras de méis brasileiros valores variando de 181 a $915 \mu \mathrm{g} . \mathrm{g}^{-1}$; Yilmaz \& Yavuz (1998) analisaram amostras de méis da Turquia e observaram valor médio de $296 \mu \mathrm{g} . \mathrm{g}^{-1}$ para o K enquanto que Nanda et al. (2003) constataram em méis indianos valores variando de 489,52 a 932,56 $\mu \mathrm{g} \cdot \mathrm{g}^{-1}$.

- O elemento $\mathrm{Ca}$, segundo elemento em quantidade, foi observado uma média de $33,598 \mu \mathrm{g} \cdot \mathrm{g}^{-1}\left(2,79\right.$ a 263,454 $\left.\mu \mathrm{g} \cdot \mathrm{g}^{-1}\right)$ para o Estado do Ceará enquanto que para o Piauí o valor médio encontrado foi de $14,471 \mu \mathrm{g} \cdot \mathrm{g}^{-1}(0,385$ a $\left.76,759 \mu \mathrm{g} \cdot \mathrm{g}^{-1}\right)$. López-García et al. (1999) analisaram amostras de méis da 
Espanha e constataram para o Ca valores variando de 42 a $132 \mu \mathrm{g} . \mathrm{g}^{-1}$; Marchini (2001) encontrou em amostras do Estado de São Paulo valores variando para o Ca de 55 a $301 \mu \mathrm{g} . \mathrm{g}^{-1}$ para méis de flores de Eucapyptus, e 1 a $202 \mu \mathrm{g} \cdot \mathrm{g}^{-1}$ para méis de flores silvestres. Braziewiez et al. (2002) trabalharam com amostras de méis da Polônia e verificaram para o Ca valores variando de 36 a $214 \mu \mathrm{g} \cdot \mathrm{g}^{-1}$.

- Para as amostras analisadas o elemento Ti foi constatado em 3 amostras (15\% do total) com os seguintes valores: $0,148 \mu \mathrm{g} \cdot \mathrm{g}^{-1}$ (amostra 14), $0,462 \mu \mathrm{g} \cdot \mathrm{g}^{-1}$ (amostra 15) e 0,235 $\mu \mathrm{g} \cdot \mathrm{g}^{-1}$ (amostra 17) para o Estado do Ceará; já para o Piauí foi constatado em oito amostras $(3,5,14,24,25,26,28$ e 29) sendo observado o valor médio de $0,112 \mu \mathrm{g} \cdot \mathrm{g}^{-1}\left(0,007\right.$ a 0,266 $\left.\mu \mathrm{g} \cdot \mathrm{g}^{-1}\right)$. Tong et al. (1975) analisaram amostras de méis americanos coletados próximas de minas, indústrias e rodovias e constataram para o Ti valores variando de 0,04 a 3,1 $\mu \mathrm{g} \cdot \mathrm{g}^{-1}$, obtendo portanto valores bem superiores aos observados no presente estudo.

- A quantidade média do elemento $\mathrm{Mn}$ foi de $1,357 \mu \mathrm{g} \cdot \mathrm{g}^{-1}(0,164 \mathrm{a}$ 4,447 $\left.\mu \mathrm{g} \cdot \mathrm{g}^{-1}\right)$ e $0,493 \mu \mathrm{g} \cdot \mathrm{g}^{-1}\left(0,014\right.$ a $\left.1,434 \mu \mathrm{g} \cdot \mathrm{g}^{-1}\right)$ para os Estados do Ceará e Piauí, respectivamente. Salinas et al. (1994) analisaram amostras de méis da Espanha e determinaram para o Mn valor médio de $0,8 \mu \mathrm{g} \cdot \mathrm{g}^{-1}$. Valores próximos aos constatados no presentes estudo foram verificados por: Kump et al. (1996) que analisaram amostras de méis da Eslovênia e encontraram valor médio de 5 $\mu \mathrm{g} . \mathrm{g}^{-1}$ e Conti (2000) que trabalhou com amostras de méis italianos e obteve para o Mn valor médio de $3 \mu \mathrm{g} \cdot \mathrm{g}^{-1}$.

- O Fe teve como valor médio $2,939 \mu \mathrm{g} \cdot \mathrm{g}^{-1}\left(0,615\right.$ a $\left.13,386 \mu \mathrm{g} \cdot \mathrm{g}^{-1}\right)$ para o Estado de Ceará e $1,722 \mu \mathrm{g} \cdot \mathrm{g}^{-1}\left(0,067\right.$ a $\left.7,053 \mu \mathrm{g} \cdot \mathrm{g}^{-1}\right)$ para o Piauí. Valores superiores aos constatados no presente estudo foram encontrados por: Morse \& Lisk (1980) que analisaram amostras de méis de diferentes países e constataram para o Fe valores variando de 5,80 a $183 \mu \mathrm{g} \cdot \mathrm{g}^{-1}$ e Conti (2000) que 
encontrou para o Fe valor médio de 4,51 $\mu \mathrm{g} \cdot \mathrm{g}^{-1}$. Já Marchini (2001) constatou em amostras do Estado de São Paulo valores variando para o Fe de 2,1 a 9,0 $\mu \mathrm{g} . \mathrm{g}^{-1}$ para méis de flores de Eucapyptus, valores estes próximos aos constatados no presente trabalho.

- O elemento Co só foi constatado em uma amostra do Ceará (5\%) com o valor de 0,071 $\mu \mathrm{g} \cdot \mathrm{g}^{-1}$ (amostras 10). Para o Estado do Piauí sua presença foi verificada em duas amostras (5,26\%), sendo observados os valores 0,037 $\mu \mathrm{g} \cdot \mathrm{g}^{-1}$ (amostra 14) e 0,039 $\mu \mathrm{g} \cdot \mathrm{g}^{-1}$ (amostra 24). Trabalho desenvolvido por Morse \& Lisk (1980) em amostras de méis de diferentes países encontraram para o Co valores variando de 0,456 a 0,770 $\mu \mathrm{g} \cdot \mathrm{g}^{-1}$.

- O Br foi constatado em três amostra (15\% do total) do Estado do Ceará, sendo observados os valores $0,910 \mu \mathrm{g} \cdot \mathrm{g}^{-1}$ (amostra 2), 0,118 $\mu \mathrm{g} \cdot \mathrm{g}^{-1}$ (amostra 15) e 0,017 $\mu \mathrm{g}^{-1} \mathrm{~g}^{-1}$ (amostra 18). Lasceve \& Gonnet (1974) obtiveram para $\mathrm{Br}$ valores variando de 0,009 a 0,27 $\mu \mathrm{g} \cdot \mathrm{g}^{-1}$; Braziewiez et al. (2002) trabalharam com amostras de méis da Polônia e encontraram para o $\mathrm{Br}$ valores variando de 0,3 a $0,7 \mu \mathrm{g} \cdot \mathrm{g}^{-1}$.

- A quantidade média de $\mathrm{Rb}$ foi de $0,998 \mu \mathrm{g} \cdot \mathrm{g}^{-1} \quad(0,061$ a 2,906 $\mu \mathrm{g} . \mathrm{g}^{-1}$ ) para o Estado do Ceará enquanto que para o Piauí o valor médio encontrado foi de $0,371 \mu \mathrm{g} \cdot \mathrm{g}^{-1}\left(0,007\right.$ a $\left.1,528 \mu \mathrm{g} \cdot \mathrm{g}^{-1}\right)$. Iskander (1996) constataram para o $\mathrm{Rb}$ valores variando de 0,88 a $0,97 \mu \mathrm{g} \cdot \mathrm{g}^{-1}$; Latorre et al. (1999) analisaram amostras de méis da Espanha e evidenciaram o valor médio de $1,5 \mu \mathrm{g} \cdot \mathrm{g}^{-1}$; Tong et al. (1975) encontraram valores variando de 0,5 a 350 $\mu \mathrm{g} \cdot \mathrm{g}^{-1}$ portanto valores bem superior aos encontrado no presente estudo.

- O Sr foi constatado em 13 amostras (65\% do total) do Estado do Ceará tendo como valor médio $0,652 \mu \mathrm{g} \cdot \mathrm{g}^{-1}\left(0,027\right.$ a $\left.4,432 \mu \mathrm{g} \cdot \mathrm{g}^{-1}\right)$. Para o Piauí este elemento foi constatado em 23 amostras $(60,52 \%$ do total) sendo verificado o valor médio de $0,145 \mu \mathrm{g} \cdot \mathrm{g}^{-1}\left(0,006\right.$ a $\left.0,5370,145 \mu \mathrm{g} \cdot \mathrm{g}^{-1}\right)$. Tong et al. 
(1975) encontraram em amostras de méis americanos próximas de minas, indústrias e rodovias valores variando de 0,03 a 2,6 $\mu \mathrm{g} \cdot \mathrm{g}^{-1}$ para o $\mathrm{Sr}$.

- O Ba foi constatado em apenas uma amostra (5\% do total) do Estado do Ceará $\left(2,041 \mu \mathrm{g} \cdot \mathrm{g}^{-1}\right)$ e em uma amostra $(2,63 \%$ do total) do Estado do Piauí $\left(11,681 \mu \mathrm{g} \cdot \mathrm{g}^{-1}\right)$. Valores inferiores aos constatados no presente trabalho foram observados por Tong et al. (1975) em méis próximas de minas, indústrias e rodovias $\left(0,04\right.$ a $\left.1,4 \mu \mathrm{g} \cdot \mathrm{g}^{-1}\right)$ e Lasceve \& Gonnet (1974) encontraram para Ba valores variando de 0,005 a 0,4 $\mu \mathrm{g} \cdot \mathrm{g}^{-1}$.

- O Hg foi constatado apenas na amostra seis (5\% do total) do Estado do Ceará $\left(0,518 \mu \mathrm{g} \cdot \mathrm{g}^{-1}\right)$. Celechovska \& Vorlova (2001) analisaram amostras de méis da República Tcheca e constataram para $\circ \mathrm{Hg}$ valores variando de 0,67 a $2,93 \mu \mathrm{g} \cdot \mathrm{g}^{-1}$.

\subsubsection{Análise de agrupamento para os elementos químicos}

Para a análise de agrupamento de componentes principais de 58 amostras (20 Ceará e 38 Piauí) de méis e dos 16 elementos químicos (16 para o Ceará e 14 para o Piauí) (Tabelas 7 e 8), foram selecionados para o Estado do Ceará 10 elementos químicos, sendo descartados 6 ( $\mathrm{Ca}, \mathrm{Fe}, \mathrm{Zn}, \mathrm{Sr}$, Ba e $\mathrm{Hg})$ que eram altamente correlacionados. Para as amostras do Estado do Piauí foram selecionados 12 elementos químicos e descartados 2 ( $\mathrm{Ni} \mathrm{e} \mathrm{Zn}$ ) que também eram altamente correlacionados.

Os resultados das estimativas das variâncias (autovalores) encontram-se nas Tabelas (10 e 11). 
Tabela 10. Estimativas das variâncias (autovalores) e porcentagem acumulada da variância total (\%), obtidas por meio da análise de componentes principais, considerando-se as 20 amostras de méis do Estado do Ceará e os 10 elementos químicos

\begin{tabular}{ccc}
\hline Componentes principais & Autovalores & \% Acumulada \\
\hline $\mathrm{Y}_{1}$ & 6,2922 & 39,33 \\
$\mathrm{Y}_{2}$ & 2,9037 & 57,47 \\
$\mathrm{Y}_{3}$ & 1,6809 & 67,98 \\
$\mathrm{Y}_{4}$ & 1,3212 & 76,28 \\
\hline
\end{tabular}

Tabela 11. Estimativas das variâncias (autovalores) e porcentagem acumulada da variância total (\%) obtidas por meio da análise de componentes principais, considerando-se as 38 amostras de méis do Piauí e os 12 elementos químicos

\begin{tabular}{ccc}
\hline Componentes principais & Autovalores & \% Acumulada \\
\hline$Y_{1}$ & 4,3045 & 30,75 \\
$Y_{2}$ & 2,4021 & 47,90 \\
$Y_{3}$ & 2,0185 & 62,32 \\
$Y_{4}$ & 1,9728 & 76,41 \\
\hline
\end{tabular}

$\mathrm{Na}$ Tabela 10 verifica-se que o primeiro componente concentrou $39,33 \%$ da variância total, o segundo $57,47 \%$, o terceiro $67,98 \%$ e o quarto $76,28 \%$ para o Estado do Ceará. Já para o Piauí na Tabela 11 verifica-se que o 
primeiro componente concentrou $30,75 \%$ da variância total, o segundo $47,90 \%$, o terceiro $62,32 \%$ e o quarto $76,41 \%$.

Para os Estados do Ceará e do Piauí observa-se que foram necessários quatro componentes principais para explicar $70 \%$ da variância total disponível entre os elementos químicos, constatando-se assim uma considerável dispersão da variância no material estudado.

Observa-se nas Figuras 14 e 15 os fenogramas elaborados pelas distâncias euclidiana média e o método UPGMA envolvendo as 58 amostras (20 Ceará e 38 Piauí) de méis e os elementos químicos.

Para definição dos grupos adotou-se os gráficos das distâncias de ligação nos sucessivos passos da análise de agrupamento (Figuras 16 e 17). Este método baseia-se na identificação de um platô no sentido vertical, o que significa que muitos grupos foram formados na mesma distância de ligação, sendo essa distância um ponto ótimo de corte no fenograma determinando o número de grupos formados. O ponto para o corte escolhido no presente trabalho foi em 50 para o Estado do Ceará e 18 para o Estado do Piauí representados pelas linhas horizontais nas Figuras 14 e 15 e pelas setas nas Figuras 16 e 17. 


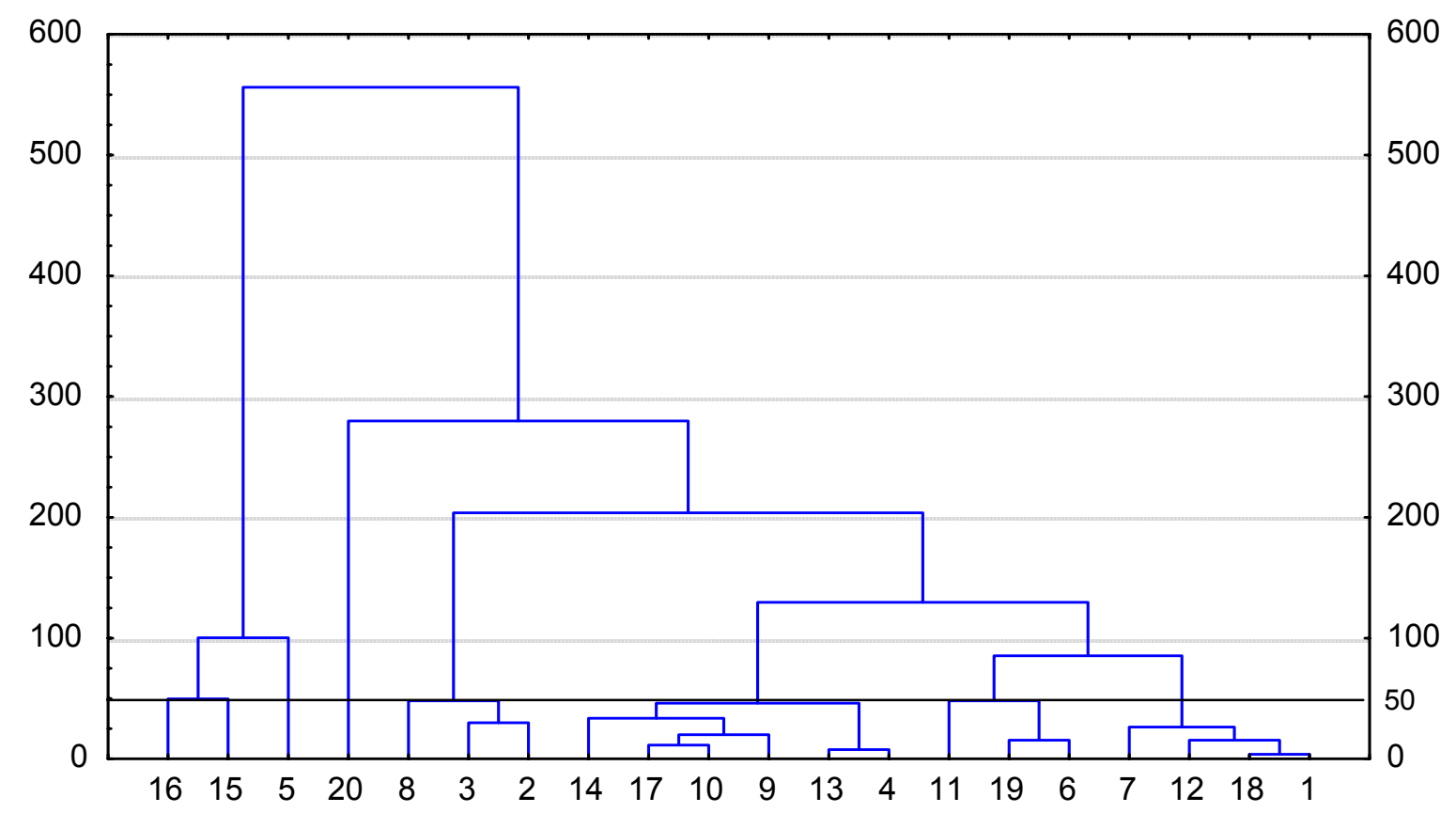

Figura 14 - Fenograma obtido pela análise de agrupamento, utilizando-se a distância euclideana média e o método UPGMA para as 20 amostras de méis de Apis mellifera do Estado do Ceará e os 10 elementos químicos selecionados 


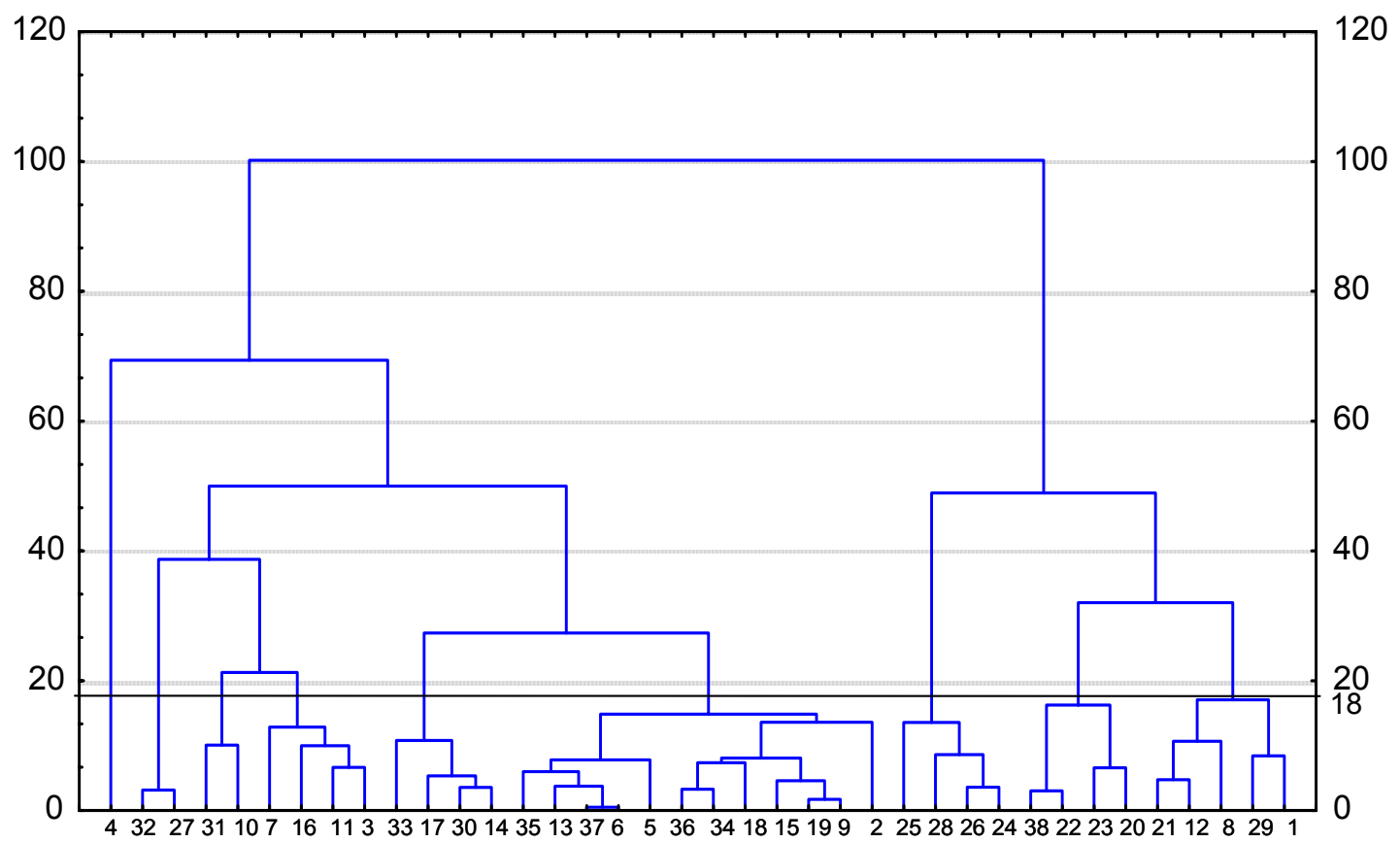

Figura 15 - Fenograma obtido pela análise de agrupamento, utilizando-se a distância euclideana média e o método UPGMA para as 38 amostras de méis de Apis mellifera do Estado do Piauí e os 12 elementos químicos selecionados 


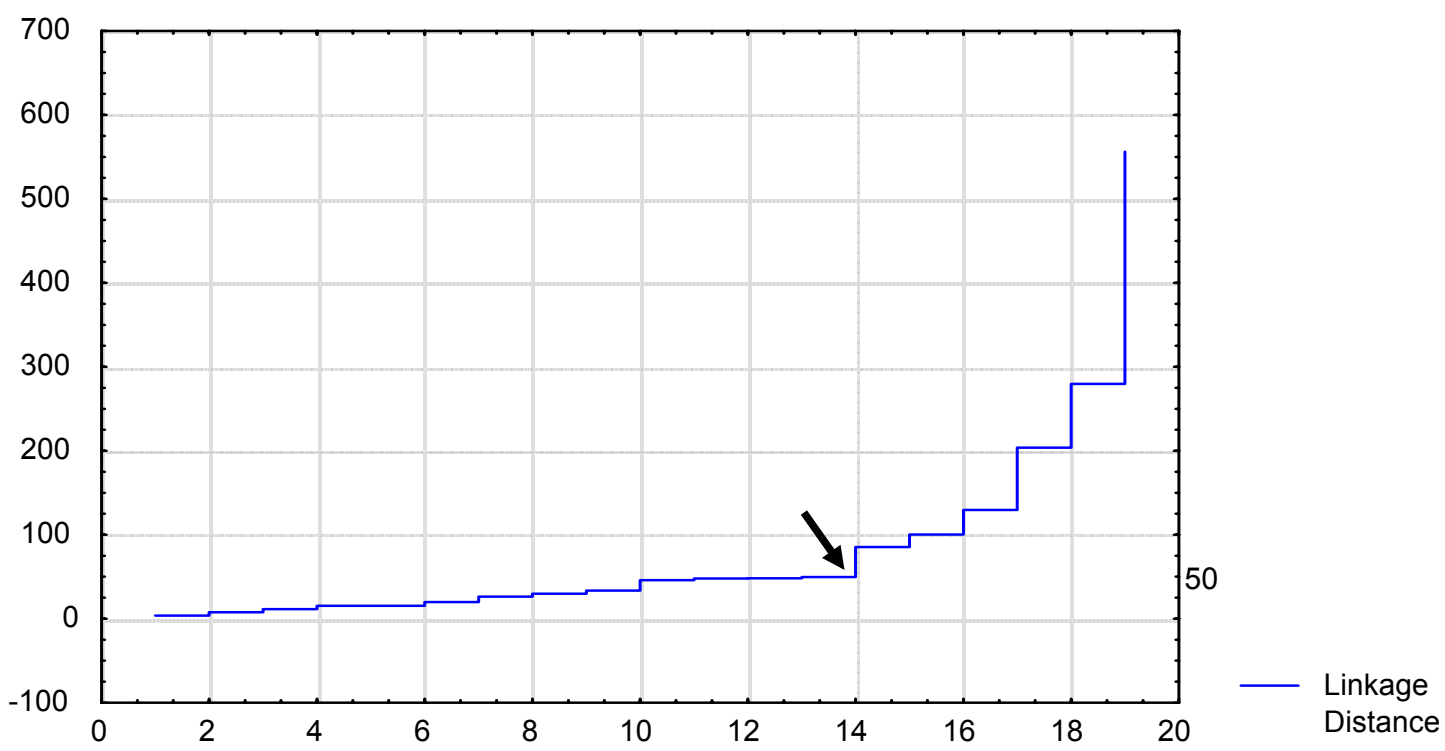

Figura 16 - Gráfico das distâncias de ligação nos sucessivos passos de agrupamento utilizando a distância euclideana média e o método do UPGMA. A seta está indicando a distância de corte no fenograma para a definição dos grupos na Figura 14 


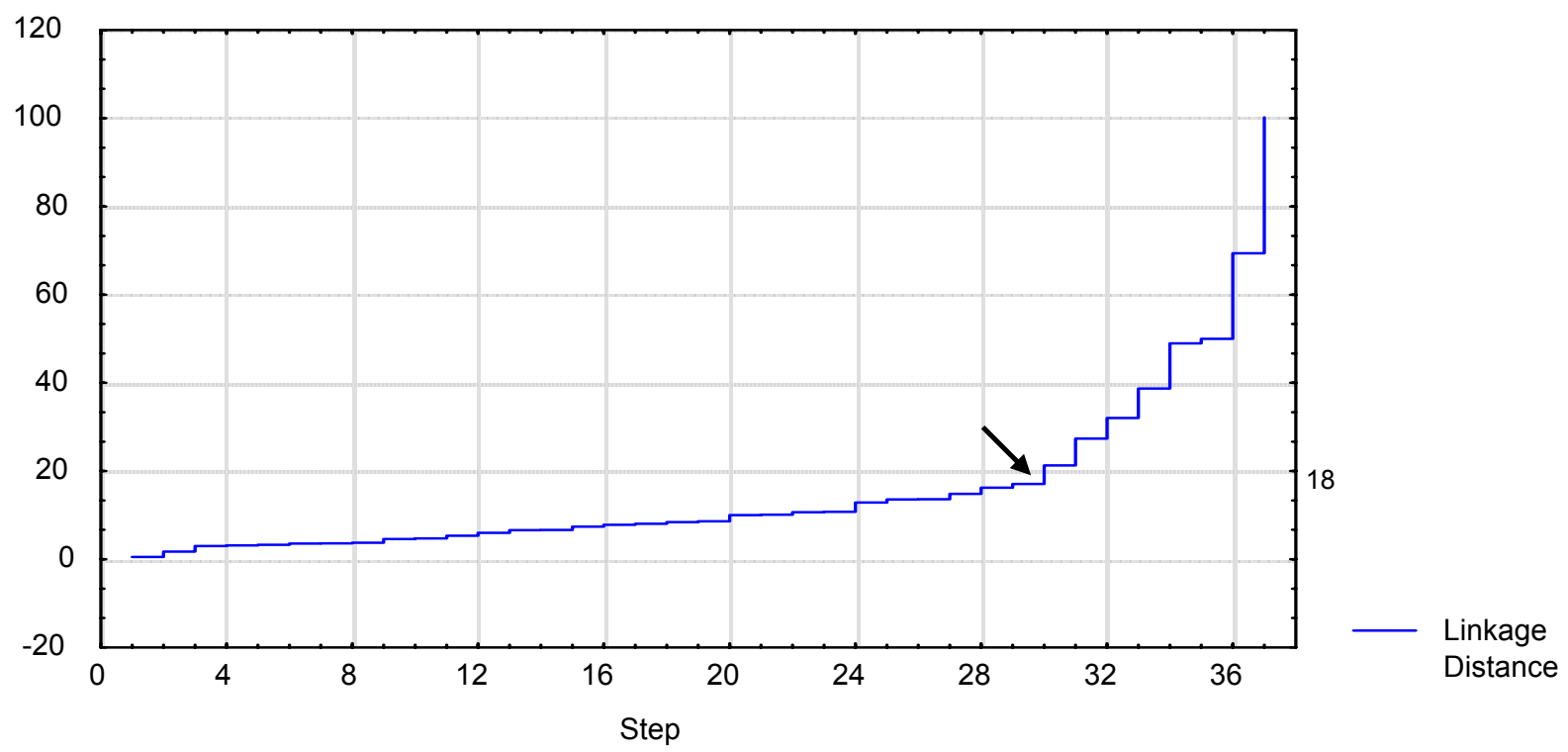

Figura 17 - Gráfico das distâncias de ligação nos sucessivos passos de agrupamento utilizando a distância euclideana média e o método do UPGMA. A seta está indicando a distância de corte no fenograma para a definição dos grupos na Figura 15

Na Figura 14 observa-se a formação de 10 grupos para as amostras do Estado do Ceará, identificados a seguir: grupo 1 encontra-se 1 amostra ( $\left.\mathrm{N}^{\circ} 16\right)$; grupo 2 encontra-se 1 amostra ( $\left.\mathrm{N}^{\circ} 15\right)$; grupo 3 encontra-se 1 amostra ( $\mathrm{N}^{\circ}$ ); ; grupo 4 encontra-se 1 amostra $\left(\mathrm{N}^{\circ} 20\right)$; grupo 5 encontra-se 1 amostra ( $\mathrm{N}^{\circ}$ 8); grupo 6 encontram-se 2 amostras $\left(\mathrm{N}^{\circ} 3\right.$ e 2); grupo 7 encontram-se 6 amostras ( $N^{0}$ 14, 17, 10, 9, 13 e 4); grupo 8 encontra-se 1 amostra ( $\left.\mathrm{N}^{\circ} 11\right)$; grupo 9 encontram-se 2 amostras $\left(\mathrm{N}^{\circ} 19\right.$ e 6$)$ e no grupo 10 encontram-se 4 amostras ( $N^{\circ} 7,12,18$ e 1).

Para as amostras do Estado do Piauí pode ser observado no fenograma (Figura 15) que foram formados 9 grupos. No grupo 1 encontra-se 1 amostra ( $\left.N^{\circ} 4\right)$; grupo 2 encontram-se 2 amostras ( $N^{\circ} 32$ e 27); grupo 3 encontram-se 2 amostras ( $N^{\circ} 31$ e 10); grupo 4 encontram-se 4 amostras $\left(N^{\circ} 7\right.$, 
16, 11 e 3); grupo 5 encontram-se 4 amostras $\left(N^{\circ} 33,17,30\right.$ e 14); grupo 6 encontram-se 12 amostras $\left(N^{\circ} 35,13,37,6,5,36,34,18,15,19,9\right.$ e 2); grupo 7 encontram-se 4 amostras $\left(\mathrm{N}^{\circ} 25,28,26\right.$ e 24), grupo 8 encontram-se 4 amostras $\left(\mathrm{N}^{\circ} 38,22,23\right.$ e 20$)$ e no grupo 9 encontram-se 5 amostras $\left(\mathrm{N}^{\circ} 21,12\right.$, 29 e 1).

Dos elementos químicos analisados para cada eixo (Tabela 12), o que mais contribuiu para a formação dos grupos no Estado do Ceará no eixo X, foi o elemento químico estrôncio (Sr), e no eixo $\mathrm{Y}$, o potássio (K). Para o Estado do Piauí dentre os elementos químicos analisados o que mais contribuiu no eixo $X$, foi o rubídio $(\mathrm{Rb})$ e no $\mathrm{Y}$, o mercúrio $(\mathrm{Hg})$.

Analisando as Tabelas 7 e 8 e as Figuras 14 e 15 verifica-se que existe uma relação entre os grupos e as concentrações do elemento K. Para as amostras dos Estados do Ceará e do Piauí os grupos e as concentrações do $\mathrm{K}$ estão distribuídas da seguinte forma: Ceará: grupo $1\left(794,4 \mu \mathrm{g} \cdot \mathrm{g}^{-1}\right)$; grupo 2

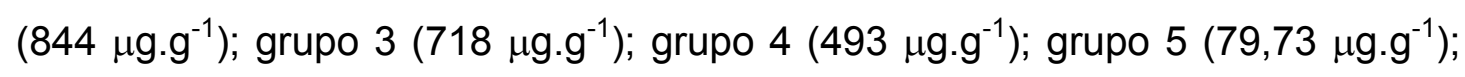
grupo 6 (16,87 a 46,68 $\mu \mathrm{g} \cdot \mathrm{g}^{-1}$ ); grupo 7 (147 a 222,25 $\left.\mu \mathrm{g} \cdot \mathrm{g}^{-1}\right)$; grupo 8 (328 $\left.\mu \mathrm{g} \cdot \mathrm{g}^{-1}\right)$; grupo $9\left(368,42\right.$ a $\left.383,76 \mu \mathrm{g} \cdot \mathrm{g}^{-1}\right)$ e no grupo $10\left(255,02\right.$ a $\left.288,29 \mu \mathrm{g} \cdot \mathrm{g}^{-1}\right)$. Piauí: grupo 1 (163,97 $\left.\mu \mathrm{g} \cdot \mathrm{g}^{-1}\right)$; grupo 2 (203,13 a 204,77 $\left.\mu \mathrm{g} \cdot \mathrm{g}^{-1}\right)$; grupo $3(174,74$ a $\left.183,06 \mu \mathrm{g} \cdot \mathrm{g}^{-1}\right)$; grupo 4 (152,3 a $\left.163,95 \mu \mathrm{g} \cdot \mathrm{g}^{-1}\right)$; grupo $5(101,22$ a 113,78 $\left.\mu \mathrm{g} . \mathrm{g}^{-1}\right)$; grupo $6\left(123,09\right.$ a $\left.144,34 \mu \mathrm{g} . \mathrm{g}^{-1}\right)$; grupo $7\left(2,18\right.$ a $\left.21,23 \mu \mathrm{g} \cdot \mathrm{g}^{-1}\right)$; grupo 8 $\left(69,16\right.$ a $\left.87,80 \mu \mathrm{g} \cdot \mathrm{g}^{-1}\right)$ e no grupo $9\left(31,73\right.$ a $\left.58,20 \mu \mathrm{g} \cdot \mathrm{g}^{-1}\right)$.

$\mathrm{O} \mathrm{K}$ é o elemento químico que no mel é encontrado em maior concentração. Crane (1983) relata que o mel contém mais $\mathrm{K}$ que qualquer outro elemento químico, menciona ainda que a quantidade de $\mathrm{K}$ é 100 vezes maior que a quantidade de Fe. 
Tabela 12. Autovalores calculados para as 58 amostras de méis analisadas dos Estados do Ceará (20 amostras) e Piauí (38 amostras) para os elementos químicos

\begin{tabular}{crrrr}
\hline Elementos químicos & \multicolumn{2}{c}{ Ceará } & \multicolumn{2}{c}{ Piauí } \\
& Eixo X & \multicolumn{1}{c}{ Eixo Y } & \multicolumn{1}{c}{ Eixo X } & \multicolumn{1}{c}{ Eixo $\mathbf{~}$} \\
\hline $\mathbf{K}$ & 0,083692 & $\mathbf{0 , 4 9 0 1 3 8}$ & 0,378539 & $-0,016030$ \\
$\mathbf{C a}$ & 0,393263 & 0,004433 & 0,279348 & $-0,052895$ \\
$\mathbf{T i}$ & $-0,045243$ & 0,202124 & 0,096824 & $-0,036901$ \\
$\mathbf{C r}$ & 0,254784 & $-0,187707$ & $-0,172490$ & 0,253550 \\
$\mathbf{M n}$ & 0,083675 & 0,369890 & 0,362567 & $-0,095835$ \\
$\mathbf{F e}$ & 0,378213 & 0,077623 & 0,373555 & 0,026136 \\
$\mathbf{C o}$ & $-0,010825$ & $-0,016457$ & $-0,157498$ & 0,217562 \\
$\mathbf{~ N i}$ & $-0,061891$ & $-0,194487$ & $-0,208573$ & 0,462004 \\
$\mathbf{C u}$ & 0,019508 & 0,379318 & 0,145908 & 0,417868 \\
$\mathbf{Z n}$ & 0,390255 & $-0,082646$ & 0,200347 & 0,430989 \\
$\mathbf{S e}$ & $-0,026360$ & $-0,008324$ & - & \\
$\mathbf{B r}$ & $-0,044443$ & $-0,314997$ & - & \\
$\mathbf{R b}$ & 0,049611 & 0,487979 & $\mathbf{0 , 4 1 3 2 2 5}$ & $-0,020303$ \\
$\mathbf{S r}$ & $\mathbf{0 , 3 9 4 1 5 9}$ & $-0,014624$ & 0,359073 & 0,110008 \\
$\mathbf{B a}$ & 0,390007 & $-0,084780$ & 0,197784 & 0,223941 \\
$\mathbf{H g}$ & 0,390017 & $-0,084780$ & 0,002136 & $\mathbf{0 , 4 8 7 4 6 1}$ \\
$\mathbf{P b}$ & & & 0,034531 & 0,013658 \\
\hline
\end{tabular}

\section{2 Microorganismos}

Os resultados das análises microbiológicas das 58 amostras de méis, dos diferentes municípios dos Estados do Ceará (20 amostras) e Piauí (38 amostras) estão apresentados nas Tabelas 13 e 14. 
Tabela 13. Presença de microorganismos em 58 amostras de méis de Apis mellifera produzidos nos Estados do Ceará (20 amostras) e Piauí (38 amostras)

\begin{tabular}{|c|c|c|c|c|}
\hline \multirow[b]{2}{*}{ Amostras } & \multicolumn{2}{|c|}{ Ceará } & \multicolumn{2}{|c|}{ Piauí } \\
\hline & $\begin{array}{c}\text { Coliformes } \\
\text { totais } \\
\text { nmp.g }\end{array}$ & $\begin{array}{c}\text { Fungos e } \\
\text { leveduras } \\
\text { ufc.g }^{-1}\end{array}$ & $\begin{array}{c}\text { Coliformes } \\
\text { totais } \\
\text { nmp.g }\end{array}$ & $\begin{array}{c}\text { Fungos e } \\
\text { leveduras } \\
\text { ufc.g }\end{array}$ \\
\hline 1 & negativo & $1,0 \times 10$ & negativo & $1,0 \times 10$ \\
\hline 2 & negativo & $1,65 \times 10^{-4}$ & negativo & $1,0 \times 10$ \\
\hline 3 & negativo & $1,0 \times 10$ & negativo & $1,0 \times 10$ \\
\hline 4 & negativo & $3,9 \times 10^{-3}$ & negativo & $3,0 \times 10^{-2}$ \\
\hline 5 & negativo & $2,0 \times 10$ & negativo & $1,5 \times 10$ \\
\hline 6 & negativo & $1,0 \times 10$ & negativo & $1,1 \times 10^{-2}$ \\
\hline 7 & negativo & $2,34 \times 10^{-3}$ & negativo & $2,0 \times 10$ \\
\hline 8 & negativo & $2,0 \times 10$ & negativo & $2,5 \times 10^{-2}$ \\
\hline 9 & negativo & $1,5 \times 10$ & negativo & $1,2 \times 10^{-2}$ \\
\hline 10 & negativo & $1,0 \times 10$ & negativo & negativo \\
\hline 11 & negativo & $1,0 \times 10$ & negativo & $2,0 \times 10$ \\
\hline 12 & negativo & $1,0 \times 10$ & negativo & $1,0 \times 10$ \\
\hline 13 & negativo & $1,5 \times 10$ & negativo & $1,0 \times 10$ \\
\hline 14 & negativo & $1,0 \times 10$ & negativo & $1,0 \times 10$ \\
\hline 15 & negativo & $1,0 \times 10$ & negativo & $2,0 \times 10$ \\
\hline 16 & negativo & $2,5 \times 10^{-2}$ & negativo & $1,5 \times 10$ \\
\hline 17 & negativo & $1,6 \times 10^{-3}$ & negativo & negativo \\
\hline 18 & negativo & negativo & negativo & $1,5 \times 10$ \\
\hline 19 & negativo & negativo & negativo & $1,0 \times 10$ \\
\hline 20 & negativo & $1,0 \times 10$ & negativo & negativo \\
\hline 21 & - & - & negativo & $1,0 \times 10$ \\
\hline 22 & - & - & negativo & $1,0 \times 10$ \\
\hline 23 & - & - & negativo & negativo \\
\hline 24 & - & - & negativo & $1,0 \times 10$ \\
\hline 25 & - & - & negativo & $1,0 \times 10$ \\
\hline 26 & - & - & negativo & $1,0 \times 10$ \\
\hline 27 & - & - & negativo & $1,0 \times 10$ \\
\hline 28 & - & - & negativo & negativo \\
\hline 29 & - & - & negativo & $2,5 \times 10$ \\
\hline 30 & - & - & negativo & $1,5 \times 10$ \\
\hline 31 & - & - & negativo & $1,5 \times 10$ \\
\hline 32 & - & - & negativo & $1,0 \times 10$ \\
\hline 33 & - & - & negativo & $4,0 \times 10$ \\
\hline 34 & - & - & negativo & $1,0 \times 10$ \\
\hline 35 & - & - & negativo & negativo \\
\hline 36 & - & - & negativo & negativo \\
\hline 37 & - & - & negativo & negativo \\
\hline 38 & - & - & negativo & negativo \\
\hline
\end{tabular}


Tabela 14. Valores mínimos, máximos e número de amostras positivas para microorganismos em 58 amostras de méis de Apis mellifera produzidos nos Estados do Ceará (20) e Piauí (38)

\begin{tabular}{|c|c|c|c|c|c|c|}
\hline \multirow{4}{*}{ Microorganismos } & \multicolumn{2}{|c|}{ Ceará } & \multicolumn{4}{|c|}{ Piauí } \\
\hline & & & № de amostras & & & № de amostras \\
\hline & Mínimo & Máximo & positivas & Mínimo & Máximo & positivas \\
\hline & & & Ceará & & & Piauí \\
\hline $\begin{array}{l}\text { Fungos e leveduras } \\
\text { ufc. } g^{-1}\end{array}$ & $1,0 \times 10$ & $1,65 \times 10^{-4}$ & 18 & $1,0 \times 10$ & $3,0 \times 10^{-2}$ & 29 \\
\hline $\begin{array}{l}\text { Coliformes totais } \\
\text { nmp. } \mathrm{g}^{-1}\end{array}$ & negativo & negativo & 0 & negativo & negativo & 0 \\
\hline
\end{tabular}


Nas Tabelas 13 e 14 observa-se que todas as amostras estudadas foram negativas para coliformes totais, entretanto houve constatações de fungos e leveduras. Para o Estado do Ceará, 18 amostras (90\% do total) foram positivas para fungos e leveduras, e 29 amostras (76,3\% do total) foram positivas para o Estado do Piauí. A contagem máxima constatada para fungos e leveduras foi de $1,65 \times 10^{-4}$ ufc.g ${ }^{-1}$ para o Ceará e de $3,0 \times 10^{-2}$ ufc.g $^{-1}$ para o Piauí.

Valores próximos aos constatados no presente estudo foram verificados por: Piana et al. (1991), que estudaram 50 amostras de méis Italianos e verificaram leveduras variando de 1 a $3,510^{-3}$ ufc.g $^{-1}$; Matuella, \& Torres (2000) trabalhando com amostras de méis produzidos nos arredores do lixão, do município de Chapecó-SC, constataram para os coliformes totais $<3,0$ nmp. $\mathrm{g}^{-1}$ e para fungos e leveduras valores de $1,0 \times 10$ a $3,2 \times 10^{-2}$ ufc.g $^{-1}$; Muratori \& Souza (2002) avaliando a característica microbiológica de amostras de méis de Apis mellifera no Piauí constataram para fungos e leveduras valores

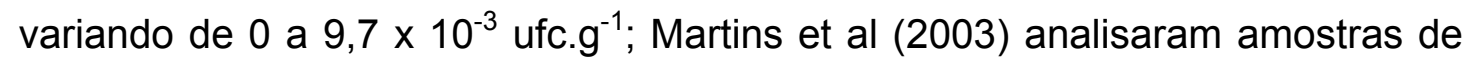
méis de Portugal e constataram a presença de fungos e leveduras em $88,8 \%$ das amostras com valores variando de $1,0 \times 10^{-2}$ a $1,0 \times 10^{-4}$ ufc. $^{-1}$; No Estado de São Paulo, Roll et al. (2003) analisaram amostras de méis industrializados e de produção doméstica não constatando coliformes totais. Entretanto, constataram a presença de fungos e leveduras em 14,3\% das amostras industrializadas e $60,87 \%$ das amostras de méis de produção domésticas.

Os esporos de bactérias, fungos e leveduras provavelmente venham de fontes primárias quando o néctar está sendo colhido, armazenado e amadurecido ou também podem ser incorporados durante o processamento uma vez que os esporos podem ser encontrados no ar (Snowdon, 1999).

Snowdon \& Cliver (1996) consideram que entre os microorganismos do mel as leveduras osmofílicas são os que mais influenciam 
na sua qualidade. A sua presença constatada no mel está em função da sua sobrevivência em condições ácidas e não serem inibidas com o açúcar.

\subsection{Análises Polínicas}

Os resultados das análises polínicas podem ser encontrados nas Tabelas 15 e 16 e nas Figuras 18, 19, 20 e 21.

A análise polínica qualitativa das 58 amostras de méis analisadas demonstrou uma grande quantidade de grãos de pólen. Foram encontrados 41 tipos polínicos, distribuídos em 17 famílias botânicas para o Estado do Ceará, e 39 tipos polínicos, distribuídos em 19 famílias botânicas para o Estado do Piauí. Estas informações podem contribuir com a caracterização dos méis dos estados em estudo quanto a sua origem botânica. 
Tabela 15. Espectro polínico de 20 amostras de méis de Apis mellifera de diferentes municípios do Estado do Ceará

\begin{tabular}{|c|c|c|c|c|c|c|c|c|c|c|c|c|c|c|c|c|c|c|c|c|c|}
\hline \multirow{2}{*}{ Família } & \multirow{2}{*}{ Tipos Polínicos } & \multicolumn{20}{|c|}{ Amostras } \\
\hline & & 1 & 2 & 3 & 4 & 5 & 6 & 7 & 8 & 9 & & & 12 & 13 & 14 & 15 & 16 & 17 & 18 & 19 & 20 \\
\hline Amaranthaceae & $\begin{array}{l}\text { Alternanthera ficoidea } \\
\text { Gomphrena sp. }\end{array}$ & & $\mathrm{PIO}$ & & $\mathrm{PIO}$ & $\mathrm{PIO}$ & $\mathrm{PI}$ & & & & & & & $\begin{array}{l}\mathrm{PII} \\
\mathrm{PIO}\end{array}$ & $\begin{array}{l}\text { PII } \\
\text { PII }\end{array}$ & $\mathrm{PIO}$ & PII & $\mathrm{PIO}$ & & & \\
\hline $\begin{array}{l}\text { Apocynaceae } \\
\text { Arecaceae }\end{array}$ & Tipo Apocynaceae & & & & & & & & & $\mathrm{PIO}$ & $\mathrm{PIO}$ & & & & & & & & & & \\
\hline $\begin{array}{l}\text { Arecaceae } \\
\text { Asteraceae }\end{array}$ & $\begin{array}{l}\text { Astrocarlutum Sp. } \\
\text { Bidens sp. }\end{array}$ & & & FIO & & & & & PA & & & & & & & & & & PIO & & $\mathrm{PIO}$ \\
\hline & $\begin{array}{l}\text { Emília sp. } \\
\text { Mikania sp. }\end{array}$ & & & $\mathrm{PIO}$ & PIO & & $\begin{array}{l}\mathrm{PIO} \\
\mathrm{PIO}\end{array}$ & $\mathrm{PIO}$ & PII & & & & & & & & & & & & \\
\hline & Tipo Asteraceae & & & PIO & PIO & & & & & & & & & & & & & & & & \\
\hline Brassicaceae & Tipo Brassicaceae & & & & & $\mathrm{PIO}$ & & PIO & PIO & & & & & & & & & & & & \\
\hline Chenopodiaceae & $\begin{array}{l}\text { Chenopodium sp. } \\
\text { Tipo Chenopodiaceea }\end{array}$ & & & PIO & & & & & & PII & PA & PII & PII & & & & & PIO & & & \\
\hline Compositae & $\begin{array}{l}\text { Vernonia cognata } \\
\text { Vernonia sp }\end{array}$ & PIO & $\mathrm{PIO}$ & & & & & & & & $\mathrm{PIO}$ & & & & & & & PIO & & $\mathrm{PIO}$ & \\
\hline Euphorbiaceae & Croton urucurana & & & PII & $\mathrm{PA}$ & & PIO & & PA & $\mathrm{PIO}$ & & & & & $\mathrm{PIO}$ & $\mathrm{PIO}$ & $\mathrm{PIO}$ & $\mathrm{PIO}$ & & & \\
\hline Fabaceae & $\begin{array}{l}\text { Croton sp. } \\
\text { Bauhiniz sp }\end{array}$ & & & & & & & & PH & & $\mathrm{PIO}$ & & & & & & & & & & \\
\hline ravacte & $\begin{array}{l}\text { Banmina sp. } \\
\text { Schrankia sp }\end{array}$ & PIO & & & & & & & & & & & & & & & & & $\mathrm{PIO}$ & & \\
\hline Lamiaceae & $\begin{array}{l}\text { Tipo Fabaceae } \\
\text { Hyptis eriophylla }\end{array}$ & PII & & PD & $\begin{array}{l}\text { PII } \\
\text { PIO }\end{array}$ & & $\mathrm{PIO}$ & PIO & & $\begin{array}{l}\text { PII } \\
\text { PII }\end{array}$ & & PIO & $\begin{array}{l}\mathrm{PII} \\
\mathrm{PII}\end{array}$ & & & & & PII & & $\mathrm{PIO}$ & $\mathrm{PIO}$ \\
\hline & Salvia sp & & & & & & & & & & & & & $\mathrm{PIO}$ & PIO & $\mathrm{PIO}$ & & $\mathrm{PIO}$ & & & \\
\hline Malvaceae & $\begin{array}{l}\text { Malvastrum sp } \\
\text { Sida sp. }\end{array}$ & & & $\mathrm{PIO}$ & & & & & & & & PII & & & & & & & & PIO & $\mathrm{PIO}$ \\
\hline Mimosaceae & Acacia sp & & & $\mathrm{PIO}$ & & & & PIO & & & & & & & & & 510 & & & & \\
\hline & $\begin{array}{l}\text { Mimosa caesalpinifolia } \\
\text { Mimosa scabrella }\end{array}$ & $\begin{array}{l}P D \\
P I O\end{array}$ & & & $P D$ & $P D$ & $P D$ & $\begin{array}{l}P D \\
P I O\end{array}$ & PII & $P D$ & $\begin{array}{l}\text { PA } \\
\text { PIII }\end{array}$ & $\begin{array}{l}\mathrm{PD} \\
\mathrm{PIO}\end{array}$ & PA & $\begin{array}{l}\text { PA } \\
\text { PIO }\end{array}$ & $P D$ & PA & $\mathrm{PD}$ & $P D$ & $\mathrm{PA}$ & PA & PA \\
\hline & $\begin{array}{l}\text { Mimosa verrucosa } \\
\text { Piptadenia sp }\end{array}$ & PIO & $\begin{array}{l}\text { PII } \\
P I O\end{array}$ & $\begin{array}{l}\mathrm{PII} \\
\mathrm{PIO}\end{array}$ & & PII & PA & & & $\begin{array}{l}\mathrm{PIO} \\
\mathrm{PII}\end{array}$ & $\begin{array}{l}\text { PII } \\
\text { PII }\end{array}$ & $P I O$ & PD & PII & PII & $\begin{array}{l}\text { PA } \\
\text { PII }\end{array}$ & $\mathrm{PIO}$ & $\begin{array}{l}\mathrm{PII} \\
P I O\end{array}$ & PII & PII & PII \\
\hline Myrtaceae & Eucalyptus sp. & & PIO & PIO & & & POP & & & & & & & & PIO & $P \mid P_{1}$ & & PIO & & PII & \\
\hline Poaceae & $\begin{array}{l}\text { Brachiaria decumbens } \\
\text { Paspalum notatum }\end{array}$ & & & PIO & & & PIO & & & $\mathrm{PIO}$ & PIO & & & & Pif & riv & & राT & & & \\
\hline Rubiaceae & $\begin{array}{l}\text { Borreria sp. } 1 \\
\text { Borreria sp. } 2\end{array}$ & PA & PII & & $\mathrm{PIO}$ & & PII & & $\mathrm{PIO}$ & & & & PII & PII & $\begin{array}{l}\mathrm{PII} \\
\mathrm{PIO}\end{array}$ & PII & $\mathrm{PIO}$ & & PD & $\mathrm{PA}$ & PD \\
\hline Sapindaceae & $\begin{array}{l}\text { Richardia sp } \\
\text { Serjania sp. }\end{array}$ & & PD & & & & & & PII & & & & PIO & & & PIO & & & & & \\
\hline & $\begin{array}{l}\text { IIpo Sapindaceae } 1 \\
\text { Tipo Sapindaceae } 2\end{array}$ & & PII & & & Fiv & & & PIO & & & & & & & & & $\mathrm{PIO}$ & & $\mathrm{PIO}$ & \\
\hline Solanaceae & $\begin{array}{l}\text { Tipo Solanaceae } 1 \\
\text { Tipo Solanaceae } 2 \\
\text { Nâo Odentificado }\end{array}$ & & & & & & PII & & PIO & $\mathrm{PIO}$ & PII & $\mathrm{PIO}$ & PII & & PIO & PIO & & & & & \\
\hline
\end{tabular}


Tabela 16. Espectro polínico de 38 amostras de méis de Apis mellifera de diferentes municípios do Estado do Piauí

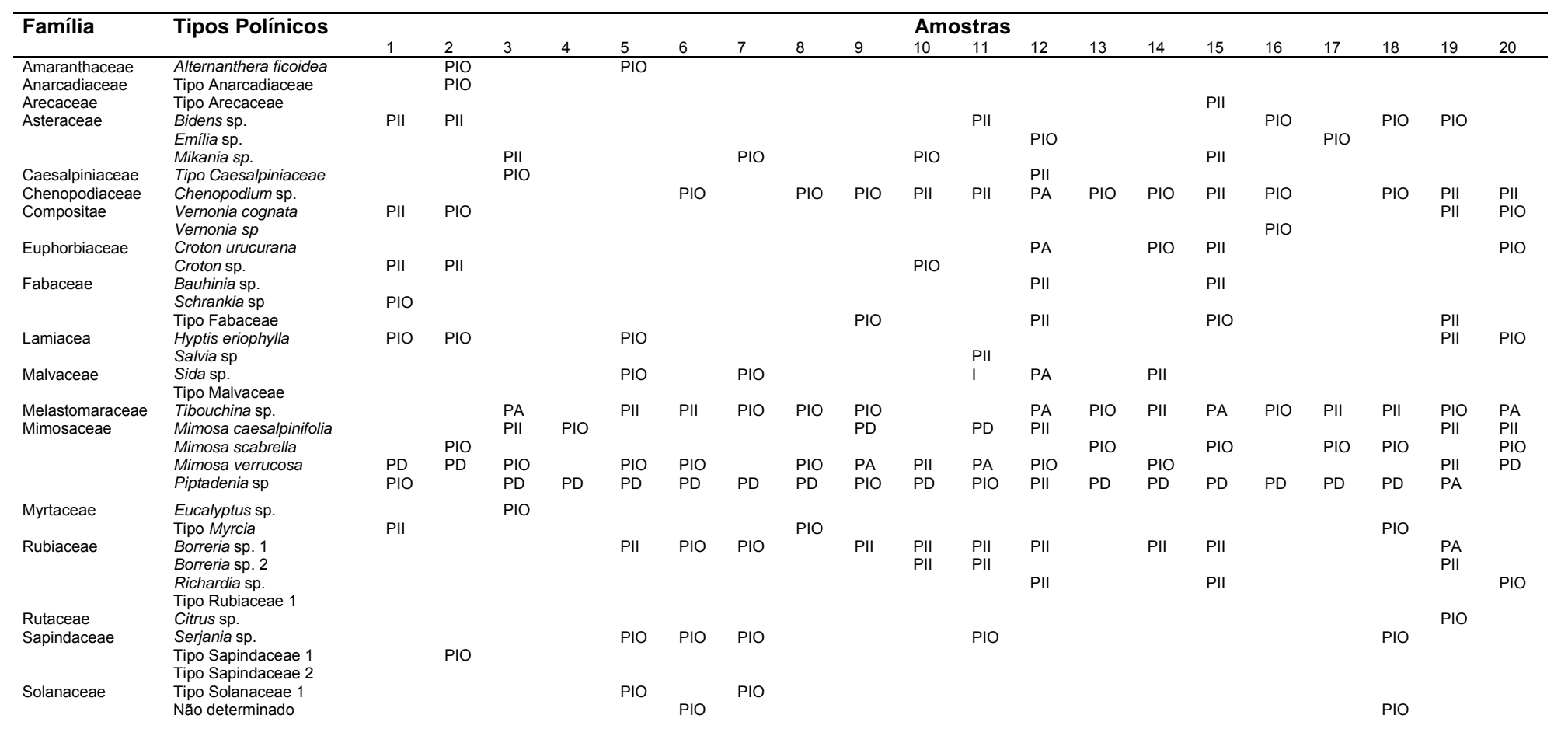




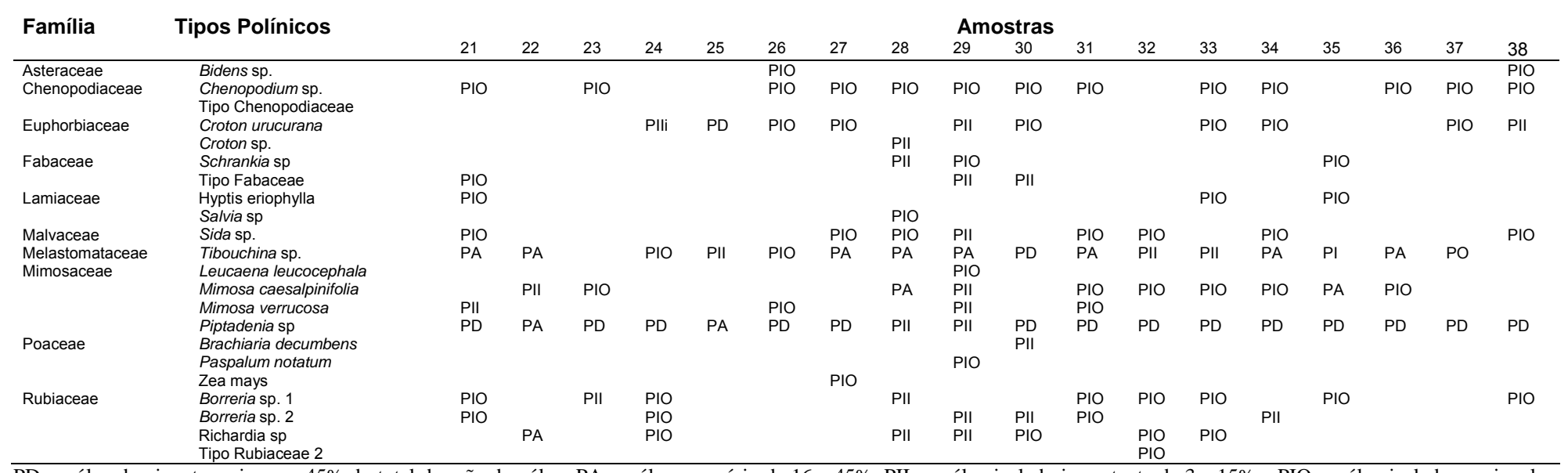

$\mathrm{PD}$ = pólen dominante maior que $45 \%$ do total de grão de pólen, PA = pólen acessório de 16 a 45\%, PII = pólen isolado importante de 3 a $15 \%$ e PIO = pólen isolado ocasional menor que $3 \%$. 


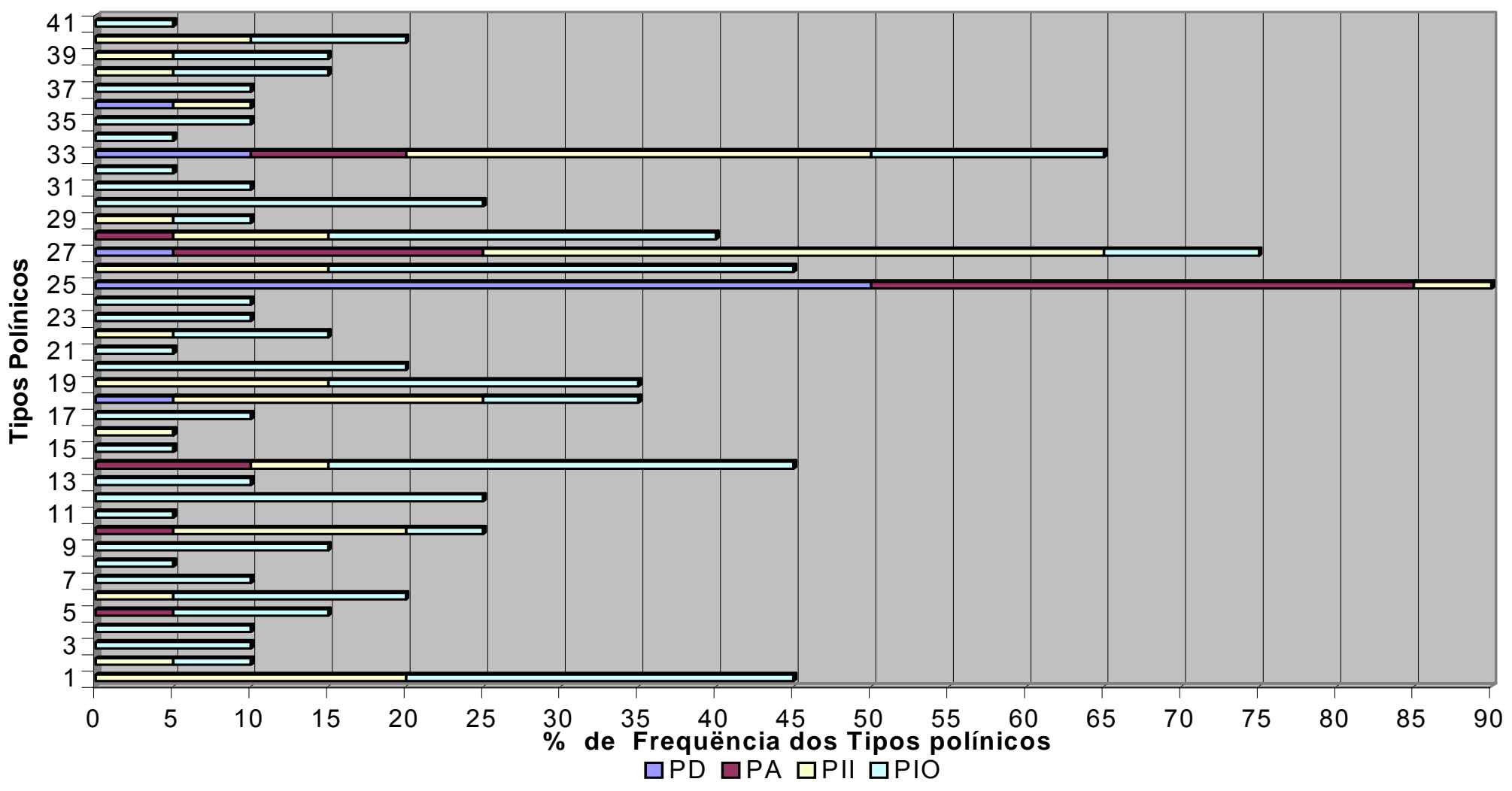

Figura 18- Porcentagem do total de 20 amostras de méis de Apis mellifera do Estado do Ceará em que aparece cada um dos 41 tipos polínicos obsevados (1-Alternanthera ficoidea, 2-Gomphrena sp., 3-Tipo Apocynaceae, 4- Astrocaryum sp., 5-Bidens sp., 6-Emília sp., 7Mikania sp., 8-Tipo Asteraceae, 9-Tipo Brassicaceae, 10-Chenopodium sp., 11-Tipo Chenopodiaceae, 12-Vernonia cognata, 13Vernonia sp., 14-Croton urucurana, 15-Croton sp., 16-Bauhinia sp., 17-Schrankia sp., 18-Tipo Fabaceae, 19-Hyptis eriophylla, 20Salvia sp, 21-Malvastrum sp., 22-Sida sp., 23-Acacia sp., 24-Leucaena leucocephala, 25-Mimosa caesalpiniaefolia, 26-M. scabrella, 27-M. verrucosa, 28-Piptadenia sp., 29-Eucalyptus sp., 30-Tipo Myrcia, 31-Brachiaria decumbens, 32-Paspalum notatum, 33-Borreria sp. 1, 34-Borreria sp. 2, 35-Richardia sp, 36-Serjania sp., 37-Tipo Sapindaceae 1, 38-Tipo Sapindaceae 2, 39-Tipo Solanaceae 1, 40Tipo Solanaceae 2 e 41-Não determinado) 


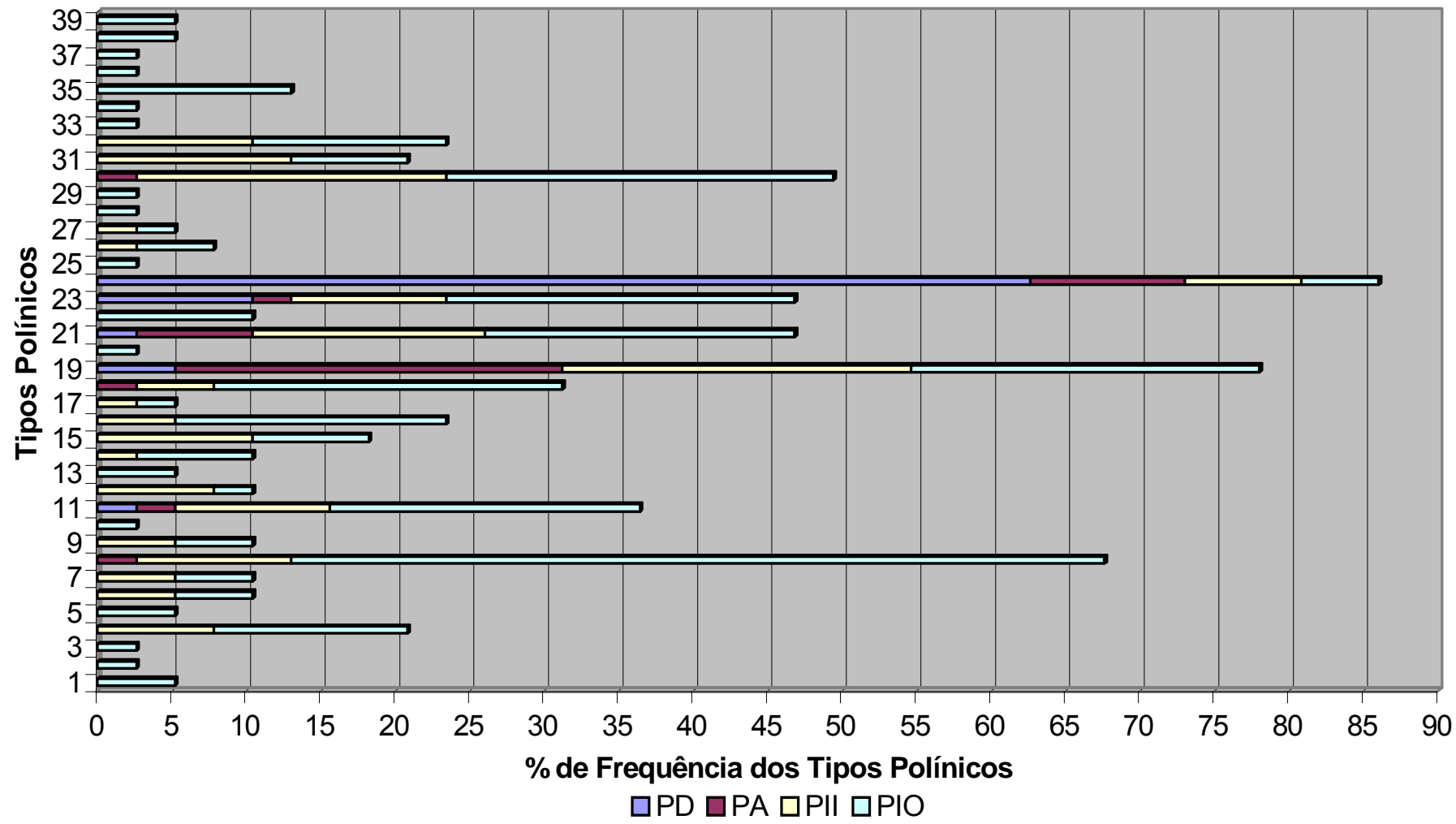

Figura 19 - Porcentagem do total de 38 amostras de méis de Apis mellifera do Estado do Piauí em que aparece cada um dos 39 tipos polínicos obsevados (1-Alternanthera ficoidea, 2-Tipo Anarcadiaceae, 3-Tipo Arecaceae, 4-Bidens sp., 5-Emília sp., 6-Mikania sp., 7-Tipo Caesalpiniaceae, 8-Chenopodium sp., 9-Vernonia cognata, 10-Vernonia sp., 11-Croton urucurana, 12-Croton sp., 13-Bauhinia sp., 14-Schrankia sp., 15-Tipo Fabaceae, 16-Hyptis eriophylla, 17-Salvia sp, 18-Sida sp., 19-Tibouchina sp., 20-Leucaena leucocephala, 21-Mimosa caesalpiniaefolia, 22-M. scabrella, 23-M verrucosa, 24-Piptadenia sp, 25-Eucalyptus sp., 26-Tipo Myrcia, 27-Brachiaria decumbens, 28-Paspalum notatum, 29-Zea mays, 30-Borreria sp. 1, 31-Borreria sp. 2, 32-Richardia sp., 33-Tipo Rubiaceae 1, 34Citrus sp., 35-Serjania sp., 36-Tipo Sapindaceae 1, 37-Tipo Sapindaceae 2, 38-Tipo Solanaceae 1 e 39-Não determinado) 


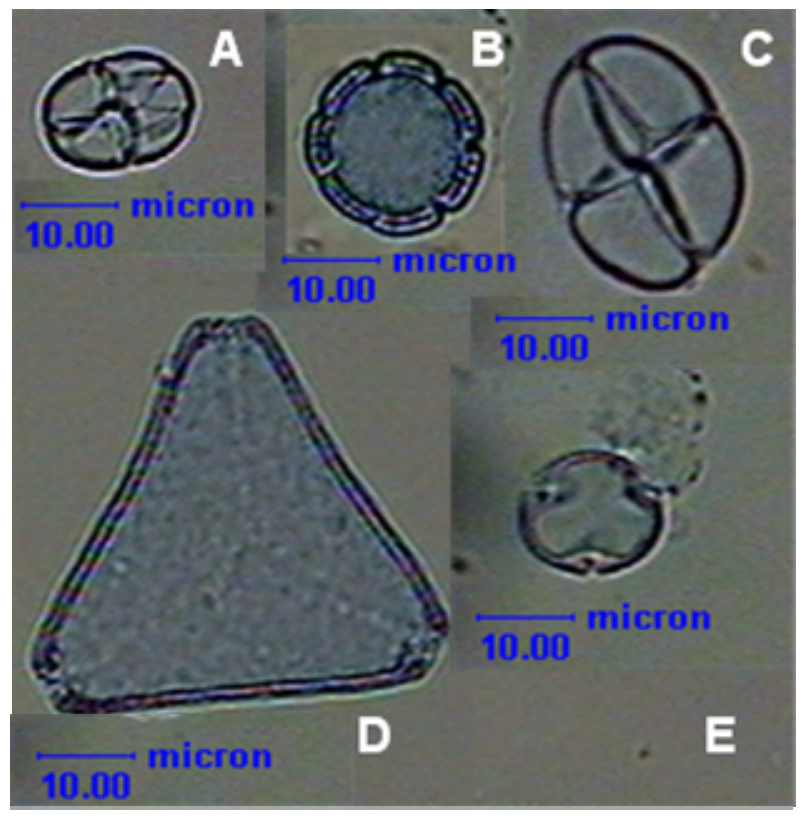

Figura 20 - Vista polar dos tipos polínicos dominantes encontrados em 20 amostras de méis de Apis mellifera do Estado do Ceará. A-Mimosa caesalpiniaefolia (Mimosaceae); B-Borreria sp. I (Rubiaceae); C-M verrucosa (Mimosaceae); D-Serjania sp. (Sapindaceae) e E-Tipo Fabaceae (Fabaceae) 


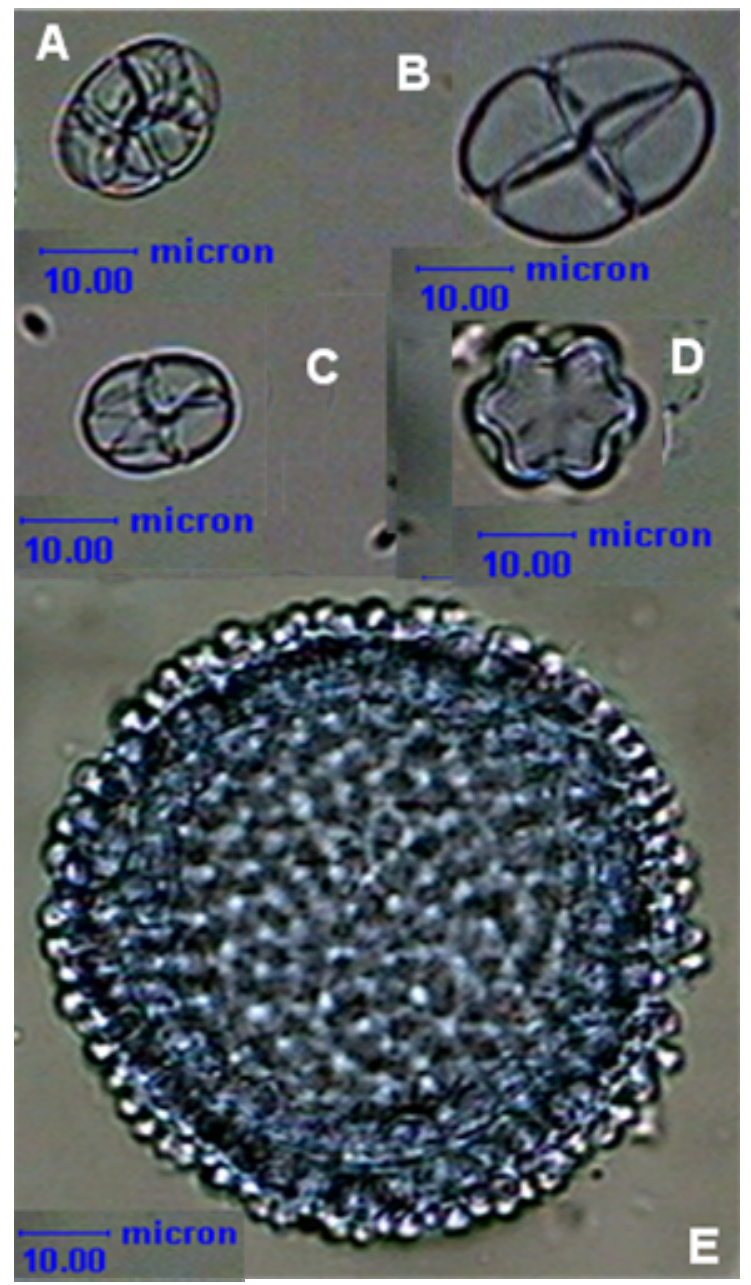

Figura 21 - Vista polar dos tipos polínicos dominantes encontrados em 38 amostras de méis de Apis mellifera do Estado do Piauí. APiptadenia sp. (Mimosaceae); B-Mimosa verrucosa (Mimosaceae); C- M. caesalpiniaefolia (Mimosaceae); D-Tibouchina sp. (Melastomatacea) e E-Croton urucurana (Euphorbiaceae) 
Nas figuras 18 e 19 observam-se as porcentagens dos diferentes tipos polínicos, classificando-os como pólen dominante ( $>45 \%$ dos grãos de pólen presentes nas amostras), pólen acessório (de 16 a 45\%), pólen isolado importante (de 3 a 15\%) e pólen isolado ocasional (<3\%). Nas Figuras 20 e 21 podem ser vizualizadas as fotomicrografias mostrando a vista polar dos tipos polínicos dominantes das amostras de méis dos Estados do Ceará (20 amostras) e do Piauí (38 amostras).

Para o Estado do Ceará foram evidenciados como pólen dominante 5 tipos diferentes: Mimosa caesalpiniaefolia (Mimosaceae) (62,5\% do total de amostras), M. verrucosa (Mimosaceae) (12,5\% do total de amostras), Borreria sp. I (Rubiaceae) (12,5\% do total de amostras), Serjania sp. (Sapindaceae) (6,25\% do total de amostras) e tipo Fabaceae (Fabaceae) (6,25\% do total de amostras) (Tabela 15). No Estado do Piauí também foram encontrados como pólen dominante 5 tipos diferentes: Piptadenia sp. (Mimosaceae) (80\% do total de amostras), $M$. caesalpiniaefolia (Mimosaceae) (5,7\% do total de amostras), $M$. verrucosa (Mimosaceae) (5,7\% do total de amostras), Croton urucurana (Euphorbiaceae) (5,7\% do total de amostras) e Tibouchina sp. (Melastomotaceae) (2,9\% do total de amostras) (Tabela 16).

Verifica-se que as amostras dos 2 estados são bastantes parecidas quanto à origem floral, principalmente por terem sido colhidas numa mesma época e em região geográfica próximas.

A análise polínica quantitativa dos méis demonstrou a importante participação da espécie $M$. caesalpiniaefolia (Mimosaceae) na constituição dos méis do Estado do Ceará. Enquanto que para o Estado do Piauí foi evidenciada a grande participação do gênero Piptadenia sp. (Mimosaceae). Estes dois tipos polínicos constatados reiteram o potencial apícola destas plantas nos estados em estudo.

Barth (1989) menciona que nos méis dos Estados do Ceará e Bahia encontram-se freqüentemente os polens de mimosáceas dos tipos $M$. 
caesalpiniaefolia, M. verrucosa e M. scabrella. A autora menciona que estes tipos polínicos não diferenciam a origem dos méis se do Estado do Ceará ou do Estado da Bahia em função da sua grande participação nos méis destes estado. Ainda grãos de pólen dos tipos Borreria verticillata e B. latifólia, em porcentagens elevadas nas amostras, podem indicar como originário do Estado do Ceará. No trabalho em estudo foi observada para o Estado do Ceará uma grande freqüência da espécie $M$. caesalpiniaefolia; sendo encontrado em 10 amostras (50\% do total das amostras) como pólen dominante, já o gênero Borreria foi constatado como pólen dominante em duas amostras (10\% do total das amostras).

Quando nas amostras de méis predomina o grão de pólen de mimosaceae do tipo $P$. moniliformis pode indicar como originário do Estado do Piauí (Barth, 1989). No trabalho em estudo foram constatados 24 amostras (63\% do total das amostras) com este gênero como pólen dominante.

Por meio da análise quantitativa dos grãos de pólen foi possível observar uma grande participação de pólen acessório nas amostras; para o Estado do Ceará $90 \%$ das amostras e para o Piauí $58 \%$ das amostras. Barth (1970b) menciona que os méis com pólen acessório são muito freqüentes, devido ao fato de que a atividade apícola brasileira é realizada de maneira rudimentar quanto ao pasto apícola. A autora salienta a importância do pólen acessório e do dominante quanto à quantidade de néctar fornecida. No trabalho em estudo foram observadas amostras com pólen acessório sem a presença de pólen dominante, no Estado do Ceará nas amostras 8, 10, 13, 15 e 18 (25\% das amostras) Tabela 15, para o Estado do Piauí nas amostras 10, 11, 12, 19, 22, 28 e $29(18,4 \%)$ Tabela 16.

Para os tipos polínicos acessórios foram constatadas as seguintes espécies vegetais: Bidens sp., Chenopodium sp., C. urucurana, $M$. caesalpiniaefolia, M. verrucosa, Piptadenia sp. e Borreria sp. 1 para o Estado do Ceará e Chenopodium sp, C. urucurana, Sida sp., Tibouchina sp., $M$. 
caesalpiniaefolia, M. verrucosa, Piptadenia sp, Borreria sp. 1 e Richardia sp. para o Estado Piauí.

Quanto ao pólen isolado importante e isolado ocasional pode ser observada sua presença em quase todas as amostras estudadas (Tabelas $15 \mathrm{e}$ 16). Este pólen tem pouca importância quanto a quantidade de néctar fornecido, entretanto fornece informação quanto à origem e procedência geográfica da amostra (Barth, 1989).

Para algumas espécies foi atribuído o termo "tipo" em função do pouco conhecimento das espécies melíferas da região em estudo. Recorrendo ao tipo polínico o qual engloba todas as espécies que possuem grãos de pólen iguais ou semelhantes, pertencendo ou não, à espécie do mesmo gênero (Barth, 1970b).

No Ceará, Freitas (2001) constatou Coccus nucifera, Alternanthera tenella e Eucalyptus sp. em méis monoflorais e predominância de mimosáceas em méis heterofloral. Já Arruda (2003) com amostras de méis da Chapada do Araripe no Estado do Ceará constatou como pólen dominante principalmente as espécies Serjania sp., M. verrucosa, tipo Solanaceae e tipo Cordia. 


\section{CONCLUSÕES}

A maioria das amostras de méis analisadas encontra-se dentro das especificações brasileiras para as características físico-químicas com exceção dos parâmetros sacarose aparente (10\% das amostras do Estado do Ceará e 5,3\% das amostras do Estado do Piauí), umidade (10\% das amostras do Estado do Ceará), atividade diastásica (35\% das amostras do Estado do Ceará e 53\% das amostras do Estado do Piauí) e HMF (20\% das amostras do Estado do Ceará e 2,63\% das amostras do Estado do Piauí).

Constatou-se a presença de elementos químicos acima dos estabelecidos na legislação para $\mathrm{Cr}(40 \%$ das amostras do Estado do Ceará e $13,15 \%$ das amostras do Estado do Piauí), Ni (2,63\% das amostras do Estado do Piauí), Zn (5,0\% das amostras do Estado do Ceará) e Pb (2,63\% das amostras do Estado do Piauí) desclassificando-se estas amostras.

As amostras estudadas são livres de coliformes totais, entretanto, foram constatados fungos e leveduras (Estado do Ceará 90\% e Estado do Piauí $76,3 \%$ das amostras).

Os meles característicos do Estado do Ceará contêm como pólen dominante principalmente Mimosa caesalpiniaefolia, já os méis do Estado do Piauí Piptadenia sp. 


\section{REFERÊNCIAS BIBLIOGRÁFICAS}

ABU-JDAYIL, B.; GHZAWI, A.A.M.; AL-MALAH, K.I.M. et al. Heat effect on rheology of light and dark-colored honey. Journal of Food Engineering, v. 51, p. 33-38, 2002.

AGANIN, A.F. Electrical condutivity of several unifloral honeys. Trudy Saratovskogo Zootekhnicheskogo Inatituta, v.21, p.137-144, 1971.

AIRA, M.J.; HORN, H.; SEIJO, M.C. Palynological analysis of honeys from Portugal. Journal of Apicultural Research, v.37, n.4, p.247-254, 1998.

AL-HINDI, R.R. Microbiological qualities of imported and locally produced honey in Saudi Arabia. Arab Gulf Journal of Scientific Research, v. 21, n. 4, p. 204-209, 2003.

Al-KHALIFA, A.S.; AL-ARIFY, I.A. Physicochemical characteristics and pollen spectrum of some Saudi honeys. Food Chemistry, v. 67, n. 1, p. 21-25, 1999.

ALMEIDA, D. de. Espécies de abelhas (Hymenoptera, Apoidea) e tipificação dos méis por elas produzidos em área de cerrado do município de Pirassununga, Estado de São Paulo. Piracicaba, 2002. 103p. Dissertação (Mestrado) Escola Superior de Agricultura "Luiz de Queiroz", Universidade de São Paulo.

ALMEIDA, D.; MARCHINI, L.C. Análises físico-químicas de amostras de méis de Apis mellifera L., provenientes de duas áreas de cerrado do Estado de São Paulo. In: ENCONTRO SOBRE ABELHAS, 5., Ribeirão Preto, 2002. Anais. Ribeirão Preto:FFCL, 2002. p. 287. 
ALMEIDA-MURADIAN, L.B.; PAMPLONA, L.; BERA, A. et al. Composição nutricional de méis comercializados no Estado de São Paulo. In: CONGRESSO BRASILEIRO DE APICULTURA, 14., Campo Grande, 2002. Anais. Campo Grande: Confederação Brasileira de Apicultura, 2002. p.81.

AMARAL, A.D.; IMPERATRIZ-FONSECA, V.L.; KLEINERT-GIOVANNINI, A. et al. Estudo comparativo entre amostras de méis com origem floral determinada; análise do teor de proteína, lipídios e carboidratos totais. In: CONGRESSO BRASILEIRO DE APICULTURA, 7., Salvador, 1986. Anais. Salvador: Confederação Brasileira de Apicultura, 1986. p.60.

AMERICAN SOCIETY FOR TESTING AND MATERIALS (A.S.T.M.). Standard Test Methods for Rheological Properties of Non-Newtonian Materials by Rotation (Brookfield type) Viscometer. Barr Harbor: ASTM Standards, s.d.p., p.1-4.

AMIN, W.A.; SAFWAT, M.; EL-IRAKI, S.M. Quality criteria of treacle (black honey). Food Chemistry, v.67, n. 1, p. 17-20, 1999.

AMPUERO, S.; BOGDANOV, S.; BOSSET, J.O. Classification of unifloral honeys with an MS-based electronic nose using different sampling modes: SHS, SPME and INDEX. European Food Research and Technology, v. 218, n.2, p.198-207, 2004.

ANDRADE, P.B.; AMARAL, M.T.; ISABEL, P. et al. Physicochemical atributes and pollen spectrum of Portuguese heather honeys. Food Chemistry, v.66, n. 4, p. 503-510, 1999.

ANUPAMA, D; BHAT, K.K.; SAPNA, V.K., Sensory and physico-chemical properties of commercial samples of honey. Food Research International, v. 36, n. 2, p. 183-191, 2003.

ARCHENTI, A. Chemical composition of honeys from Chubut province. Revista de Ciências Agrárias, v.5, n.1/4, p.12-28, 1984.

ARCHENTI, A.; DASSO, I. Composición química de mieles de la provincia de Chubut. La Alimentación Latinoamericana, n.138, p.11-19, 1983. 
ARRUDA, C.M.F.de. Características físico-químicas e polínicas de amostras de méis de Apis mellifera L., 1758 (Hymenoptera, Apidae) da região da Chapada do Araripe, Município de Santana do Cariri, Estado do Ceará. Piracicaba, 2003. 86p. Dissertação (Mestrado) - Escola Superior de Agricultura "Luiz de Queiroz", Universidade de São Paulo.

ASSOCIATION OF OFFICIAL ANALYTICAL COUNCIL (A.O.A.C.) Official methods of Analysis. 2. Ed.Washington: AOAC, 1990. 1018p.

ATAGO Co. Refratômetro para mel. Abelhas, v. 31, n. 362/363, p.9, 11-12, 41,44, 1988.

ATROUSE, O.M.; ORAN, S.A.; AL-ABBADI, S.Y. Chemical analysis and identification of pollen grains from different Jordanian honey samples. International Journal of Food Science and Technology, v. 39, n.4, p. 413417, 2004.

AUBERT, S.; GONNET, M. Measure de la couleur dês miels. Apidologie, v. 14, p. 105-118, 1983.

AZEREDO, L.C.; AZEREDO, M.A.A.; SOUZA, S.R. et al. Protein contents and physicochemical properties in honey samples of Apis mellifera of different origins. Food Chemistry, v.80, p.249-254, 2003.

AZEREDO, M.A.A.; AZEREDO L. da C.; SOARES, J. de C.A. Determinação de potássio em méis após precipitação com tetrafenilborato de sódio e separação em coluna de troca-iônica. Química Nova, v.21, n.5, p.512-515, 1998.

AZEREDO, M.A.A.; AZEREDO, L.C.; DAMASCENO, J.G. Características físicoquímicas dos méis do município de São Fidélis-RJ. Ciência e Tecnologia de Alimentos, v.19, n.1, p.3-7, 1999.

BAGGIO, A.; PRANDIN, L.; DAMOLIN, O. et al. Monitoraggio microbiologico nelle sale di smielatura. Industrie Alimentari, v. 42, n. 427, p. 717-720, 2003. 
BALDI-CORONEL, B.; DALL'OGLLIO, A.M.; LEZCANO, S.; Caracterización físico químico de las mieles de la Provincia de Entre Rios. In: CONGRESSO IBERO LATINOAMERICANO DE APICULTURA, 5., Mercedes, 1996. Anais. Mercedes: Cooperativa CALMER, 1996. p.218-222.

BALDI-CORONEL, B.; DALL'OGLLIO, A.M.; LEZCANO, S. et al. Caracterización físico químico de las mieles de la Provincia de Entre Rios. Alimentación Latinoamericana, n.199, p.39-44, 1993.

BALENOVIC, J.; PERKCVAC, M.; PAPIC, J. Hydroxymethylfurfural content and amylase activity in honey. Prehrambeno Tehnoloska Revija, v.26, n.4, p.143-146, 1988.

BARROS, G.C. de; MENDES, E.S.; SILVA, L.B.G. da et al. Physico-chemical and microbiological quality of honey sold in Recife, PE. Higiene Alimentar, v.17 n. 112, p.53-58, 2003.

BARTH, O.M. Pollenspektrum einiger brasilianischer Honige. Zeitschrift für Bienenforschung, v.9, p.410-419, 1969.

BARTH, O.M. Análise microscópica de algumas amostras de mel. 1. Pólen Dominante. Anais da Academia Brasileira de Ciências, v.42, p.351-366, 1970a.

BARTH, O.M. Análise microscópica de algumas amostras de mel. 2. Pólen Acessório. Anais da Academia Brasileira de Ciências, v.42, p.571-590, 1970b.

BARTH, O.M. Análise microscópica de algumas amostras de mel. 3. Pólen Isolado. Anais da Academia Brasileira de Ciências, v.42, p.747-772, 1970c.

BARTH, O.M. Análise microscópica de algumas amostras de mel. 4. Espectro polínico de algumas amostras de mel do Estado do Rio de Janeiro. Revista Brasileira de Biologia, v.30, p.575-582, 1970d. 
BARTH O.M. Análise microscópica de algumas amostras de mel. 5. Melato ("honeydew") em mel de abelhas. Revista Brasileira de Biologia, v.30, p.601-608, 1970e.

BARTH, O.M. Análise microscópica de algumas amostras de mel. 6. Espectro polínico de algumas amostras de mel dos Estados da Bahia e do Ceará. Revista Brasileira de Biologia, v.31, p.431-434, 1971a.

BARTH, O.M. Mikroskopische Bestandteile brasilianischer Honigtauhonige. Apidologie, v.2, p.157-167, 1971b.

BARTH, M.O. O pólen no mel brasileiro. Rio de Janeiro: Gráfica Luxor, 1989. $152 p$.

BARTH, O.M. Pollen in monofloral honeys from Brazil. Journal of Apicultural Research, v.29, p.89-94, 1990.

BARTH, O.M. Monofloral and wild flower honey pollen spectra at Brazil. Ciência e Cultura, v.48, p.163-165, 1996.

BARTH, O.M. Pollen analysis of Brazilian Propolis. Grana, v.37, p.97-101, 1998.

BARTH, O.M. Melissopalynology in Brazil: a review of pollen analysis of honeys, propolis and pollen loads of bees. Scientia Agricola, v. 61, n. 3, 2004.

BASTOS, D.H.M.; SILVA, J.R. Análise de méis produzidos na região Bragantina. LECTA, v.12, n.2, p.121-134, 1994.

BASTOS, E.M.A.F. Grão de pólen e estruturas secretoras de plantas como indicadores da origem botânica do mel e da própolis. In: CONGRESSO BRASILEIRO DE APICULTURA, 12., Salvador, 1998. Anais. Salvador: Confederação Brasileira de Apicultura, 1998. p.71-72.

BASTOS, E.M.A.F. Origem botânica do mel e da própolis produzidos por abelhas, determinados por observações em campo, métodos microscópicos e RAPD. In: CONGRESSO BAIANO DE APICULTURA, 1., Salvador, 2002. Anais. Salvador: Editora UESC, 2002. p.32-33. 
BASTOS, E.M.A.F.; SILVEIRA, V.M.; SOARES, A.E. Pollen spectrum of honey produced in cerrado areas of Minas Gerais State (Brazil). Brazilian Journal of Biology, v.63, n.4, p.599-615. 2003.

BASTOS, E.M.; BRANDÃO, M.; SILVEIRA, F.R.C. da. Espectro polínico dos méis produzidos no parque da Serra do Caraça - MG. Daphne, v. 5, n. 1, p. 40-45, 1995.

BASTOS, E.M.; BRANDÃO, M. Inventário da flora apícola de Barão dos Cocais, Minas Gerais- III. Daphne, v.4, p.54-60, 1994.

BASTOS, E.M.; GONÇALVES, T.; BATISTA, E.B. et al. Análise microscópica de amostras de mel do estado de Minas Gerais - I. Daphne, v.1, p.10-13, 1991.

BATH, P.K.; SINGH, N. A comparison between Helianthus annuus and Eucalyptus lanceolatus honey. Food Chemistry, v.67, n.4, p.389-397, 1999.

BENDINI, J.N.; FARIA JÚNIOR, L.R.R.; BARRETO, L.M.R.C. Análise físicoquímica dos méis produzidos em quinze municípios do Vale do Paraíba. In: CONGRESSO BRASILEIRO DE APICULTURA, 14., Campo Grande, 2002. Anais. Campo Grande: Confederação Brasileira de Apicultura, 2002, p.63.

BOGDANOV, S. Honey quality and international regulatory standards: review by the international honey commission. Bee World, v. 80, n. 2, p. 61-69, 1999.

BOGDANOV, S.; MARTIN, P.; LÜLLMANN, C. Harmonized methods of the european honey commission. Apidologie, Extra issue, p.1-59, 1997.

BOGDANOV, S; IMDORF, A; KILCHENMANN, V. et al. The contaminants of the bee colony. Bulgarian Journal of Veterinary Medicine, v. 6, n. 2, p. 59-70, 2003.

BOLETIN OFICIAL ESPAÑOL (B.O.E.) Orden de 12 de junio de 1986, de la Presidencia del Gobierno por la que se aprueban los métodos oficiales de analisis para la miel. B.O.E., Madrid, 18 junio de 1986, n. 145, p. 2219522202. 
BONVEHÍ, J.S.; COLL, F.V. Characterization of citrus honey (Citrus spp.) produced in Spain. Journal of Agricultural Food Chemistes, v. 43, p.20532057, 1995.

BRANDÃO, M.; BASTOS, E.M. Espectro polínico do mel produzido na Serra da Piedade, Município de Caeté (MG). Daphne, v.5, p.10-14, 1995.

BRANDÃO, M.; BASTOS, E.M.; SILVEIRA, F.R.C. Inventário da flora apícola de São Gonçalo do Rio Abaixo, MG. Daphne, v.3, p.24-33, 1993.

BRASIL. Ministério da Agricultura. Agência Nacional de Vigilância Sanitária. Decreto $\mathrm{n}^{\circ}$. 55.871, 26 de marco de 1965. http://www.anvisa.gov.br/legis/decreto/55871 65.html.(15 jul. 2004).

BRASIL. Ministério da Agricultura. Agência Nacional de Vigilância Sanitária. Portaria $\mathrm{n}^{\circ}$. 685, 27 de agosto de 1998. http://www.anvisa.gov.br/legis/especifica/ contaminantes. (15 jul. 2004)

BRASIL. Ministério da Agricultura. Instrução normativa $\mathrm{n}^{\circ} 11$, de 20 de outubro/2000. Regulamento técnico de identidade e qualidade do mel. http://www.agricultura.gov.br/sda/dipoa/anexo (30 jan 2001).

BRAZIEWIEZ, J.; FIJAL, I.; CZYEWSKI, T. et al. Pixe and XRF anlysis of honey samples. Nuclear Instruments and Methods in Physics Research, v. 187, p. 231-237, 2002.

BULDINI, P.L; CAVALLI, S; MEVOLI, A. et al Ion chromatographic and voltammetric determination of heavy and transition metals in honey. Food Chemistry, v. 73, n. 4, p.487-495, 2001.

BUNZL, K.; KRACKE, W. Cs, Sr, and $\mathrm{K}$ in different types of honey. Health Psychology, v.41, n.3, p.554-558, 1981.

BUTTA, A.; CASERIO, G.; BIZZOZERO, M. et al. Indagine sulla qualità merceologica e sulle carattrristiche microbiologiche di mieli in commericio. Industrie Alimentari, v.22, n.210, p.838-844, 1983. 
CAMPOS, G. Melato no mel e sua determinação através de diferentes metodologias. Belo Horizonte, 1998. 178p. Tese (Doutorado) - Escola de Veterinária, Universidade Federal de Minas Gerais.

CANO, C.B. Caracterização dos méis monoflorais de eucalipto e laranja do Estado de São Paulo pela análise polínica e físico-química. São Paulo, 2002. 211p. Tese (Doutorado) - Faculdade de Ciências Farmacêuticas, Universidade de São Paulo.

CANO, C.B.; FELSNER, M.L.; MATOS, J.R. et al. Comparison of methods for determining moisture content of citrus and eucalyptus brazilian honeys by refractometry. Journal of Food Composition and Analysis, v.14, p.101109, 2001.

CARNEIRO, J.G.M.; SOUZA, D.C.; MURATORI, M.C.S. et al. Características físico-químicas de 132 amostras de mel de abelhas da microrregião de Simplício Mendes, PI. In: CONGRESSO BRASILEIRO DE APICULTURA, 14., Campo Grande, 2002. Anais. Campo Grande: Confederação Brasileira de Apicultura, 2002. p.76.

CAROLI, S.; FORTE, G.; ALESSANDRELLI, M. et al. A pilot study for the production of a certified reference material for trace elements in honey. Microchemical Journal, v.67, p.227-233, 2000.

CAROLI, S.; FORTE, G.; LAMICELI, A.L. et al. Detemination of essential and toxic trace elements in honey by inductively coupled plasma-based techniques. Talanta, v. 50, p.327-336, 1999.

CARVALHO, C.A.L. de; MARCHINI, L.C. Tipos polínicos coletados por Nannotrigona testaceicornis e Tetragonisca angustula (Hymenoptera, Apidae, Meliponinae). Scientia Agricola, v.56, n.3, p.717-722, 1999.

CARVALHO, C.A.L. de; MARCHINI, L.C.; SODRÉ, G. da S. et. al. Análises de amostras de méis provenientes do recôncavo da Bahia. In. ENCONTRO SOBRE ABELHAS, 4., Ribeirão Preto, 2000. Anais. Ribeirão Preto: Faculdade de Filosofia Ciências e Letras, 2000a. p.352. 
CARVALHO, C.A.L. de; MARCHINI, L.C.; SODRÉ, G. da S. et al. Características físico-químicas de amostras de méis da Bahia: 1. Porcentagem de cinzas. In: CONGRESSO BAIANO DE APICULTURA, 1., Salvador, 2000. Anais. Salvador: Editora UESC, 2000b. p.105.

CARVALHO, C.A.L. de; MARCHINI, L.C.; SODRÉ, G. da S. et al. Características físico-químicas de amostras de méis da Bahia: 1. porcentagem de cinzas. In: CONGRESSO BAIANO DE APICULTURA, 1., Salvador, 2002. Anais. Salvador: UESC, 2002. p.105.

CARVALHO, C.A.L. de; MARCHINI, L.C.; TEIXEIRA, G.M. et al. Características físico-químicas de amostras de méis da Bahia. In: CONGRESSO BRASILEIRO DE APICULTURA, 12., Salvador, 1998. Anais. Salvador: Confederação Brasileira de Apicultura, 1998, p.200.

CAVIA, M.M.; FERNÁNDEZ-MUIÑA, M.A.; GÖMEZ-ALONSOA, E. et al. Evolution of fructose and glucose in honey over one year: in.uence of induced granulation. Food Chemistry, v. 78, p. 157-161, 2002.

CELECHOVSKA, O.; VORLOVA, L. Groups of honey - physicochemical properties and heavy metals. Acta Veterinaria, v. 10, n. 1, p.91-95, 2001.

CELLI, G.; MACCAGNANI, B.; PORRINI, C. et al. Honey bees as bioindicators of environmental pollution. Bulletin of Insectology, v. 56, n. 1, p.137-139, 2003.

CHAVES, S.A.M. Análise polínica do mel da região de Secretário, Petrópolis RJ. Revista Brasileira de Apicultura, v. 95, p.18-20, 1995.

CODEX ALIMENTARIUS COMMISSION (C.A.C.). Official methods of analysis. v. 3, Supl 2, p.(s.n.p.) 1990 .

COMI, G.; MANZANO, M.; LENARDON, M. et al. Microbiological and chemicalphysical aspects of various honeys. Industrie Alimentari, v. 39, n. 395, p. 966-975, 2000.

CONTI, M.E. Lazio region (central Italy) honeys: a survey of mineral content and typical quality parametres. Food Control, v.11, p.459-463, 2000. 
CORNEJO, L.G. Tecnologia de miel. In: SEEMANN, P.; NEIRA, M. (Ed.). Tecnologia de la produccion apicola. Valdivia: Universidad Austral de Chile, Facultad de Ciencias Agrarias, 1988. p.145-171.

CORTOPASSI-LAURINO, M.; GELLI, D.S. Analyse pollinique, propriétés physico-chimiques et action antibactérienne des miels d'abeilles africanisées Apis mellifera et de Méliponinés du Brésil. Apidologie, v. 22, p. 61-73, 1991. COSTA, L.S.M.; ALBUQUERQUE, M.L.S.; TURGO, L.C. et al. Determination of non-volatile compounds of different botanical origin brazilian honeys. Food Chemistry, v. 65, p. 347-352, 1999.

CRANE, E. Honey: a comprehensive survey. London: Heinemann, 1975. 608p.

CRANE, E. Livro do mel. Trad. de Astrid Kleinert Giovannini. São Paulo: Nobel, 1983. 226p.

CRECENTE, R.P.; LATORRE, C.H. Pattern recognition analysis applied to classification of honeys from two geographic origins. Journal of Agricultural and Food Chemistry, v.41, p.560-564, 1993.

CRUZ, C.D.; REGAZZI, A.J. Modelos biométricos aplicados ao melhoramento genético. Viçosa: Universidade Federal de Viçosa, 1994. p.277-374.

DAELLEN-BACH, K.K. The use of honeybee. Gleanings in Bee Culture, v.109, n. 10, p. 530-531, 1981.

D'ALBORE, G.R.; PERSANO-ODDO, L. Flora apistica italiana. Milano: Federazione Apicoltori Italiani, 1978. 51p.

DAYRELL, I.O.; VITAL, N.C. Comparação entre dois métodos oficiais para determinação de hidroximetilfurfural (HMF) em mel brasileiro. Ciência e Tecnologia de Alimentos, v.11, n.1, p.137-141, 1991.

DE-LEONARDIS, W.; DE-SANTIS, C.; FICHERA, G. et al. Importance of Castanea sativa Mill. in honeys of central and north-eastern Sicily on the basis of the pollen grain analysis. Ecologia Mediterranea, v. 26 n, 1/2, p.169-175, 2000. 
DEL-LUNGO, T.; CIURLO, R.; NOVARI, G. et al. II Miele argentino: produzione, commercializzazione e caratteristiche. Industrie Alimentari, v.30, n.292, p.361-366, 1991.

DEMALSY, F.M.J.; VINCENT, B.; BEAULIEU, F. Teneur en minéraux et origine géographique des miels du Canada. Apidologie, v. 22, p.77-91, 1989.

DEVILLERS, J.M.; PHAM-DELÈGUE, M.H.; DORÉ, J.C. Classification of monofloral honeys based on their quality control data. Food Chemistry, v. 86, n. 2, p. 305-312, 2004.

DIEZ, M.J.; ANDRES, C.; TERRAB, A. Physicochemical parameters and pollen analysis of Moroccan honeydew honeys. International Journal of Food Science and Technology, v. 39, n. 2, p. 167-176, 2004.

DOZO, A.M.M. de. Determinacion de azucares en mieles producidas en la provincia de Buenos Aires - Republica Argentina. In: CONGRESSO BRASILEIRO DE APICULTURA, 5.; CONGRESSO LATINO-IBEROAMERICANO DE APICULTURA, 3., Viçosa, 1980. Anais. Viçosa: Universidade Federal de Viçosa, 1980. p.312-316.

DURKEE, L.H.A Pollen profile from woden bog in North-Central lowa. Ecology, v.52, n.5, p.837-844, 1971.

EL-ETRE, A.Y. Natural honey as corrosion inhibitor for metals and alloys. I. copper in neutral aqueous solution. Corrosion Science, v. 40, n. 11, p. $1845-1850,1998$.

EL-ETRE, A.Y.; ABDALLAH, M. Natural honey as corrosion inhibitor for metals and alloys. li. C-steel in hihg saline water. Corrosion Science, v. 42, p. 731738, 2000.

EL-SHERBINY, G.A.; RIZK, S.S.; EL-ASHWAH, F.A. Chemical composition of citrus honey produced in A. R. E. Agricultural Research Review, v.58, n.3, p.289-297, 1980.

ERDTMAN, G. Pollen morphology and plant taxonomy - Angiosperms. Stockholm: Almqvist \& Wiksell, 1952. 539 p. 
ESCOBAR-MARTÍNEZ, C.A.E.; MEZA, G.G.G.; MENDOZA, M.R.Q. Mieles de abejas de flora Paraguaya: composición, tipificación y normalización. San Lorenzo: Ministerio de Agricultura y Ganaderia, Universidad Nacional de Asunción, Asociación Suiza para el Desarrollo y la Cooperación, 1992. 31p.

FALLICO, B.; ZAPPALA, M.; ARENA, E.; VERZERA, A. Effects of conditioning on HMF content in uni.oral honeys. Food Chemistry, v. 85, p. 305-313, 2004.

FELLER-DEMALSY, M.J.; VICENT, B.; BEAULIEU, F. Teneur en minéraux et origine géogrphique des miels du Canada. Apidologie. v.20, n. 1, p. 77-91, 1989.

FERNANDES, E.C.L. Morfologia dos grãos de isótipos de Myrtaceaes paranaenses. Boletim da Universidade Federal do Paraná, Botânica, v. 2, p. 1-11, 1967.

FERNÁNDEZ-SALGUERO, J.; GÓMEZ, R. Aportación al estudio de los alimentos españoles de humedad baja. Alimentaria, v.29, n.229, p.83-85, 1992.

FERREIRA, M.B. Plantas apícolas no Estado de Minas Gerais. Informe Agropecuário, v. 7, p.40-47, 1981.

FLECHTMANN, C.H.W.; CALDAS FILHO, C.F.; AMARAL, E. et al. Análise de méis do Estado de São Paulo. Boletim de Indústria Animal, v.21, p.65-73, 1963.

FRAZIER, W.C.; WESTHOFF, D.C. Microbiología de los alimentos. 4. ed. Espanha: Acribio, 1993. 681p.

FREITAS, B.M. Potencial de caatinga para a produção de pólen e néctar para a exploração apícola. Fortaleza, 1991. 140p. Dissertação (Mestrado)Universidade Federal do Ceará.

FREITAS, B.M. Caracterização palinológica de algumas amostras de mel do Ceará. Ciência Agronômica, v.32, p.22-29, 2001. 
FRÍAS, I.; HARDISSON, A. Estudio de los parámetros analíticos de interés en la miel. II: Azúcares, cenizas y contenido mineral y color. Alimentaria, v.28, n.235, p.41-43, 1992.

FURUTA, T.; OKIMOTO, Y. Further investigation on honey yeasts. Bulletin-ofthe-Faculty-of-Agriculture-Tamagawa-University, v.18, p.32-38, 1978.

GILLIAM, J. Microbial sterility of the intestinal honey bee, Apis mellifera. Annals of the Entomological Society of America, v.64, p. 315-316, 1971.

GILLIAM, M.; MOFFETT, J.O.; KAUFFELD, N.M. Examination of floral nectar of citrus, cotton and Arizona desert plants for microbes. Apidologie, v.14, p.299-302, 1983.

GILLIAM, M.; PREST, D.B. Microbiology of feces of the larval honey bee, Apis mellifera. Journal of Invertebrate Pathology, v. 49, p.70-75, 1987.

GILLIAM, M.; VALENTINE, D.K. Bacteria isolated from the intestinal contents of foraging worker honey bee, Apis mellifera: the genus Bacillus. Journal of Invertebrate Pathology, v.28, p. 275-276, 1976.

GÓMEZ, M.E.M.; HERNANDEZ, E.G.; GOMEZ, J.Y.M. et al. Physicochemical analysis of Spanish commercial Eucalyptus honeys. Journal of Apicultural Research, v.32, n.3/4, p.121-126, 1993.

GONZÁLES, A.P.; BURIN, L.; BUERA, M.P. Color changes during storage of honeys in relation to their composition and initial color. Food Research International, v.32, p.185-191, 1999.

HASE, S.; AIDA, Y. Studies on the quality of honey on the market in Japan, with special reference to its relation to the "Codex Alimentarius". In: INTERNATIONAL APICULTURAL CONGRESS, 30., Nagoya, 1985. Proceedings. Nagoya: Apimondia, 1985. p.338-342. Resumo 290 em Apicultural Abstracts, v.39, n.1, p.77, 1988.

HEBBAR, H.U.; NANDINI, K.E.; LAKSHMI, M.C. et al. Microwave and infrared heat processing of honey and its quality. Food Science and Technology Research, v. 9, n. 1, p. 49-53, 2003. 
HERMOSÍN, I.; CHICÓN, R.M.; CABEZUDO, M.D. Free amino acid composition and botanical origin of honey. Food Chemistry, v. 83, p. 263-268, 2003.

HORN, H.; alunos da disciplina análise de mel da Universidade de Hoheinheim, Alemanha. Méis brasileiros: resultados de análises físico-químicas e palinológicas. In: CONGRESSO BRASILEIRO DE APICULTURA, 11., Teresina, 1996. Anais. Teresina: Confederação Brasileira de Apicultura, 1996. p.403-429.

HOWER, F.N. Plantas melíferas. Barcelona: Reverté, 1953. 35p.

HUIDOBRO, J.F.; SIMAL, J. Determination of sugars in honey. Anales de Bromatologia, v. 36, n. 2 p. 247-264, 1984.

IBRAHIM, S.H.; SOLIMAN, N.Z.; WISSA, H. Studies on the properties of the major Egyptian honey types and on honey ripening. Agricultural Research Review, v.55, n.1, p.125-129, 1977.

IMPERATRIZ-FONSECA, V.L.; GIOVANNINI, A.; GUIBI, L.S. et al. Preliminary study of Brazilian honeys. In: INTERNATIONAL APICULTURAL CONGRESS, 30., Nagoya, 1985. Proceedings. Nagoya: Apimondia, 1985. p.312.

ISENGARD, H.D.; SCHULTHEISS, D. Water determination in honey: Karl Fischer titration, an alternative to refractive index measurements?. Food Chemistry, v. 82, n. 1, p. 151-154, 2003.

ISKANDER, F.Y. Assessment of trace elements in honey produced on uranium mining reclaimed land. The Science of the Total Environment, v. 192, p. 119-122, 1996.

IVANOV, T.S.; CHERVENAKOVA, I. Contents of some macro, oligo, and trace elements in honey, royal jelly and pollen. Zhivotnovudni Nauki, v.21, n.6, p.65-69, 1984. Resumo 989 em Apicultural Abstracts, v.37, n.3, p.246, 1986. 
IWAMA, S.; MELHEM, T.S. The pollen spectrum of the honey of Tetragonisca angustula angustula Latrelle (Apidae, Meliponinae). Apidologie, v. 10, n. 3, p.275-295, 1979.

JOLIFFE, I.T. Discarding variables in a principal component analysis. I Real date. Applicant Statistical, v.21, n.1, p.21-31, 1973.

JUNZHENG, P.; CHANGYING, J. General rheological model for natural honeys in China. Journal of Food Engineering, v.36, p.165-168, 1998.

KOMATSU, S.S. Caracterização físico-química de méis de Apis mellifera L., 1758 (Hymenoptera: Apidae) de diferentes municípios do Estado de São Paulo. Piracicaba, 1996. 90p. Tese (Doutorado) - Escola Superior de Agricultura "Luiz de Queiroz", Universidade de São Paulo.

KOMATSU, S.S.; MARCHINI, L.C. Physical and chemical characteristics of honeys from wild flowers of Apis mellifera from various locations in the State of São Paulo, Brazil. In: CONFERENCE ON TROPICAL BEES: MANEGEMENT AND DIVERSITY, 6., San José, Costa Rica, 1996. Proceedings. San José: IBRA, 1996 p. 22.

KOMATSU, S.S.; MARCHINI, L.C.; MORETI, A.C. de C.C. Análises físicoquímicas de amostras de méis de flores silvestres, de eucalipto e de laranjeira, produzidos por Apis mellifera no Estado de São Paulo. 1. Índice de diastase e hidroximetilfurfural. Revista de Agricultura, v.76, n.3, p.381392, 2001.

KOMATSU, S.S.; MARCHINI, L.C.; MORETI, A.C. de C.C. Análises físicoquímicas de amostras de méis de flores silvestres, de eucalipto e de laranjeira, produzidos por Apis mellifera L., 1758 (Hymenoptera, Apidae) no Estado de São Paulo. 2. Conteúdo de açúcares e de proteína. Ciência e Tecnologia de Alimentos, v.22, n.2, p.143-146, 2002.

KUMP, P.; NECEMER, M.; SNAJDER, J. Determination of trace elements in bee honey, ponen and tissue by total reflection and radioisotope $\mathrm{X}$-ray fluorescence spctrometry. Spectrochimica Acta, v. 51, p.499-507, 1996. 
LASCEVE, G.; GONNET, M. Analyse par radioactivation du contenu minéral d'un miel. Possibilité de préciser son origine géographique. Apidologie, v.5, n.3, p.201-223, 1974.

LATORRE, M.J.; PEÑA, R.; PITA, C. et al. Chemometric classification of honeys according to their type. II. Metal content data. Food Chemistry, v. 66, n. 2, p. 263-268, 1999.

LEITA, L.; MUHLBACHOVA, G.; CESCO, S.; et al. Investigation of the use of honey bee ond honey bee products to assess heavy metals contamination. Environumental Monitoring and Assessment, v. 43, p. 1-9, 1996.

LIAKOS, V.; POLYZOPOULOU, Z.; ROUMPIES, N. Population dynamics of bee colonies located in airborne contaminated regions. Journal of the Hellenic Veterinary Medical Society, v. 53, n. 3, p. 219-227, 2002.

LIN, Y.C.; SHEU, S.Y.; KONG, H.H. Physicochemical characteristics of certain Taiwan honeys. Taiwan ke Hsueh, v.31, n.1, p. 34-39, 1977. Resumo 1440 em Apicultural Abstracts, v.30, n.4, p.296, 1979.

LÓPEZ-GARCIA, I.; VIÑAS, P.; BLANCO, C. et al. Fast determination of calcium, magnesium and zinc in honey using continuous flow flame atomic absorption spectrometry. Talanta, v. 49, p.597-602, 1999.

LOUVEAUX, J. Le miel. Cahiers de Nutrition et de Diétetique, v.1, p.57-70, 1985.

LOUVEAUX, J.; MAURIZIO, A.; VORWOHL, G. Methods of Melissopalinology. Bee World, v. 59, n. 4, p.139-157, 1978.

LYNN, E.G.; ENGLIS, D.T.; MILUM, V.G. Effect of processing and storage on composition and color of honey. Food Research, v.1, p. 23-27, 1936.

MAGALHÃES, E. de O.; SICUPIRA, P.R.; TERRA, P.S. Levantamento preliminar da flora apícola sul da Bahia. In: CONGRESSO BRASILEIRO DE APICULTURA, 11., Piauí 1996. Anais. Piauí: Confederação Brasileira de Apicultores, 1996. p.326. 
MAGALHÃES, E.O.; BARRETO, W.S.; SANTOS, J.R. Determinação de umidade em méis produzidos na região sul da Bahia. In: CONGRESSO BAIANO DE APICULTURA, 1., Salvador, 2002. Anais. Salvador: Editora da UESC, 2002. p.109.

MARCHINI, L.C. Caracterização de amostras de méis de Apis mellifera L., 1758 (Hymenoptera: Apidae) do Estado de São Paulo, baseada em aspectos físico-químicos e biológicos. Piracicaba, 2001. 111p. Tese (Livre Docência) Escola Superior de Agricultura "Luiz de Queiroz", Universidade de São Paulo.

MARCHINI, L.C.; MORETI, A.C. de C.C. Características físico-químicas de amostras de mel de cinco diferentes espécies de eucaliptos. In: SIMPÓSIO LATINO AMERICANO DE CIÊNCIA DE ALIMENTOS, 4., Campinas, 2001. Resumos. Campinas: R. Vieira Gráfica, 2001. p.42.

MARCHINI, L.C.; RODRIGUES, A.C.L.; MORETI, A.C de C.C. Características qualitativas de méis que passaram por diferentes tipos de descristalização. In: CONGRESSO BRASILEIRO DE APICULTURA, 12., Teresina, 1996. Anais. Teresina: Confederação Brasileira de Apicultura, 1996. p.348.

MARCHINI, L.C.; CARVALHO, C.A.L. de; ROS, P.B. Tipos polínicos coletados por Patamona cuoira (HYMENOPTERA, APIDAE, MELIPONINAE) In: INTERNARTIONAL APICULTURAL CONGRESS, 35., Belgium, 1997. Anais. Apimondia Publishing House, Bucharest: Belgium, 1997, p.290.

MARCHINI, L.C.; CARVALHO, C.A.L. de; ALVES, R.M.O. et al. Características físico-químicas de amostras de méis da abelha uruçu (Melipona scutellaris). In: CONGRESSO BRASILEIRO DE APICULTURA, 12., Salvador, 1998. Anais. Salvador: Confederação Brasileira de Apicultura, 1998. p.201.

MARCHINI, L.C.; RODRIGUES, A.C.L.; MORETI, A.C. de C.C. HMF (Hidroximetilfurfural) e diastase de méis submetidos a dissolução de cristais por aquecimento. Boletim de Indústria Animal, v.57, n.1, p.85-91, 2000. 
MARCHINI, L.C.; SODRÉ, G. da S.; MORETI, A.C. de C.C. Condutividade elétrica, teor de proteína, viscosidade e teor de água de amostras de mel de flores de laranjeira produzido por Apis mellifera L. no Estado de São Paulo. (compact disc). In: SIMPÓSIO INTERNACIONAL DE INICIAÇÃO CIENTÍFICA DA UNIVERSIDADE DE SÃO PAULO, 10., Piracicaba, 2002. Piracicaba: Universidade de São Paulo, 2002.

MARCHINI, L.C.; MORETI, A.C.de C.C.; SILVEIRA NETO, S.; Physico-chemical composition of honey samples and the swarm development of Apis mellifera L. 1758 (Hymenoptera, Apidae), in five different Eucalyptus species. Boletim do Centro de Pesquisa e Processamento de Alimentos, v. 21, n. 1, p. 193-206, 2003.

MARCHINI, L.C.; SODRÉ, G. da S.; SABADIN, J. Tipificação físico-químicos de méis de (Apis mellifera) provenientes de diferentes município do Estado de Tocantins. (compact disc). In: CONGRESSO BRASILEIRO DE APICULTURA, 15., Natal, 2004. Natal: CONBRAPI, 2004a.

MARCHINI, L.C.; SODRÉ, G. da S; SABADIN, J. Análises físico-químicos de méis de (Apis mellifera) provenientes de diferentes município do Estado do Paraná. (compact disc). In: CONGRESSO BRASILEIRO DE APICULTURA, 15., Natal, 2004. Natal: CONBRAPI, 2004b.

MARCHINI, L.C.; SODRÉ, G. da S; MORETI, A.C. de C.C. Mel brasileiro: composição e normas. Ribeirão Preto: A.S.P., 2004c. 131p.

MARDIA, L.V.; KENI, J.T.; BIBBY, J.M. Multivariate analysis. London: Academic Press, 1979. 521p.

MARTINEZ, G.M.E.; GUERRA, H. E.; MONTILLA, G.S. et al. Physicochemical analysis of Spanish commercial Eucalyptus honey. Journal of Apicultural Research, v.32, n.3/4, p.121-126, 1993.

MARTINS, H.M.; MARTINS, M.L.; BERNARDO. F.M. A. Bacillaceae spores, fungi and aflatoxins determination in honey. Revista Portuguesa de Ciencias Veterinarias, v. 98, n. 546, p. 85-88, 2003. 
MATEO, R.; BOSCH-REIG, F. Sugar profiles of Spanish unifloral honeys. Food Chemistry, v.60, n.1, p.33-41, 1997.

MATEO, R.; BOSCH-REIG, F. Classification of Spanish unifloral honeys by discriminate analysis of electrical conductivity, color, water content, sugars and $\mathrm{pH}$. Journal of Agricultural and Food Chemistry, v.46, p.393-400, 1998.

MATUELLA, M.; TORRES, V.S. Teste da qualidade microbiologica do mel produzido nos arredores do lixao no Municipio de Chapeco - SC. Higiene Alimentar, v.14, n.70, p.73-77, 2000.

MENDES, E.; PROENÇA, E.B.; FERREIRA, I.M.P.L.V.O. et al. Quality evaluation of portuguese honey. Carbohydrate Polymers, v. 37, n. 3, p. 219-223, 1998.

MENDONÇA, K.; SODRÉ, G. da S.; MARCHINI, L.C. Parâmetros físico-químicos de méis de Apis mellifera provenientes do município de Cáceres-Mato Grosso. (compact disc). In: CONGRESSO BRASILEIRO DE APICULTURA, 15., Natal, 2004. Natal: CONBRAPI, 2004.

MERIN, U.; BERNSTEIN, S.; ROSENTHAL, I.A. Parameter for quality of honey. Food Chemistry, v. 63, n. 2, p.241-242, 1998.

MESALLAM, A.S.; EL-SHAARAWY, M.I. Quality attributes of honey in Saudi Arabia. Food Chemistry, v.25, n.1, p.1-11, 1987.

MIDURA, T.F.; SNOWDEN, S.; WOOD, R.M. et al. Isolation of Clostridium botulinum from honey. Journal of Clinical Microbiology., v.9, p.282-283, 1979.

MIGDAL, W.; OWCZARCZYK, B.H.; KEDZIA, B. et al. Microbiological decontamination of natural honey by irradiation. Radiation Physics and Chemistry, v. 57, p. 285-288, 2000.

MILUM, V.G. Some factores affecting the color of honey. Journal of Economic Entomology, v. 41, p. 495-505, 1948. 
MONTENEGRO, G.; PIZARRO, R.; AVILA, G.; et al. Botanical origin and chemical properties of honeys from the Arid Mediterranean region of Chile. Ciencia e Investigacion Agraria, v. 30, n. 3, p. 161-174, 2003

MOORE, P.D.; WEBB, J.A. Anales illustrated guide to pollen analysis. London: Hodder and Stoughton, 1978. 133p.

MORAES, R.M. de Análise de mel. Pindamonhangaba: Centro de Apicultura Tropical, IZ/SAA, 1994. SNP. 1V., (Manual técnico).

MORAES, R.M. de; MANTOVANI, D.M.B. Composição química de méis de diferentes fontes florais. In: CONGRESSO BRASILEIRO DE APICULTURA, 7., Salvador, 1986. Resumos. Salvador: Confederação Brasileira de Apicultura, 1986. p.58.

MORAES, R.M. de; TEIXEIRA, E.W. Análise de mel. Pindamonhangaba, 1998. 42p. (Manual Técnico).

MORETI, A.C. de C.C.; MARCHINI, L.C.; TEIXEIRA, E.W. et al. Caracterização das plantas apícolas do Centro de Apicultura Tropical / Instituto de Zootecnia, em Pindamonhangaba, SP. In: CONGRESSO BRASILEIRO DE APICULTURA, 12., Salvador, 1998. Anais. Salvador: Confederação Brasileira de Apicultura, 1998. p.179.

MORETI, A.C. de C.C.; CARVALHO, C.A.L. de; MARCHINI, L.C. et al. Espectro polínico de amostras de méis de Apis mellifera L. coletadas na Bahia. Bragantia, v. 59, n. 1, p. 1-6, 2000a.

MORETI, A.C. de C.C.; MARCHINI, L.C.: OLIVEIRA, P.C.F. de. Principais tipos polínicos observados em amostras de mel silvestre, produzido por abelhas (Apis mellifera L.) no Estado de São Paulo. In: ENCONTRO SOBRE ABELHAS, 4., Ribeirão Preto, 2000. Anais. Ribeirão Preto: Faculdade de Filosofia, Ciências e Letras, Faculdade de Medicina, Universidade de São Paulo, 2000b. p.345. 
MORLOT, M.; LOUBLIER, Y.; RICARD, M. et al. Physico-chemical, palynological and organoleptic characterization of a urban honey on Sophora japonica. Apidologie, v. 32, n. 2, p. 178-179, 2001.

MORRISON, D.F. Multivariate statistical methods. 2. ed. Tokyo: Mc Grow Hill, 1981. $415 p$.

MORSE, R.A.; LISK, D.J. Elemental analysis of honey from several nations. American Bee Journal, v. 120, p. 522-523, 1980.

MOSSEL, B.; BHANDARI, B.; D'ARCY, B. et al. Use of an Arrhenius Model to Predict Rheological Behaviour in some Australian Honeys. Lebensmittel Wissenschaft und Technologie, v. 33, p. 545-552, 2000.

MOTTA JÚNIOR, L.C.; SILVA, M.R.M.; SILVA, J.M. Análise polínica do mel de Apis mellifera L., da área indígena Carú, município de Bom Jardim, Maranhão. In: CONGRESSO NACIONAL DE BOTÂNICA, 53.; REUNIÃO NORDESTINA DE BOTÂNICA, 25., Recife, 2002. Resumos. Recife: Sociedade Botânica do Brasil, 2002. p.146.

MOURA, S.G. de; SOUZA, D.C.; CARNEIRO, J.G.M. Variação da cor e do teor de acidez em méis em função do tempo de armazenamento nas condições de Teresina/Piauí. In: CONGRESSO BRASILEIRO DE APICULTURA, 14., Campo Grande, 2002. Anais. Campo Grande: Confederação Brasileira de Apicultura, 2002. p.101.

MUNROE, J.A. The viscosity and thixotropy $f$ honey. Journal of Entomology, V. 36, p. 79-777, 1943.

MURATORI, M.C.S.; SOUZA, D.C. Características microbiológicas de 132 amostras de mel de abelha do Piauí. In: CONGRESSO BRASILEIRO DE APICULTURA, 14., Campo Grande, 2002. Anais. Campo Grande: Confederação Brasileira de Apicultura, 2002. p.77.

NAKANO, H.; SAKAGUCHI, G. Na unusually heavy contamination of honey products by Clostridium botulinum type $\mathrm{F}$ and Bacillus alvei. FEMS Microbiology Letters, v.79, p.171-178, 1991. 
NAKANO, H.; OKABE, T.; HASHIMOTO, H. et al. Incidence of Clostridium botulinum in honey of various origins. Japanese Journal of Medical Science and Biology, v.43, p.183-195, 1990.

NANDA, V.; SARKAR, B.C.; SHARMA, H.K et al. Physico-chemical properties and estimation of mineral content in honey produced from different plants in northern India. Journal of Food Composition and Analysis, v. 16, n. 5, p. 613-619, 2003.

NARAYAMA, N. Studies in Indian honeys and bees waxes. Poona: Central Bee Research Institue, 1970. 13p./ Resumo 420 em Apicultural Abstrates, v. 24, n. 2, p. 90, 1973.

NEVAS, M.; HIELM, S.; LINDSTRO, M. et al. High prevalence of Clostridium botulinum types $A$ and $B$ in honey samples detected by polymerase chain reaction. International Journal of Food Microbiology, v. 72, p. 45-52, 2002.

NOBRE, A.L. da R. Determinação de metais em méis por voltametria de redissolução anódica e adsortiva. São Carlos, 1990. 182p. Tese (Doutorado) - Instituto de Física e Química de São Carlos Departamento de Química e Física Molecular, Universidade de São Paulo.

NÜRNBERG, H.W. The voltammetric approach in trace metal chemistry of natural waters and atmospheric precipitation. Analysis Chimie Acta, v. 164, p. 1-21, 1984.

NÜRNBERG, H.W. Voltammetric trace analysis in ecological chemistry of toxic metals. Pure \& Applied Chemistry, v.54, n.4, p. 853-878, 1982.

ORTIZ-VALBUENA, A. The ash content of 69 honey samples from La Alcarria and neighbouring areas, collected in the period 1985-1987. Cuadernos de Apicultura, n.5, p.8-9, 1988. Resumo 638 em Apicultural Abstracts, v.40, n.4, p.360, 1989 . 
PAMPLONA, B.C. Exame dos elementos químicos inorgânicos encontrados em méis brasileiros de Apis mellifera e suas relações físico-biológicas. São Paulo, 1989. 131p. Dissertação (Mestrado) - Instituto de Biociências, Universidade de São Paulo.

PENG, Z.F.; PAN, J.G. Protein content in honey and its effects on precipitation of beverage. Food Science, v.12, p.6-8, 1994.

PERSANO-ODDO, L.P.; VALDI, E.; ACCORTI, M. Diastatic activity in some unifloral honeys. Apidologie, v.21 n.1 p. 17-24, 1990.

PERSANO-ODDO, L.; PIAZZA, M.G.; SABATINI, A.G. et al. Characterization of unifloral honeys. Apidologie, v.26, p.453-465, 1995.

PERSANO-ODDO, L.; PIRO, R.; BRUNEAU, E. et al. Main European unifloral honeys: descriptive sheets. Apidologie, v.35, p.38-81, 2004a.

PERSANO-ODDO, L.; PIANA, L.M.; BOGDANOV, S. et al. Botanical species giving unifloral honey in Europe. Apidologie, v.35, p.82-93, 2004b.

PFAU, L.A.; RUHLE, E.R. Concurso de mel: método de avaliar a qualidade do mel. In: CONGRESSO BRASILEIRO DE APICULTURA, 7., Salvador, 1986.

Resumos. Salvador: Confederação Brasileira de Apicultura, 1986. p.58-59.

PIANA, L.M.; PODA, G.; CESARONI, D. et al. Research on microbial characteristics of honey samples of Udine province. Rivista della Societa Italiana di Scienza dell' Alimentazione, v.20, p.293-301, 1991.

PIANA, L.M.; PERSANO-ODDO, L.; BENTABOL, A. et al. Sensory analysis applied to honey: state the art. Apidologie, v.35, p.26-37, 2004.

PIAZZA, M.G.; PERSANO-ODDO, L. Bibliographical review of the main European unifloral honeys. Apidologie, v.35, p.94-111, 2004.

PREGNOLATO, W.; PREGNOLATO, N.P. (Coord.). Normas analíticas do Instituto Adolfo Lutz. 3. ed. São Paulo: Instituto Adolfo Lutz, 1985. v.1, 533p: Métodos químicos e físicos para análise de alimentos.

PRZYBYLOWSKI, P.; WILCZYNSKA, A Honey as an environmental marker. Food Chemistry, v.74, n.3, p. 289-291, 2001. 
RÊGO, J.G.S.; XIMENES, R.S.S.; CARNEIRO, J.G.M. Hidroximetilfurfural e diastase em amostras de méis de Apis mellifera. In. ENCONTRO SOBRE ABELHAS, 5., Ribeirão Preto, 2002. Anais. Ribeirão Preto: Faculdade de Filosofia, Ciências e Letras, Faculdade de Medicina, Universidade de São Paulo, 2002. p.285.

REIO, L.; ENGLUND, L. Honey and its composition. Var Föda, v.37, n.2, p.42-62, 1985. Resumo em CAB Abstracts on CD-ROM, v.2, 1987-1989 .

RENDÓN, S.R. Estudio de la composicion fisico-quimica de las mieles extremeñas y extranjeras. In: CONGRESSO IBERO LATINOAMERICANO DE APICULTURA, 5., Mercedes, 1996. Anais. Mercedes: Cooperativa CALMER, 1996. p.174-183.

REYNALDI, F.J.; LOPEZ, A.C.; ALBO, G.N. et al. Differentiation of Ascosphaera Apis isolates by rep-PCR fingerprinting and determination of chalkbrood incidence in Argentinean honey samples. Journal of Apicultural Research, v. 42, n. 4, p. 68-76, 2003.

RODRIGUES, A.C.L.; MARCHINI, L.C.; HADDAD, M.L. Características qualitativas da parte cristalizada e do sobrenadante e diferentes méis. CONGRESSO BRASILEIRO DE APICULTURA, 11., Teresina, 1996. Anais. Teresina: Confederação Brasileira de Apicultura, 1996. p.349.

RODRIGUES, A.E.; SILVA, E.M.S. da; BESERRA, E.M.F. et al. Análise físicoquímica dos méis de abelha Apis mellifera e Melipona scutellaris. In: CONGRESSO BRASILEIRO DE APICULTURA, 14., Campo Grande, 2002. Anais. Campo Grande: Confederação Brasileira de Apicultura, 2002. p.62.

RODRÍGUEZ, G.O. de; FERRER, de B.S.; FERRER, A. et al. Characterization of honey produced in Venezuela. Food Chemistry, v. 84, 499-502, 2004.

ROLL, V.L.M.; BOMBO, A.J.; LOPES, T.F. et al. Honey consumption in the state of São Paulo: a risk to human health?. Anaerobe, v. 9, 299-303. 2003.

RUIZ-ARGUESO, T.; RODRíGUEZ-NAVARRO, A. Microbiology of ripening honey. Applied Microbiology, v. 30, p.893-896, 1975. 
SABATINI, A.G.; PERSANO-ODDO, L.; PIAZZA, M.G. et al. Glucide spectrum in the main Italian unifloral honeys. 1: Fructose and glucose. Apicoltura, v.5, p.35-46, 1989.

SALINAS, F.; ESOINOSA-MANSILLA, A.; BERZAS-VEVADO, J.J. Flow-injection determination of HMF in honey by Winkler method. Journal of Analytical Chemistry, v.340, n.4, p.250-252, 1991.

SALINAS, F.; MONTERO de ESPANHA, F.; OSÓRIO, E. et al. Determination of mineral elements in honey from diferente origem by flow injection analysis coupled to atomic spectroscopy. Revista Espanhola de Ciencias y Tecnologia de Alimentos, v. 34, p. 441-449, 1994.

SANCHO, M.T.; MUNIATEGUI, S.; HUIDOBRO, J.F. et al. Aging of honey. Journal of Agricultural and Food Chemistry, v.40, p.134-138, 1992.

SANCHO, M.T.; MUNIATEGUI, S.; HUIDOBRO, J.F. et al. Provincial classification of Basque Country (northern Spain) honeys by their chemical composition. Journal of Apicultural Research, v.30, n.3/4, p.168-172, 1991.

SANNA, G.; PILO, M.I.; PIU, P.C. et al. Determination of heavy metals in honey by anodic stripping voltammetry at microeletrodes. Analysis Chimie Acta, v.415, p.165-173, 2000.

SANTOS JÚNIOR, M.C.; SANTOS, F.A.R. Identificação botânica de méis da Bahia: estudo palinológico In: CONGRESSO NACIONAL DE BOTÂNICA, 53.; REUNIÃO NORDESTINA DE BOTÂNICA, 25., Recife, 2002. Resumos. Recife: Sociedade Botânica do Brasil, 2002. p.191.

SANTOS, C.F.O. Morfologia e valor taxonômico do pólen das principais plantas apícolas. Piracicaba, 1961. 92p. Dissertação (Mestrado) - Escola Superior de Agricultura "Luiz de Queiroz", Universidade de São Paulo.

SANTOS, C.F.O. Características morfológicas dos grãos de pólen das principais plantas apícolas. Anais da ESALQ, v.20, p.175-228, 1963. 
SANTOS, C.F.O. Avaliação do período de florescimento das plantas apícolas no ano de 1960, através do pólen contido nos méis e dos coletados pelas abelhas (Apis mellifera) Anais Escola Superior de Agricultura "Luiz de Queiroz. v. 21, p.253-264, 1964.

SANTOS, C.F.O. Análise polínica de alguns méis do Estado de São Paulo. In: CONGRESSO BRASILEIRO DE APICULTURA, 3. Piracicaba, 1974. Anais. Piracicaba ESALQ, 1974. p. 273-278.

SANTOS, C.F.O. Morfologia do pólen de algumas compostas apícolas. Anais da ESALQ, v.35, p.441-456, 1978.

SANTOS, N.C.R.; SILVA, L.A.; FIGUEROA, L.E.R. et al. Plantas visitadas por Apis mellifera L. no município de Alagoinhas-BA: dados preliminares. In: CONGRESSO NACIONAL DE BOTÂNICA, 53.; REUNIÃO NORDESTINA DE BOTÂNICA, 25., Recife, 2002. Resumos. Recife: Sociedade Botânica do Brasil, 2002. p.261.

SAS INSTITUTE. SAS/STAT: user's guide - version 6. 4. Ed. Cary, 1990.

SAWYER, R.M.; PICKARD, R.S. Honey identification. Cardiff: Academic Press, 1988. $115 p$.

SCHADE, J.W.; MARSH, G.; LECKERT, J.E. Diastase activity and hydroxymethylfurfural in honey and their influence in detecting heat alteration. Food Research, v.23, p.446-463, 1958.

SEEMANN, P.; NEIRA, M. Tecnología de la producción apícola. Valdivia: Universidad Austral de Chile; Facultad de Ciencias Agrarias Empaste, 1988. $202 p$.

SEIJO, M.C.; AIRA, M.J.; MENDEZ, J. Palynological differences in the pollen content of Eucalyptus honey from Australia, Portugal and Spain. Grana, v. 42, n. 3, p.183-190, 2003.

SEIJO, M.C.; AIRA, M.J.; IGLESIAS, I. et al. Palynological characterization of honey from La Coruña province (NW Spain). Journal of Apicultural Research, v.31, n.3/4, p.149-155, 1992. 
SERRA-BONVEHÍ, J.; VENTURA-COLL, F. Characterization of citrus honey (Citrus spp.) produced in Spain. Journal of Agricultural and Food Chemistry, v.43, p.2053-2057, 1995.

SERRANO, S.; VILLAREJO, M.; ESPEJO, R. et al. Chemical and physical parameters of Andalusian honey: classification of Citrus and Eucalyptus honeys by discriminant analysis. Food Chemistry, v. 87, n.4, p. 619-625, 2004

SHALTOUT, O.E. Storage stability of minced ostrich meat as affected by some added natural ingredients during refrigeration. Alexandria Journal of Agricultural Research, v. 47, n. 2, p. 127-137, 2002.

SHAMALA, T.R.; JYOTHI, Y.P.S.; PALLE, S. et al. Antibacterial effect of honey on the in vitro and in vivo growth of Escherichia coli. World Journal of Microbiology and Biotechnology, v. 18, n. 9, p. 863-865, 2002.

SILVA, D.J.; QUEIROZ, A.C. de. Determinação do nitrogênio total e da proteína bruta. In: SILVA, D.J.; QUEIROZ, A.C. de. Análise de alimentos: métodos químicos e biológicos. 3. ed. Viçosa: UFV, 2002. p. 57-75.

SILVA, R. do N.; MONTEIRO, V.N.; ALCANFOR, J.D. et al. Comparação de métodos para a determinação de açúcares redutores e totais em mel. Ciências e Tecnologia de Alimento, v. 23, n. 3, 337-341, 2003.

SILVA, S.J.R.; ABSY, M.L. Análise de pólen encontrado em amostras de mel de Apis mellifera L. (Hymenoptera, Apidae) em uma área de savana de Roraima, Brasil. Acta Amazônica, v.30, p.579-588, 2000

SIMAL, J.; HUIDOBRO, J. Parámetros de calidad de la miel. III. Acidez (pH libre, lactónica \& total) e índice de formol. Offarm, v.3, n.9, p.532, 1984.

SMITH, F.G. Deterioration of the colour of honey. Journal of Apicultural Research, v.6, n.2, p.95-98, 1967.

SNOWDON, J.A. The microbiology of honey- meeting your buyers'specifications (Why they do what they do) American Bee Journal, v.1, p. 51-60, 1999. 
SNOWDON, J.A.; CLIVER, D.O. Microorganisms in honey. International Journal of Food Microbiology, v. 31, p.1-26, 1996.

SODRÉ, G. da S. Características físico-químicas e análises polínicas de amostras de méis de Apis mellifera L., 1758 (Hymenoptera: Apidae) da região litoral norte do Estado da Bahia. Piracicaba, 2000. 83p. Dissertação (Mestrado) - Escola Superior de Agricultura "Luiz de Queiroz", Universidade de São Paulo.

SODRÉ, G. da S.; MARCHINI, L.C.; MORETI, A.C.de C.C. et al. Análises polínicas de méis de Apis mellifera L., 1758 (Hymenoptera: Apidae) do litoral norte do Estado da Bahia. Revista de Agricultura. v. 76, n. 2, p. 215-225, 2001.

SODRÉ, G. da S.; MARCHINI, L.C.; CARVALHO, C.A.L. de. Características físico-químicas de amostras de méis de abelha Apis mellifera da região litoral norte do Estado da Bahia. Revista de Agricultura, v.77, n.2, p.243-256, 2002a.

SODRÉ, G. da S.; MARCHINI, L.C.; CARVALHO, C.A. L. de et al. Características físico-químicas de amostras de méis de Apis mellifera provenientes de diferentes municípios da Bahia. In. ENCONTRO SOBRE ABELHAS, 5., Ribeirão Preto, 2002. Anais. Ribeirão Preto: Faculdade de Filosofia, Ciências e Letras, Faculdade de Medicina, Universidade de São Paulo, 2002b. p.286.

SODRÉ, G. da S.; MARCHINI, L.C.; ARRUDA, C.M.F. de et al. Viscosidade e umidade de amostras de méis de Apis mellifera provenientes de estados da região Nordeste do Brasil. (compact disc) In: SIMPÓSIO INTERNACIONAL DE INICIAÇÃO CIENTÍFICA DA UNIVERSIDADE DE SÃO PAULO, 10., Piracicaba, 2002. Piracicaba: Universidade de São Paulo, 2002c. 
SODRÉ, G. da S.; MARCHINI, L.C.; MORETI, A.C. de C. et al. Análises multivariadas com base nas características fisico-químicas de amostras de méis de Apis mellifera L. (Hymenoptera: Apidae) da região litoral noret no Estado da Bahia. Archivos Latinoamericano de Produção Animal, v.11, n.3, p.129 - 137, 2003.

SOLOVEVE, T.Y. Determination of adulteration of honey on the basis of characteristics of honeys from single or multiple flower sources. Resumo em Apicultural Abstracts, v.22, n.1, p.52-3, 1971.

SOPADE, P.A.; HALLEY, P.; BHANDARI, B. et al. Application of the WilliamsLandel-Ferry model to the viscosity-temperature relationship of Australian honeys. Journal of Food Engineering, v. 56, p.67-75, 2002.

SORIA, A.C.; GONZALEZ, M.; LORENZO, C.D.E. et al. Characterization of artisanal honeys from Madrid (Central Spain) on the basis of their melissopalynological, physicochemical and volatile composition data. Food Chemistry, v. 85, n. 1, p.121-130, 2004.

SPETTOLI, P.; CECCHINI, A.; MATCOVICH, P. Indigine sulle caratteristiche fisico-chimiche di mieli del Friuli Orientale. Industrie Alimentari, v. 22, n. 210, p.849-858, 1983.

SPORNS, P.; PLHAK, L.; FRIEDRICH, J. Alberta honey composition. Food Research International, v.25, n.2, p.93-100, 1992.

STEFANINI, R. Variability and analysis of Italian honeys. Apiacta, v. 19, n. 4, p.109-114, 1984.

STONOGA, V.I.; FREITAS, R.J.S. de. Conteúdo de água e açúcares em mel de abelha. Boletim da CEPPA, v.9, n.1, p.9-16, 1991.

SVOBODA, J. Teneur en strontium 90 dans les abeilles et dans leurs produits, Bulletin of Apicultural v. 5, n. 1, p. 101-103, 1962.

TADDIA, M; MUSIANI, A; SCHIAVI, S. Determination of heavy metals in honey by Zeeman electrothermal atomic absorption spectrometry. Annals Chimie, v. 94, n. 1/2, p. 107-111, 2004. 
TANTILLO, G.; DI-PINTO, A.; VERGARA, A. Caratteristiche del miele italiano e di importazione e proposta di standard qualitativi per miele di alta qualita. Industrie Alimentari, v. 39, n. 395, p. 980-986, 2000.

TEMIZ, A.I. Composition and characteristics of honeys from the Izmir region, and effects of different storage methods. (compact disc) Ege Bolge Zirai Arastirma Enstitusu Yayinlari, v.31, n.11, p.113, 1983. Resumo em CAB Abstracts, v.1, 1984-1986.

TERRAB, A.; DIEZ, M.J.; HEREDIA, F.J. Palynological, physico-chemical and colour characterization of Moroccan honeys: I. River red gum (Eucalyptus camaldulensis Dehnh) honey. International Journal of Food Science and Technology, v. 38, n. 4, p. 379-386, 2003.

TERRAB, A; ESCUDERO, M.L.; GONZALEZ, M.M.L. et al. Colour characteristics of honeys as influenced by pollen grain content: a multivariate study. Journal of the Science of Food and Agriculture, v. 84, n. 4, p. 380-386, 2004.

THRASYVOULOU, A.T. The use of HMF and diastase as criteria of quality of Greek honey. Journal of Apicultural Research, v.25, n.3, p.186-195, 1986.

THRASYVOULOU, A.; KARANASIOS, B.; INFANTIDIS, M. Some characteristics of Greek commercial honeys. (compact disc), Scientific Annals of the School of Agriculture, v.25, p.51-63, 1982. Resumo em CAB Abstracts on v.1, 1984-1986.

THRASYVOULOU, A.; MANIKIS, J.; TSELIOS, D. Liquefying crystallized honey with ultrasonic waves. Apidologie, v.25, n.3, p.297-302, 1994.

THRASYVOULOU, A.; MANIKIS, J. Some physicochemical and microscopic characteristics of Greek unifloral honeys. Apidologie, v.26, n.4, p.441-452, 1995.

TONG, S.S.C.; MORSE, R.A.; BACHE, C.A. et al. Elemental analysis of honey as na indicator of pollution. Forty-seven elementes in honey produced near highway, industrial and mining areas. Archives of Environmental Health, v.30, p.329-332, 1975. 
TOSI, E.; CIAPPINI, M.; RÉ, E. et al. Honey thermal treatment effects on hydroxymethylfurfural content. Food Chemistry, v. 77, n. 1, p. 71-74, 2002.

TYSSET, C.; ROUSSEAU, M. Problem of microbes and hygiene of commercial honey. Review Medicine Veterinary, v. 132, p.591-600, 1981.

UÑATES, M.A.; AGUILAR, A.B.; PIOLA, H.D. et al. Estudio físico-químico de mieles de la provincia de San Luis-República Argentina. Archivos Latinoamericanos de Nutrición, v.49, n.2, p.193-196, 1999.

VON DER OHE, W.; PERSANO-ODDO, L.; PIANA, L.M. et al. Harmonized methods of melissopalynology. Apidologie, v.35, p.18-25, 2004.

VANDERZANT, C. SPLITTSTOESSER, D.F. Compendium of methods for the microbiological examination of foods. 3. ed. Washington: American Public Health Association (APHA), 1992. 525p.

VANSELL, G.H.; FREEBORN, S.B. Preliminary report on the investigations of the source of diastase in honey. Journal of Economic Entomology. v. 22, p.922-926, 1926.

VELEMÍNSKÝ, M.; LÁZNICKA, P.; STARÝ, P. Honeybee (Apis mellifera) as evironmental monitors of heavy metals in Czechoslovakia. Acta Ethologica, v.87, p.37-44, 1990.

VERÍSSIMO, M.T.L. Saiba o que é o HMF. Apicultura no Brasil, v.4, n.24, p.31, 1988.

VIDAL, R.; FREGOSI, E.V. de. Mel: características, análises físico-químicas, adulterações e transformações. Barretos: Instituto Tecnológico Científico "Roberto Rios", 1984. 95p.

VIT-OLIVER, P.; MARTORELLI, L.G.; PALACIOS, S.L. Classificación de mieles comerciales venezuolanas. Archivos latinoamericano de Nutricion, v. 44, n. 1, p. 39-44, 1994.

VORLOVA, L.; CELECHOVSKA, O. Activity of enzymes and trace element content in beehoney. Acta Veterinaria, v. 71, n. 3, p.375-378, 2002. 
VORWOHL, G. Die beziehungen zwischen der elektrischen leitfahigkeit der honige und ihrertrachtmassigen herkufct. Annales Abeille, v7, n. 4, p.301309, 1964.

WARD, A.F.; MARCIELLO, L.F.; CARRARA, L. et al. Simultaneuus determination of marjor, minor and trace elements in agricultural and biological samples by inductivelly coupled argonplasma spectrometry. Spectroscopy Letters, v. 13, p.803-831, 1980.

WHITE JÚNIOR, J.W. Composition of honey. En: Honey a comprehensive survey. CRANE. E. (Ed). London, Heinemann, 1976. p.157-206p.

WHITE JÚNIOR, J.W. Honey. Advances in Food Research, v.22, p.287-374, 1978.

WHITE JÚNIOR, J.W.; RUDYJ, O.N. The protein content of honey. Journal of Apicultural Research, v.17, n.4, p.234-238, 1978.

WHITE JÚNIOR, J.W. Methods for determining carbohydrates, hydroxymethylfurfural and proline in honey; Collaborative study. Journal of the Association of the Official Analytical Chemistry, v.62, n.3, p.515-526, 1979.

WHITE JÚNIOR, J.W. Quality evaluation of honey: role of HMF and diastase assays. Part II. American Bee Journal, v.132, n.12, p.792-794, 1992.

WHITE JÚNIOR, J.W. The role of HMF and diastase assays in honey quality evaluation. Bee World, v. 75, n.3, p. 104-107, 1994.

WHITE JUNIOR, J.W.; SUBERS, M. H.; SCHEPARTZ, A.I. The identification of inhibine, the antibacterial factor in honey as hydrogen peroxide and its origin in a honey glucose oxidase system. American Bee Journal, v. 102, p. 43043170, 1962.

WOOTTON, M.; EDWARDS, R.A.; FARAJI-HAREMI, R. Effect of accelerated storage conditions on the chemical composition and properties of Australian honey. 2. Changes in sugar and free amino acid contents. Journal of Apicultural Research, v. 15, p.29-34, 1976. 
YAZGAN, S.; ORN, H.; SENGARD, H.D. Honey as bioindicator for screening heavy metal content of the environment. Apidologie, v. 33, n. 5, p.475-476, 2002.

YILMAZ, H.; YAVUZ, O. Content of some trace metals in honey from southeastern Anatolia. Food Chemistry, v.65, p.475-476, 1998.

ZUCCHI, P.; BASSIGNANI, V.; CARPANA, E. Honey microbiology. Industrie Alimentari, v. 40, n. 409, p. 1346-1350, 2001. 